\title{
Signaling pathways involved in regulation of glucose -6 -phosphate dehydrogenase (G6PD) by arachidonic acid
}

Indrani Talukdar

West Virginia University

Follow this and additional works at: https://researchrepository.wvu.edu/etd

\section{Recommended Citation}

Talukdar, Indrani, "Signaling pathways involved in regulation of glucose - 6 -phosphate dehydrogenase (G6PD) by arachidonic acid" (2006). Graduate Theses, Dissertations, and Problem Reports. 4274.

https://researchrepository.wvu.edu/etd/4274

This Dissertation is protected by copyright and/or related rights. It has been brought to you by the The Research Repository @ WVU with permission from the rights-holder(s). You are free to use this Dissertation in any way that is permitted by the copyright and related rights legislation that applies to your use. For other uses you must obtain permission from the rights-holder(s) directly, unless additional rights are indicated by a Creative Commons license in the record and/ or on the work itself. This Dissertation has been accepted for inclusion in WVU Graduate Theses, Dissertations, and Problem Reports collection by an authorized administrator of The Research Repository @ WVU.

For more information, please contact researchrepository@mail.wvu.edu. 


\title{
Signaling Pathways Involved in Regulation of Glucose-6-Phosphate Dehydrogenase (G6PD) by Arachidonic Acid
}

\section{Indrani Talukdar}

\author{
Dissertation submitted to the School of Medicine \\ at West Virginia University \\ in partial fulfillment of the requirements \\ for the degree of \\ Doctor of Philosophy \\ in \\ Biochemistry and Molecular Biology
}

Lisa M. Salati, Ph.D., Chair

Janet L. Cyr, Ph.D.

Daniel Flynn, Ph.D.

Peter H. Mathers, Ph.D.

Michael R. Miller, Ph.D.

Department of Biochemistry and Molecular Pharmacology

Morgantown, West Virginia

2006 


\section{ABSTRACT \\ Signaling Pathways Involved in Regulation of Glucose-6-Phosphate Dehydrogenase (G6PD) by Arachidonic Acid}

\section{Indrani Talukdar}

Glucose-6-phosphate dehydrogenase (G6PD) is the rate-limiting enzyme of pentose phosphate pathway and provides NADPH for de novo fatty acid biosynthesis. For the later reason, G6PD is known as a lipogenic enzyme. Insulin induces expression of G6PD mRNA via activating the PI3 kinase pathway in primary rat hepatocytes. Addition of arachidonic acid, a polyunsaturated fatty acid, in the medium interferes with the PI3 kinase pathway, and thus inhibits the insulin-mediated induction of G6PD. Arachidonic acid in the presence of insulin induces p38 MAP kinase pathway over insulin treatment alone. Activation of p38 MAP kinase by arachidonic acid interferes with the insulin signal transduction pathway by phosphorylating IRS-1 at Ser-307 and preventing PI3 kinase activation and Akt-phosphorylation. Inhibition of the p38 MAP kinase pathway by using a specific inhibitor, SB203580, attenuates the inhibitory effect of arachidonic acid on G6PD and at the same time reverses its effect on IRS-1 and Akt-phosphorylation.

Arachidonic acid also activates AMP-activated protein kinase (AMPK) in primary rat hepatocytes by phosphorylating it at Thr-172. Activators of AMPK, AICAR and metformin inhibit the induction of G6PD mRNA by insulin. AICAR induces phosphorylation of p38 MAP kinase in primary rat hepatocytes. AICAR-mediated inhibition of G6PD mRNA expression is dependent on the activation of the p38 MAP kinase pathway, as in the presence of the p38 MAP kinase inhibitor the inhibitory effect of AICAR on G6PD mRNA expression is abolished. AICAR also interferes with PI3 kinase pathway by inducing Ser-307 phosphorylation of IRS-1 and inhibiting Akt phosphorylation. Thus, this AMPK activator mimics the effect of arachidonic acid both on insulin signaling pathway and on G6PD mRNA expression.

Activation of the mammalian target of rapamycin (mTOR) pathway by insulin is required for the insulin-mediated induction of G6PD mRNA expression. Arachidonic acid inhibits the phosphorylation of the downstream effector protein of mTOR, S6K-1 at Thr-389 which suggests it interferes with activation of mTOR. This provides an indirect evidence of the activation of AMPK by arachidonic acid in primary rat hepatocytes, as activation of AMPK results in the inhibition of mTOR/S6K-1 pathway. However, inhibition of mTOR, rather than activation, rules out the possibility of involvement of this pathway in the interference of the PI3 kinase activation upon arachidonic acid treatment. We also have ruled out the possibility of involvement of protein kinase $\mathrm{C}$ (PKC), as neither activators of PKC mimic the action of arachidonic acid on G6PD nor inhibitors of PKC can abolish the effect of arachidonic acid on G6PD mRNA expression. 


\section{Acknowledgement:}

First, I would like to sincerely thank my advisor, Dr. Lisa Salati for her constant support and guidance throughout my graduate career. Coming to a foreign country, I was not sure if I would be able to continue my education. For her encouragement and willingness to consider my candidatcy in the department of Biochemistry, I was able to pursue my Ph.D. I will forever remain grateful for this opportunity. In this regard, I would like to thank the entire faculty in the department of Biochemistry and Molecular Pharmacology for helping and motivating me in taking a step towards becoming a complete researcher. I would like to thank my committee members for their advice, which were very helpful in formulating my hypotheses and keeping me on track.

I would like to thank all my lab members Viola, Brian, Ali and Callee for creating such a wonderful work atmosphere. In this regard, I would specially like to thank Viola. She was always there with her advice and help when I needed them most, not only as a postdoctoral fellow in the lab, but also as a very precious friend. In my joyous as well as frustrating moments, she gave me support and confidence. I thank her from the bottom of my heart.

Next, I would like to thank my parents, brother and in-laws for their love and constant support. They are eagerly waiting for the first Ph.D. degree in both the families. I would like to specially mention my father, Mr. Bimalendu Chakraborty, who always had immense confidence in me and did everything he possibly could to help reach my goals.

I would also like to thank Dr. Sudeshna Bandyopadhyay and her family in Morgantown, who never let me feel that I am so far from home. I would also like to thank all my dear friends in the department and outside, for their help and support.

Last, but not least, I would like to thank my husband Saswata Talukdar. Without his unconditional love, support and encouragement, this would have been just an impossible dream. Whatever I have achieved, it is because of him. Without him always at my side, this work would not have been successfully completed. 


\section{List of Abbreviations:}

4EBP-1

$\mathrm{ACC}$

AICAR

AMPK

ATF1

CREB

CPT-1

COX

DAG

DGLA

DHA

DNP

EET

EGF

eIF-4E

EPA

ESE

ESS

FAS

G6Pase

G6PD

GAP

GAPDH

Gi

GLA

GLUT 4

GPCR

Grb2

GSK3
Eukaryotic initiation factor binding protein 1

Acetyl-CoA carboxylase

5-aminoimidazole-4-carboxamide ribonucleotide

AMP activated protein kinase

Activating transcription factor-1

cAMP response binding protein

Carnitine: palmitoyl-CoA transferase-1

Cyclooxygenase

Diacyl glycerol

Dihomo-gamma-linolenic acid

Docosahexaenoic acid

Dinitrophenol

Epoxyeicosatrienoic acid

Epidermal growth factor

Eukaryotic translation initiation factor $4 \mathrm{E}$

Eicosa pentanoic acid

Exonic splicing enhancer

Exonic splicing silencer

Fatty acid synthase

Glucose-6-phosphatase

Glucose-6 phosphate dehydrogenase

GTPase activating protein

Glyceraldehyde-3-phosphate dehydrogenase

Inhibitory $\mathrm{G}$ protein

Gamma-linolenic acid

Glucose transporter 4

G protein coupled receptor

Growth factor receptor-bound protein 2

Glycogen synthase kinase 3 
HNF4

HnRNP

HSP

IGF

IKK-—

IRS

JNK/SAPK

LDL

LOX

LXR

MAP kinase

MKK

MKKK

mTOR

nSREBP

PAK

PDGF

PDK-1

PEPCK

PH domain

PI3 kinase

PI

PIKK

PIP2

PIP3

PKA

PKB

PKC

aPKC

cPKC

nPKC

PLC

PPAR

PSREBP

PTB domain
Hepatic nuclear factor-4-alpha

Heterogeneous nuclear ribonucleoprotein

Heat shock protein

Insulin like growth factor

Inhibitor $\square \mathrm{B}$ kinase

Insulin receptor substrate

c-JUN NH2-terminal protein kinase/stress activated protein kinase

Low density lipoprotein

Lipooxygenase

Liver $\mathrm{X}$ receptor

Mitogen activated protein kinase

MAP kinase kinase

MKK kinase

Mammalian target of rapamycin

Nuclear SREBP

p-21-activated protein kinase

Platelet-derived growth factor

Phosphoinositide-dependent kinase-1

Phosphoenolpyruvate carboxykinase

Pleckstrin homology domain

Phosphoinositide 3-kinase

Phosphatidylinositol

Phosphatidylinositol kinase related kinase

Phosphatidylinositol 4,5-bisphoaphate

Phosphatidylinositol 3,4,5-trisphoaphate

Protein kinase A

Protein kinase $\mathrm{B}$

Protein kinase $\mathrm{C}$

Atypical PKC

Conventional PKC

Novel PKC

Phospholipase $\mathrm{C}$

Peroxisome proliferator activated receptor

Precursor SREBP

Phospho-tyrosine binding domain 
PUFA

RXR

S6K-1

SCD

SRE

SREBP

SR proteins

$\mathrm{T} 3$

TNF $\square$

TOR

TORC1

TORC2

TSC

UTR
Polyunsaturated fatty acid

Retinoid X receptor

p70 S6 kinase-1

Stearoyl-CoA desaturase

Sterol regulatory element

Sterol regulatory element binding protein

Serine and arginine rich domain-containing proteins

2,2',5'-triiodo-L-thyronine

Tumor necrosis factor alpha

Target of rapamycin

TOR complex 1

TOR complex 2

Tuberous sclerosis protein

Untranslated region 


\section{Table of Contents}

Chapter 1 ............................................................................................... 1

Introduction............................................................................................ 1

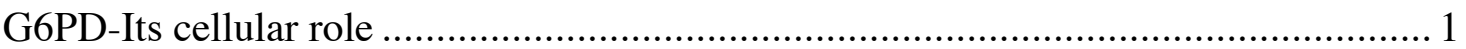

The structure of the G6PD gene .......................................................... 1

Regulation of G6PD by hormonal and nutritional factors......... 2

G6PD gene regulation by nutritional factors:....................................................... 2

G6PD gene regulation by hormonal factors: ..................................................... 3

Humoral factors are not involved in transcriptional regulation of G6PD ................... 4

Posttranscriptional regulation of G6PD..................................5

Regulated splicing of pre-mRNA in the nucleus......................... 6

Splicing of G6PD pre-mRNA is the regulatory step...................9

Polyadenylation of G6PD is not a regulatory step................................................... 10

Exon 12 of G6PD contains the cis-acting element for PUFA-

mediated regulation......................................................... 10

Insulin signaling. ........................................................................... 12

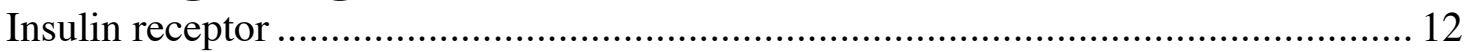

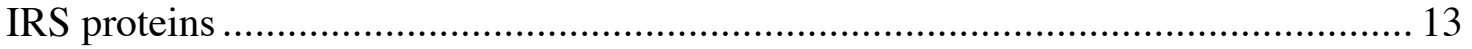

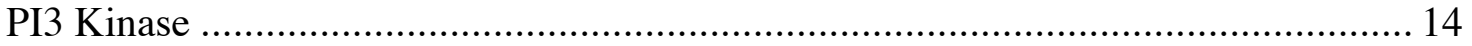

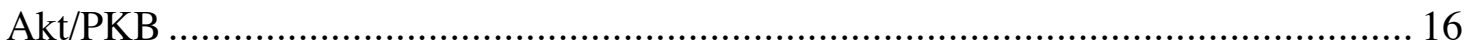

Signaling pathways that interfere with the insulin signal

transduction..................................................................... 18

MAP kinases ................................................................................ 18

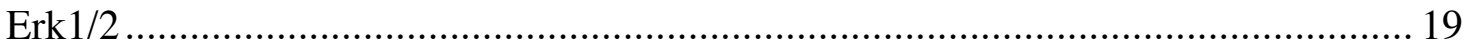

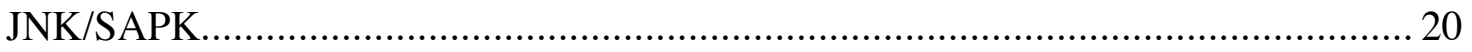

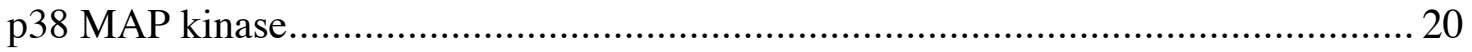

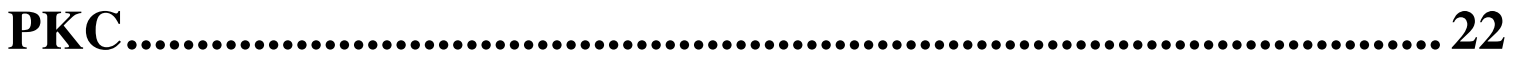

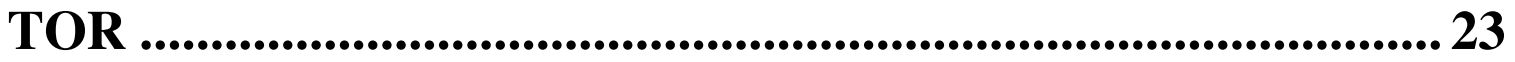

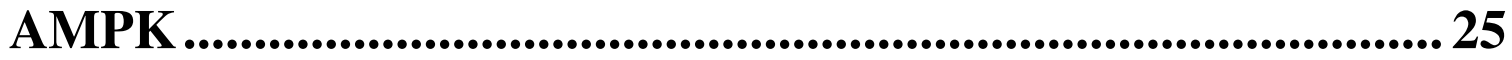

AMPK and metabolic gene regulation: .......................................................... 27

PUFA

PUFA-mediated regulation of gene expression:............................................... 29

Interference of insulin signal transduction pathway by various signaling molecules: ................................................................ 31

Summary and hypothesis: ................................................. 36

References.................................................................. 40 
Chapter 2 .....................................................................557

Title: Arachidonic acid inhibits the insulin induction of glucose-6-phosphate dehydrogenase via p38 MAP kinase..................................................................... 57

Chapter 3 .................................................................................... 76 Title: Involvement of AMP-activated protein kinase (AMPK) in arachidonic acidmediated inhibition of G6PD mRNA expression. .................................................. 76

Summary: ...................................................................... 102

Appendix: ....................................................................... 104 


\section{Chapter 1}

\section{$\underline{\text { Introduction }}$}

\section{G6PD-Its cellular role}

Glucose-6-phosphate dehydrogenase (G6PD) is the first and the rate-limiting enzyme in the pentose phosphate pathway. This enzyme oxidizes glucose-6-phosphate into 6-phosphogluconate, and produces NADPH, the major source of reducing equivalents that cells need for protection against reactive oxidation species. G6PD, along with 6-phosphogluconate dehydrogenase provide 50\% of the NADPH essential for de novo fatty acid biosynthesis in liver and adipose tissue and thus is considered to be a lipogenic enzyme.

G6PD is the only enzyme that makes NADPH in erythrocytes and thus helps in maintaining the reduced state of glutathione. Deficiency of G6PD makes the erythrocytes prone to oxidative damage. Induction of G6PD expression due to oxidative stress has been observed in many cell types $(162,198)$. Incubation of rat hepatocytes with acetaldehyde or ethanol also increases expression of $\operatorname{G6PD}(102,177,183)$. A genetic deficiency of G6PD is associated with hemolytic anemia in response to consumption of fava beans, viral illnesses, and drugs such as antimalarial agents, sulfonamide antibiotics, nonsteroidal anti-inflammatory agents, and even aspirin. Point mutations within the coding region of the gene results in a relative decrease in G6PD enzyme activity (201). G6PD-deficient individuals are also hypolipidemic, displaying both decreased serum cholesterol and triacylglycerol concentration $(118,166)$, underscoring the importance of G6PD activity for reductive biosynthetic reactions.

\section{The structure of the G6PD gene}

The G6PD gene in humans, mice, and rats is located on the $\mathrm{X}$ chromosome (xq 
28), spans $18.5 \mathrm{~kb}$, and contains 13 exons and 12 introns $(121,195)$. The protein produced from the mRNA is about $59 \mathrm{kDa}$ and consists of two to four subunits per molecule and thus forms a homodimer or a homotetramer of the active enzyme (150). The G6PD promoter is embedded in a $\mathrm{CpG}$ island that is conserved between mice, rats and humans $(121,195)$. The promoter of G6PD contains a TATA-like element and numerous stimulatory protein 1 (Sp1) elements, but no CAAT element (121, 151, 154, 195). The translational start site of G6PD is located in exon 2 and has been mapped in mice, rats, and humans $(55,84,121,189)$. The number of introns and exons is also conserved and the sequence identity is $87 \%$ between the mouse cDNA and the human cDNA. The sizes of the mRNA in mice, rats and humans are $2341 \mathrm{bp}, 2319 \mathrm{bp}$, and 2167 bp respectively. There are some unique characteristics about the G6PD gene. The second intron is about $11 \mathrm{~kb}$, which accounts for over half the size of the gene. The size of exon 13 is very large (811 nucleotides); the 3'untranslated region (3'UTR) is also large (720 nucleotides) and contains one polyadenylation site (5).

\section{Regulation of G6PD by hormonal and nutritional factors}

While G6PD enzyme activity is expressed in all cells, its synthesis is regulated only in liver and adipose tissue in response to diet and hormones. Consistent with other lipogenic enzymes, prolonged starvation decreases G6PD activity, whereas, G6PD activity as well as mRNA accumulation is induced several fold in the livers of intact animals fed a fat-free, high-carbohydrate diet after starvation $(81,175)$.

\section{G6PD gene regulation by nutritional factors:}

Consumption of a fat-free, high-carbohydrate diet, containing glucose or fructose, causes the largest increase in G6PD enzyme activity. The effect of fructose is greater than glucose and feeding intact animals a diet containing starch as a source of carbohydrate does not show as great an effect $(56,98)$. Primary rat hepatocytes incubated with $0-25$ $\mathrm{mM}$ glucose also show increasing amounts of G6PD activity (161). A similar effect was 
observed when HepG2 cells were incubated with various concentrations of glucose. Enhanced accumulation of G6PD mRNA was found within $12 \mathrm{~h}$ with as low as $1 \mathrm{mM}$ glucose, and a maximum 5-fold induction was observed with $25 \mathrm{mM}$ glucose (B.Griffith and L. Salati, unpublished). Other lipogenic and glycolytic genes such as malic enzyme, spot14, and pyruvate kinase are also regulated by monosaccharides. The regulatory factor for the carbohydrate stimulation of these genes is thought to be an intermediate in the metabolism of glucose and fructose $(68,196)$.

In contrast to the stimulatory effect of a high-carbohydrate diet, G6PD activity and mRNA accumulation are decreased in animals fed a diet rich in polyunsaturated fatty acid (PUFA) $(39,40,99,175)$. In the presence of similar carbohydrate intake, the addition of linoleate (18:2), or linolenate (18:3) in the diet decreases the activity of G6PD in rats (38). At the same time, arachidonic acid (20:4) or eicosapentanoic acid (20:5) inhibit G6PD gene expression in rat hepatocytes $(161,176,213)$. Addition of saturated fatty acids to the diet such as palmitate (16:0), and stearate (18:0), and monounsaturated fatty acids such as oleate (18:1), do not inhibit G6PD activity $(38,40)$. Similarly, saturated or monounsaturated fatty acids do not inhibit G6PD gene expression in primary rat hepatocytes. The inhibitory effect of dietary PUFA on G6PD is specifically observed in liver. The diet containing PUFA does not inhibit G6PD gene expression in adipose tissue (39).

\section{G6PD gene regulation by hormonal factors:}

The effect of starvation and refeeding on G6PD gene expression suggests a role for insulin and glucagon in the regulation of this gene (122). Streptozotocin-treated rats whose pancreatic $\square$-cells are destroyed and thus insulin secretion is abolished, are not capable of inducing G6PD activity upon refeeding (14). In diabetic rats, the increase in G6PD activity upon refeeding is attenuated in both liver and adipocytes, which is restored upon insulin replacement therapy $(15,67,69)$. Glucagon and cyclic AMP prevent the induction of G6PD upon fasting/refeeding of intact animals (63). 
G6PD is also regulated by thyroid hormone and glucocorticoids. Thyroidectomy decreases G6PD expression, which is restored upon treatment with thyroid hormone. 2,2', 5'-triiodo-Lthyronine (T3), the active form of thyroid hormone, induces G6PD expression in hypothyroid rats without involving an increase in G6PD mRNA (58). However, upon T3 administration, G6PD activity is induced 2-fold in hyperthyroid rats and this parallels the mRNA abundance (126). Adrenalectomized rats do not induce G6PD gene expression upon refeeding (14). Glucocorticoids by themselves do not have a significant effect but they amplify the insulin stimulation of G6PD (183).

G6PD regulation by hormonal factors is also observed in primary rat hepatocytes in culture. Incubation of rat hepatocytes with insulin results in a 3- to 4-fold increase in G6PD activity and mRNA abundance (108, 161, 176, 228). Glucocorticoids also positively regulate G6PD gene expression. Glucocorticoids and insulin show additive effect on G6PD (183). Unlike in intact animals, T3 and glucagon do not show any effect on G6PD mRNA expression in cultured hepatocytes $(134,228)$.

\section{Humoral factors are not involved in transcriptional regulation of G6PD.}

In sharp contrast to the regulation of other lipogenic enzymes, starvation, refeeding, insulin, or high dietary fat do not regulate the transcriptional activity of the G6PD $(85,175,176)$. No difference in the rate of transcription of the gene was observed with nuclear run-on assays with liver nuclei of mice or rats, either starved or refed with high-carbohydrate diet, or fed with low- or high-fat diets. Whereas, transcription of fatty acid synthase (FAS) and stearoyl-CoA desaturase (SCD), two other lipogenic enzymes regulated by PUFA, was decreased $70 \%$ in animals fed a high-fat diet (175). Starvation and refeeding induced transcription of these two genes 65-and 19-fold respectively. Incubation of rat hepatocytes with insulin, glucose and arachidonic acid likewise did not change the rate of transcription of G6PD, however, a similar treatment with insulin decreased the rate of transcription of phosphoenolpyruvate carboxykinase (PEPCK) indicating that insulin was active in this system (176). 


\section{Posttranscriptional regulation of G6PD}

A lack of change in the rate of transcription by different dietary factors raised the possibility of posttranscriptional regulation of the G6PD mRNA. Genes transcribed into pre-mRNA are processed before they are released into the cytoplasmic pool of mature mRNA. The processing of pre-mRNA involves 5' capping, 3' polyadenylation and splicing of introns. Any of these steps could be involved in post-transcriptional regulation.

Comparing the abundance of G6PD mRNA in different cellular fractions in starved and refed mice and mice fed a high-fat diet, it was confirmed that posttranscriptional regulation of G6PD occurs inside the nucleus (85). Refeeding starved mice resulted in a 18-fold increase in cytoplasmic mRNA abundance and a 13-fold increase in G6PD mRNA in the nucleus. This suggested that regulation of G6PD in this dietary paradigm occurred primarily in the nucleus. Moreover, the change in G6PD mRNA abundance in the cytoplasm was parallel to that in the nucleus, which confirmed that nucleocytoplasmic transport of the mature mRNA was not regulated.

Inhibition of G6PD expression by dietary PUFA also involves a nuclear step. In the livers of mice fed a high-fat diet compared to animals fed a low-fat diet, accumulation of G6PD mRNA in the nucleus was inhibited 60-70\%. Inhibition of G6PD in total RNA, which is more representative of cytoplasmic RNA, paralleled the inhibition seen in the nucleus (85). Similar results were observed in primary rat hepatocytes incubated with arachidonic acid to inhibit the insulin- and glucose-mediated induction of G6PD (175). Incubation of rat hepatocytes with arachidonic acid caused about 50\% inhibition of cytoplasmic mRNA abundance and about $60 \%$ inhibition of nuclear mRNA abundance, mimicking the above results in the intact animals. Because changes in the amount of G6PD mRNA occur in the nucleus and precede the changes in amount of G6PD mRNA 
in the cytoplasm, steps involved in processing of the nascent G6PD transcript, that is splicing, and/or polyadenylation, may be sites of regulation.

\section{Regulated splicing of pre-mRNA in the nucleus}

In all eukaryotic cells the primary transcript of the gene or the pre-mRNA is processed into mature mRNA inside the nucleus before it moves to the cytoplasm for protein translation. Splicing of introns of the pre-mRNA is one of the most important processing steps in all eukaryotes. Splicing involves the recognition of the exon-intron boundaries by various splicing factors known as small ribonuclear proteins or snRNPs. Binding of various snRNPs to the pre-mRNA produces multicomponent complexes known as spliceosomes. Different snRNPs recognize different consensus sequences present in the introns. For example, $\mathrm{U} 1 \mathrm{snRNP}$ recognizes a consensus GU sequence at the 5' splice junction, whereas U2 snRNP binds at the branch point site, a consensus sequence of YNYRAY ( $\mathrm{Y}$ is pyrimidine and $\mathrm{R}$ is purine base). U2 snRNP auxiliary factor 65 and 35 (U2AF 65 and 35 respectively), also known as non-snRNP splicing factors, bind at the polypyrimidine tract and at the 3' splice junction with a consensus AG sequence respectively in the introns. A tri-snRNP complex known as U4/U6.U5 finally binds to the pre-mRNA, which, after a vast rearrangement, brings the two adjacent exons into closer proximity and the splicing of the intervening intron takes place. Two adjacent exons are finally ligated after two trans-esterification reactions (107).

Regulated splicing often involves splicing co-activators and/or co-repressors in the nucleus in addition to the snRNPs. Splicing co-activators are typically members of the SR (RNA binding proteins composed of an RNA recognition motif and a serine (S) and arginine (R) rich domain) family of proteins whereas splicing co-repressors belong to the hnRNP (heterogeneous nuclear ribonucleoprotein) family. The SR protein binding site in an exon is known as the exonic splicing enhancer (ESE) sequence $(17,71)$ whereas hnRNP-binding site in an exon is known as exonic splicing silencer (ESS) sequence (117, 171, 203). Recognition of ESE sequences by SR proteins efficiently recruits U2 snRNP at 
the branch point and also U2AF 65 and 35 at their corresponding binding sites (31). ESE and ESS sequences could be localized on separate exons or could be juxtaposed on the same exon. In the later case, a competition between the SR and the hnRNP proteins takes place for binding. Recruitment of hnRNP proteins in an exon thus, inhibits the binding of SR proteins and in turn, interferes with the recruitment of snRNPs and an inhibition of splicing takes place.

Both the SR and hnRNP proteins are regulated by phosphorylation and dephosphorylation $(66,106,217,230)$. Phosphorylation/dephosphorylation of these proteins change their localization in various compartments in the nucleus and/or facilitates the nuclear-cytoplasmic shuttling of the protein.

Phosphorylation/dephosphorylation of these proteins may also change their binding affinity for other interacting proteins or the affinity for the RNA $(217,225)$. Depending on the availability of these proteins in the activated form in the nucleus, SR or hnRNP binds, and an induction or repression of splicing takes place.

Most studies of regulated splicing have focused on alternative exon inclusion; that is, depending on various conditions, one or a group of exons are either excluded or included during formation of a mature mRNA from a primary transcript. G6PD mRNA is not alternatively spliced, however, the constitutive splicing of this mRNA is regulated; that is, under all conditions, all of the 13 exons of G6PD are spliced but the efficiency of this splicing event varies under different hormonal and nutritional status $(5,191)$. There are only few examples where humoral factors regulate splicing efficiency of constitutively spliced exons. Diverse mechanisms appear to be involved in this type of post-transcriptional regulation. For example, regulated expression of thymidylate synthase during the cell cycle requires its promoter and a spliceable intron but is not specific to any intron of the mRNA (100). Splicing of the tumor necrosis factor-alpha (TNF-alpha) mRNA requires a cis-acting element in the 3'-UTR of the transcript (140). Dietary carbohydrate, refeeding and insulin enhance the stability of the pre-mRNA of the single intron of spot-14 mRNA $(5,26,205)$. Spot-14 is a protein involved in lipid metabolism. Splicing is the postulated mechanism for the regulation of Spot-14, however, 
further characterization and molecular details involved in this regulation have not been reported yet.

Regulation of alternative splicing is better characterized, however, involvement of various signal transduction pathways in alternative splicing is a relatively new area to explore. As regulation of alternative splicing involves phosphorylation/dephosphorylation events of the SR/hnRNP proteins, involvement of different signaling pathways that activate various kinases/phosphatases is not surprising. Insulin-mediated activation of the phosphoinositide 3-kinase (PI3 kinase) pathway regulates splicing of exon $\square \mathrm{II}$ of protein kinase C (PKC) $\square$ involving phosphorylation of the SR protein SRp40 $(146,147)$. Activation of the Erk mitogen-activated protein kinase (MAP kinase) pathway, PKC and Ras are involved in splicing of exon v5 of CD44 and exons 4-6 of CD45 $(105,208)$. Activation of p38 MAP kinase and its upstream effector MAP kinase kinase (MKK) 3/6 by osmotic shock or UV irradiation has been shown to modulate sub-cellular distribution of hnRNP A1, which in turn regulates alternative splicing of adenovirus E1A pre-mRNA reporter construct (199). Involvement of signaling pathways in regulation of constitutive splicing has not yet been explored. Regulation of G6PD gene expression is mediated via the PI3 kinase and MAP kinase pathways (discussed in chapters 2 and 3). Involvement of these signaling pathways in the regulation of constitutive splicing of G6PD mRNA would be a novel finding.

When an mRNA is not spliced efficiently or polyadenylated, it is degraded by one of two different pathways inside the cell nucleus. In the first pathway, RNA that is not completely processed does not leave the site of transcription in the nucleus (16). Specific proteins recruited by the spliceosome, most likely mark correct splicing and initiate the export of the RNA to the cytoplasm. Lack of splicing does leave these marks and the RNA is not exported, but degraded in the nucleus. In yeast and mammalian cells, the degradation is catalyzed by a complex of exonucleolytic enzymes called the nuclear exosomes $(16,127,128)$. Several questions like how in a multi-intron transcript the correct and complete splicing of all introns are detected or what proteins or signals are responsible to recruit the exosomes to a mRNA, remain to be answered. 
The second pathway of nuclear RNA degradation is due to the presence of the premature stop codons in the RNA transcript. This decay pathway appears to need either the presence of a Kozak consensus sequence or an internal ribosomal entry site in the RNA (206). Some components of the translational machinery may act as a scanner and detect the premature termination codon and target the mRNA for degradation $(13,127$, 159). G6PD mRNA does not contain premature termination codons, but inefficiently spliced pre-mRNA, which retains one or more introns, can give the appearance of an mRNA containing premature stop codons. Whether nuclear exosomes are responsible in this pathway too, is not known.

\section{Splicing of G6PD pre-mRNA is the regulatory step}

To investigate whether splicing of G6PD pre-mRNA is the regulatory step in the post-transcriptional regulation of G6PD, different nuclear fractions were isolated from the livers of mice that had been starved and then refed a high-carbohydrate diet. The insoluble nuclear fraction contains pre-mRNAs that are both newly synthesized and are undergoing processing whereas the nuclear membrane fraction contains mature mRNA $(35,52)$. Two probes containing different exon-intron boundaries of G6PD were used in RNase protection assay to quantify and compare the amounts of unspliced and spliced RNA in the livers of starved and high-carbohydrate refed mice. During refeeding, the rate of accumulation of spliced RNA significantly increased over the unspliced RNA (5). To further confirm that the regulation occurs at the level of splicing, RNase protection assays were performed using a probe that crosses multiple splice junctions (exon8-intron8exon9-intron9) (5). The different protected fragments detected in the insoluble nuclear fractions of starved and refed mice liver were unspliced (exon8-intron8-exon9-intron9), partially-spliced (exon8-exon9-intron9) and fully-spliced RNA. Refeeding caused a greater accumulation of partially-spliced and fully-spliced RNA compared to the starved mice. At the same time, the ratio of partially-spliced RNA to unspliced pre-mRNA and the ratio of fully-spliced RNA to the unspliced pre-mRNA increased when the starved 
mice were refed with a high-carbohydrate diet. These results confirmed that the regulation of splicing was an early process inside the nucleus. Similar results were obtained in mice fed with a low-fat vs. a high-fat diet. The low-fat diet caused a greater accumulation of spliced mRNA compared to the high-fat diet (5).

\section{Polyadenylation of G6PD is not a regulatory step.}

Improper 3' end formation of the pre-mRNA can cause enhanced degradation of the transcript. To test whether this phenomenon is associated with the dietary regulation of the G6PD gene, the length of the poly (A) tail of the mRNA was measured by an RNase $\mathrm{H}$ assay on mRNA from the nuclear insoluble fraction of livers from starved and refed mice. It was found that, despite large changes in overall mRNA accumulation, the length of the poly (A) tail remained the same in both dietary conditions (5). Similarly, the inhibition of G6PD reporter RNA in hepatocytes incubated with arachidonic acid was also independent of the polyadenylation signal present in the construct (191).

\section{Exon 12 of G6PD contains the cis-acting element for PUFA- mediated regulation}

All of the results indicating regulated splicing of G6PD mRNA raised the question of whether a specific RNA sequence is responsible for the regulated splicing. To investigate this, different pre-mRNA reporter constructs representing subsets of the $18-\mathrm{kb}$ gene, were made and transfected into primary hepatocytes (191). Transcription of these

reporter constructs was driven by the CMV promoter. Expression of RNA from a reporter construct containing intron 6 through the 3'UTR (pCMV7-13 3'UTR) of G6PD was inhibited by $50 \%$ when cells were treated with insulin and arachidonic acid, compared to cells treated with insulin alone, and the endogenous G6PD gene expression in rat liver was attenuated to the same extent. Reporter constructs containing sequences upstream of intron 6 ligated to the 3'UTR were not regulated by arachidonic acid. Replacing the CMV promoter with G6PD promoter in these reporter constructs did not change the result, indicating that the effect of arachidonic acid was not promoter specific. Expression 
of $\square$-actin mRNA was not affected by arachidonic acid, showing that PUFA specifically regulates G6PD RNA expression and it is not a generalized effect. These results confirmed that the regulation of G6PD expression requires an RNA sequence located somewhere between intron 6 and the 3'UTR of G6PD pre-mRNA.

To further define the RNA sequence regulating mRNA splicing of G6PD, successive 5' deletions of the reporter construct pCMV7-13 3'UTR were done and the new constructs were transiently transfected into primary rat hepatocytes (191). The amount of reporter RNA was decreased in the presence of arachidonic acid in all constructs containing sequences between the start of exon 12 to the 3 ' end of the gene. Furthermore, this region of the gene was able to confer inhibition by arachidonic acid onto a heterologous RNA, - -galactosidase, which by itself is not regulated by arachidonic acid. Deletion of exon 12 from the reporter construct abrogated the inhibition by arachidonic acid. Thus, it was confirmed, that exon 12 contains a cis-acting element involved in inhibition of G6PD RNA accumulation by arachidonic acid.

This idea was further supported when mice fed a high-fat diet had a much higher accumulation of partially-spliced RNA containing intron 11 compared to the low-fat diet fed mice. At the same time, the high-fat diet caused a $61 \%$ inhibition of the accumulation of the fully-spliced RNA. This data indicated that high-fat diet might inhibit the splicing of intron 11. The retention of pre-mRNA with this intron in the nucleus subsequently would result in the degradation of the incompletely spliced RNA (191). These data, together, confirmed that the posttranscriptional regulation of G6PD by a high-fat diet or arachidonic acid takes place at the level of splicing in the nucleus and the potential cisacting element for this regulation is located within exon 12 of G6PD mRNA. 


\section{Insulin signaling.}

Insulin is a major signaling molecule in intermediary metabolism. Carbohydrate and lipid metabolism are regulated by insulin in various tissues, including liver, muscle, brain and adipocytes. Insulin is secreted from the pancreatic beta cells in response to consumption of dietary carbohydrate. Upon secretion, the primary role of insulin is to maintain blood glucose level. Insulin helps to mobilize glucose transporters (like GLUT 4), to the plasma membrane of skeletal muscle and adipose tissue so that blood glucose can be internalized by these tissues. Insulin increases the activity of the glycolytic and lipogenic enzymes whereas it inhibits gluconeogenesis in various organs. Regulation of genes involved in carbohydrate and lipid metabolism by insulin also helps to maintain blood glucose concentration. Upon secretion, insulin binds to the insulin receptor on the cell membrane and activates the insulin signaling. For regulation of energy homeostasis and intermediary metabolism, insulin signaling through the PI3 kinase pathway is most important for its regulatory properties (169). G6PD is highly regulated by insulin and inhibition of the PI3 kinase pathway abolishes the insulin-mediated induction of G6PD in primary rat hepatocytes (202).

Here I am discussing, in brief, the PI3 kinase pathway, highlighting certain proteins in this pathway such as the insulin receptor, insulin receptor substrates (IRS), PI3 kinase and the down stream effector protein Akt/PKB.

\section{Insulin receptor.}

The insulin receptor is a trans-membrane receptor and belongs to the receptor tyrosine kinase family. It is composed of two alpha and two beta subunits that are linked via disulfide bonds. The alpha subunits are in the extracellular domain and bind insulin, whereas the beta subunits span the membrane and contain the ATP binding and tyrosine kinase domains. Upon binding to insulin, the beta subunits trans autophosphorylate each other on tyrosine residues via their kinase domain. Tyr-phosphorylation of the insulin receptor activates the receptor, which in turn binds to the downstream protein IRS in the signaling cascade. Recognition and binding of the IRS molecules to the insulin receptor is the required step towards the activation of the PI3 kinase pathway. 


\section{IRS proteins.}

The downstream effector molecule of the insulin receptor is IRS. IRS proteins act as mediators for the activation of PI3 kinase via insulin. Four members of IRS proteins have been identified and are named as IRS-1-4 (187, 188). IRS-1 and -2 are widely distributed in mammalian tissues, IRS-3 is found in adipose tissue, fibroblasts and in liver cells, IRS-4 is found in embryonic kidney cells. All family members of IRS proteins contain N-terminal pleckstrin homology $(\mathrm{PH})$ domain and phospho-tyrosine-binding domain (PTB) (169). The PTB domain binds directly to the insulin and insulin-like growth factor-1 (IGF-I) receptors at the Tyr-phosphorylated NPEY motif. The PH domain of IRS-1 is necessary for the association with the receptor and it also mediates the association of IRS-1 with membrane-bound phosphoinositides (226). The IRS proteins contain multiple tyrosine phosphorylation sites like YMxM and YxxM motifs. The tyrosine in the YMxM motif is the target for phosphorylation by the insulin receptor kinase (170). Other tyrosine phosphorylation sites of IRS-1 are recognized by various adaptor proteins like growth factor receptor-bound protein 2 (Grb2), Nck, Crk, tyrosine-phosphatases like SHP2 and tyrosine kinases like Fyn etc (227). IRS proteins are also phosphorylated at tyrosine residues by JAK family associated tyrosine kinase receptors for growth hormone and various cytokines, however; IRS proteins are not substrates for epidermal growth factor (EGF)-receptor, or platelet-derived growth factor (PDGF)-receptor tyrosine kinases $(188,207)$. Tyrosine phosphorylation at various residues of IRS-1 by different stimuli can cause diverse signaling responses.

There is some degree of functional overlap between IRS-1 and -2. IRS-1 knockout mice are only mildly insulin resistant, suggesting that IRS-2 is capable of substituting for IRS-1, in the insulin signal transduction pathway. In fibroblast cell lines derived from IRS-1 knock out mice, activation of the PI3 kinase pathway could be restored to same degree by retrovirus-mediated expression of IRS-1 or IRS-2 (24); however, functional overlap between IRS-1 and -2 is not total. Targeted disruption of the IRS-2 gene in mice showed that IRS-1 cannot compensate for the loss of IRS-2, as these mice developed overt diabetes, reflecting a failure of a complementary role for IRS-1 
(212). Activation of IRS proteins is thus absolutely necessary for the activation of the insulin signal transduction pathway, failure of which leads to the insulin resistance and inhibition of insulin-mediated regulation of gene expression and impairment of lipid and glucose homeostasis.

\section{PI3 Kinase}

The downstream effector molecule of IRS proteins in the insulin-signaling pathway is known as PI3 kinase. Activation of this kinase plays the most important role in mediating the effect of insulin in the intermediary metabolism and gene expression. Activation of the insulin receptor activates PI3 kinase, which turns on a signaling cascade further downstream in this pathway. PI3 kinase is responsible for the following phosphorylation reactions:

1) Conversion of phosphatidylinositol 4,5-bisphosphate, [PI (4,5) P2] (PIP2) into phosphatidylinositol 3,4,5-trisphosphate, [PI (3,4,5) P3] (PIP3),

2) Conversion of phosphatidylinositol 4-phosphate, [PI (4) P] into phosphatidylinositol 3,4-bisphosphate [PI $(3,4)$ P2], and

3) Conversion of phosphatidylinositol (PI) into phosphatidylinositol 3-phosphate (PI3P).

Conversion of PIP2 into PIP3 is considered the main function of PI3 kinase $(179,181)$.

There are four classes of PI3 kinases. Class 1a, 1b, 2 and 3. Class 1a PI3 kinase accounts for the activation of signaling upon insulin stimulation. This class is composed of an adapter/regulatory subunit and a catalytic subunit $(82,87)$. Class $1 \mathrm{~b}$ is regulated by G-proteins but not by insulin. The catalytic subunit but not the adapter subunit of this class of PI3 kinase shares significant sequence homology to that of class 1a (180). Class 2 PI3 kinase is widely expressed and is activated by insulin, however; this class of PI3 kinase is incapable of converting PIP2 into PIP3, a key mediator of insulin signaling, and thus it seems unlikely that this class of PI3 kinase would mediate common insulin responses $(48,200)$. Class 3 PI3 kinase can only use PI as its substrate to produce PI3P. As insulin does not increase the cellular level PI3P, it is unlikely that this class of PI3 kinase will play any role in insulin signaling (41). 
The domain structure of class 1a PI3 kinase is well characterized. The molecular mass of the catalytic subunit is $110 \mathrm{kDa}$ and there are three highly homologous isoforms

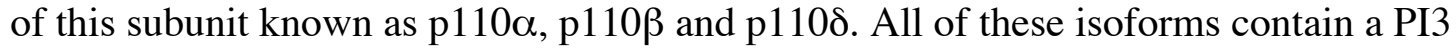
kinase adapter protein binding domain and Ras binding domain at the $\mathrm{N}$-terminus and a kinase domain at the C-terminus $(82,87)$. The adapter/regulatory subunit of class 1 a PI3 kinase is encoded by at least three genes, which provide homologous products. Two

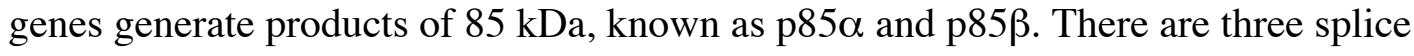
variants of $\mathrm{p} 85 \square$ known as p85 $\square 1, \mathrm{p} 55 \square$ and p50 $\square$. All of these gene products contain two C-terminal SH2 domains and a p110-binding domain in between the SH2 domains. The isoforms, p85 $\square, \mathrm{p} 85 \square$ and p85 $\square 1$ each contain a SH3 domain, a Bcr/Rac GAP homology domain $(\mathrm{BH})$ and two proline-rich regions (P1 and P2) at the N-terminus. The p55 $\square$ and p50 $\square$ isoforms lack the $\mathrm{N}$-terminal $\mathrm{SH} 3, \mathrm{BH}$ or the proline-rich domains and instead have short novel sequences at the $\mathrm{N}$-terminus. This is probably due to the fact that they arise from alternate transcriptional start sites. The p55 $\square$ is highly expressed in brain and muscle and the p50 $\square$ is expressed in brain, muscle, liver and kidney $(9,70,89)$. The variability in structure and expression level of the regulatory subunit of PI3 kinase in different organs suggests that this kinase might be activated via diverse mechanisms adding to complexity to the signaling pathway.

The SH2 domains of $\mathrm{p} 85$ bind with high selectivity to the phosphorylated YxxM and YMxM sequences (174). Both of these sequences are tyrosine-phosphorylated in IRS-1. Upon insulin stimulation, IRS-1 is phosphorylated at its several tyrosine residues, which are then recognized and bound by the $\mathrm{SH} 2$ domains of the PI3 kinase. In vitro studies show that the insulin receptor phosphorylates IRS-1 on four tyrosine residues in the YMxM motif (Tyr-608, 628, 939 and 987 in rat IRS-1) and one (Tyr-460) in the YxxM motif. Deletion of these sites abolishes the ability for binding of IRS-1 to the PI3 kinase $(158,186)$. Binding of PI3 kinase to IRS-1 directly stimulates its activity. The simultaneous occupancy of both the $\mathrm{SH} 2$ domains of $\mathrm{p} 85$ by phospho-tyrosine residues of IRS-1 efficiently recruits and activates the PI3 kinase. The stable complex formation 
between IRS-1 and PI3 kinase is necessary for the activation of PI3 kinase (141), which eventually relays the insulin-signal to the downstream effector protein Akt/PKB.

\begin{abstract}
Akt/PKB
The downstream protein of PI3 kinase in insulin signaling pathway is Akt/PKB, whose activation by insulin gives an indirect measure of the activation of the PI3 kinase pathway and thus is absolutely required to carry out the function of insulin in the intermediary metabolism. Akt/PKB is a PH domain containing Ser/Thr kinase that is largely activated by insulin and various growth factors. There are three isoforms of PKB, $\square, \square$ and $\square$ PKB $\square$ is the major isoform activated by insulin in muscle, liver and adipocytes. PKB $\square$ is activated in adipocytes in response to insulin signaling, however; PKB $\square$ is only responsive to insulin in cell culture models (205). Activation of the PI3 kinase pathway is both necessary and sufficient for the activation of all isoforms of Akt. In this regard, Akt activation is abolished by inhibitors of PI3 kinase, the dominant negative isoforms of the PI3 kinase adapter/regulatory subunit and the mutant insulin receptor which is unable to activate PI3 kinase $(6,25,54)$.
\end{abstract}

Growth factors and insulin increase activation of Akt/PKB by phosphorylating it. The phosphorylation sites of PKB $\square$ are at Thr-308 at the activation loop and Ser-473 at the C-terminal hydrophobic tail (3). The kinase responsible for the phosphorylation at Thr-308 of PKB $\square$ has been characterized as phosphoinositide-dependent kinase-1 (PDK1). PDK-1 also phosphorylates PKB $\square$ at Thr-309 and PKB- $\square$ at Thr-305. PDK-1 has a single PH domain, which binds to PIP3. Upon insulin stimulation PIP3 binds directly to Akt as well at its $\mathrm{N}$ terminal PH domain. Binding of PIP3 to both PDK1 and Akt eventually recruits both of them to the plasma membrane and this promotes efficient phosphorylation of Akt at Thr-308 by PDK1 $(4,178)$. The kinase responsible for the Ser473 phosphorylation is only recently identified. The mammalian target of rapamycin (mTOR)-rictor complex has been shown to be the kinase responsible for the Ser-473 phosphorylation of Akt (164) (discussed in detail later). 
The downstream targets of Akt/PKB share a common phosphorylation site. An optimal peptide substrate of Akt/PKB has a Ser as the phosphoacceptor site, a bulky hydrophobic amino acid at +1 , a Ser/Thr at -2 and conserved arginine residues at -3 and -5 positions (138). Some of the common targets of Akt/PKB are, glycogen synthase kinase 3 (GSK3), 6-phosphofructo-2-kinase, the Forkhead family of transcription factors including FKHR, and AFX, an upstream kinase in MAP kinase signaling pathway Raf, mTOR, the endothelial nitric oxide synthase eNOS and the pro-apoptotic protein BAD (165). Ser-phosphorylation of GSK3 by Akt, inactivates this protein, which leads to activation of glycogen synthesis (43). The Ser-phosphorylation of transcription factors FKHR and AFX by Akt also inactivates them, leading to a down regulation of the target genes (23). Activation of mTOR by Akt leads to protein translation and metabolic gene regulation (discussed in detail later), whereas, regulation of Raf by Akt mediates a cross talk between the PI3 kinase and the MAP kinase pathways (234). Thus, it is evident that the activation of insulin signaling which leads to the activation of Akt regulates various cellular processes. 


\section{Signaling pathways that interfere with the insulin signal transduction}

Various signaling pathways interfere with the PI3 kinase signaling, which results in decreased insulin sensitivity or causes insulin resistance. Activation of various MAP kinases, the target of rapamycin (TOR) pathway and various isoforms of PKC have been reported to inhibit the PI3 kinase pathway. AMP activated protein kinase (AMPK) is shown to inhibit lipogenic gene expression and at the same time, modulates the PI3 kinase pathway. Non-esterified fatty acid or high-fat diet containing PUFAs has been shown to activate some or all of these pathways, which in turn interferes with insulin signal transduction. In this section I am going to discuss in brief these signal transduction molecules. A schematic diagram of mechanism of inhibition of PI3 kinase pathway by these molecules is shown in figure 1 and will be discussed in a separate section.

\section{MAP kinases}

MAP kinases are a family of protein kinases, which phosphorylate at specific Ser and Thr residues of their target proteins. These kinases are highly conserved among the species and are required to regulate various cellular processes, for example, gene expression, metabolism, mitosis, cell proliferation and programmed cell death (210). Phosphorylation/dephosphorylation of MAP kinase target proteins can turn on or off their activity, which in turn can switch on or off a cellular event. Some of the target proteins for the MAP kinases include other protein kinases, transcription factors and cytoskeletal proteins.

MAP kinases themselves are regulated by phosphorylation cascades (156). There are different MAP kinase kinases (MKKs) that selectively phosphorylate and activate specific MAP kinases. MKKs are in turn activated and phosphorylated by MKK kinases (MKKKs). In multi-cellular organisms, three well-characterized subfamilies of MAP kinases exist. They are known as Erk1/2, c-Jun NH2-terminal kinase/ stress-activated 
protein kinase (JNK/SAPK) and p38 MAP kinases. Each of these MAP kinases has specific MKKs and MKKKs (92).

\section{Erk1/2}

Erk 1 and 2 are widely expressed and are involved in the regulation of cell growth and proliferation. These two proteins are 43 and $41 \mathrm{kDa}$ respectively and contain more than $85 \%$ sequence identity (20). The relative abundance of Erk 1 and 2 varies depending on the tissue type. Various stimuli including growth factors, cytokines, virus infection, ligands for the G-protein coupled receptors, transforming agents and carcinogens activate them. Upon activation both Erk 1 and 2 are phosphorylated on Tyr and Thr residues in the activation domain. For both Erk1 and Erk2 the Tyr and Thr residues are separated by a glutamate residue, forming a TEY activation loop (148).

The upstream MKK that phosphorylates and activates Erk 1/2 is known as MEK. There are two isoforms of MEK, MEK 1 and 2 and both activate Erk1/2, in vitro (231). The MKKK that activates and phosphorylates MEK is known as Raf. There are three different isoforms of Raf, known as A-Raf, B-Raf and Raf-1. Raf-1 is ubiquitously expressed, B-Raf is mostly expressed in neuronal tissues and A-Raf is found in urogenital tissue. Most studies have been done on Raf-1. Cellular localization, phosphorylation of Tyr, Thr and Ser residues, and protein-protein interactions have all been implicated for the regulation and the activation of Raf-1. Raf- 1 is activated by small G protein $\mathrm{H}-, \mathrm{K}-$ and N-Ras. The phosphorylation state of Raf-1 is influenced by various protein kinases like Src, PKC, the p21-activated protein kinase (PAK), and Akt/PKB (129). Various substrates of Erk 1/2 have been identified, among them the transcription factors cAMPresponse element binding protein (CREBP) and sterol regulatory element binding protein (SREBP), which are involved in metabolic gene regulation $(19,218)$. Activation of Erk interferes with the insulin-signaling pathway (Fig. 1, blue lines), details of which will be discussed later. 


\section{JNK/SAPK}

This subfamily of MAP kinases was first isolated and characterized as the stressactivated protein kinase and as a binding partner of c-Jun (80). c-Jun is a component of AP-1 transcriptional complex. JNK phosphorylates c-Jun and enhances its transcriptional activity. The purified JNK proteins are 46 and $54 \mathrm{kDa}(80)$. There are three isoforms of JNK known as JNK 1, 2 and 3 which shares more than $85 \%$ sequence identity. All the JNK/SAPKs are activated upon phosphorylation at Thr and Tyr residues at their active sites separated by a proline residue, making a TPY activation loop (109). Cytokines, ligands for $\mathrm{G}$ protein-coupled receptors, various forms of stresses, growth factors, and transforming agents activate this MAP kinase.

The upstream MKKs that activate JNK upon phosphorylation are known as MKK4 and MKK7. MKK4 is also known as SEK1, MEK4, JNKK1 and SKK1. Synonyms for MKK7 are MEK7, JNKK2 and SKK4. MKK4 and 7 preferentially phosphorylate the Tyr and the Thr residues in the TPY activation loop $(111,224)$. Regulation of the JNK pathway is influenced by many MKKKs. There are 13 different MKKKs that can regulate JNK that allows a wide range of stimuli to activate this MAP kinase (149). Activation of this MAP kinase causes impairment of insulin signal transduction pathway (Fig. 1, blue lines), which leads to insulin resistance in diabetes and obesity. Details of these mechanisms will be discussed later.

\section{p38 MAP kinase}

p38 MAP kinase is a 38-kDa-protein member of the MAP kinase family. There are four subfamilies of p38 MAP kinase, $\square, \square, \square$ and $\square$. The p38 MAP kinase $\square$ and $\square$ genes are ubiquitously expressed; however, p38 MAP kinase $\square$ and $\square$ are expressed differentially in various tissues. p38 MAP kinase $\square$ is predominantly expressed in skeletal muscle, and p38 MAP kinase $\square$ is expressed in lung, kidney, testis, pancreas and small intestine. These p38 MAP kinase isoforms have $60 \%$ sequence identity within the group, but only $40-45 \%$ to the other MAP kinase family members (139). 
p38 MAP kinase is activated by inflammatory cytokines, growth factors, ligands for $\mathrm{G}$ protein-coupled receptors, viruses, stresses, etc (215). The p38 MAP kinases have Thr and Tyr residues at their active sites separated by a glycine residue, making a TGY activation loop (72). The upstream kinases that phosphorylate and activate p38 MAP kinase are known as MKK3 and 6. MKK6 preferentially phosphorylates p38 MAP kinase $\square, \square, \square$ and $\square$. With the exception of p38 MAP kinase $\square$, all the others are activated by MKK3. p38 MAP kinase $\square$ and $\square$ can also be activated by JNK kinase MKK4 and 7 (50, $79,139,149)$.

Further upstream activators known to activate p38 MKK, are diverse, which explains the fact that p38 MAP kinase can be activated by various stimuli. The known MKKKs are MTK1, MLK2/MST, MLK3/PTK/SPRK, DLK/MUK/ZPK, ASK1/MAPKKK5 and TAK1 (139). Different MKKKs function to mediate different upstream signals. The low molecular weight GTP-binding proteins like Rac and CDC42 are upstream activators of p38 MAP kinase pathway. Rac/CDC42 can directly activate p38 MKKK via binding with MLK1 and 2. PAK 1, 2 and 3 can be activated upon binding with Rac/CDC42 and their dominant negative mutants have been shown to inhibit p38 MAP kinase activation (11). Small G protein, Ras, activates p38 MAP kinase as well. Dominant negative Ras abolishes the interleukin-mediated activation of p38 MAP kinase while the constitutively active Ras activates this MAP kinase in primary fibroblasts. Activated Ras associates with TAK1, an MKKK, which activates the p38 MAP kinase pathway $(124,144)$.

The first identified substrate of p38 MAP kinase $\square$ is MAP kinase-activated protein kinase 2 (MAPKAP 2). In vivo activation of this kinase is inhibited by a specific inhibitor of p38 MAP kinase $\square$ and $\square$, SB203580 (57). The other downstream substrate, which was identified subsequently, was MAPKAP 3. MAPKAP 2/3 are known to activate heat shock protein 27 (HSP 27), cAMP response binding protein (CREB), activating transcription factor -1 (ATF1) etc $(182,190)$. Other protein kinases which have recently been found as downstream substrates for p38 MAP kinase $\square$ and $\square$ are, MAP kinase interaction protein kinase, MNK1 (known to bind with translation initiation 
factor eIF-4E), p38 MAP kinase regulated/activated kinase, PRAK (a stress activated kinase), mitogen- and stress-activated kinase, MSK etc. Some transcription factors are also phosphorylated and activated by p38 7 , for example, ATF-2, ATF-1, CHOP, p53, C/EBP etc $(79,139,149)$.

Activation of p38 MAP kinase pathway has been shown to regulate expression of various genes. Some of the examples of positive regulation are activation of proliferator activated receptor $\square$ (PPAR $\square$ in 3T3L1 adipocytes (49), collagenase 1 and 3 in fibroblasts (209), cyclooxygenase 2 (COX-2) in Hela and in monocytes (184) and interleukins 1, 6 and 8 in monocytes and macrophages (64). Activation of p38 MAP kinase negatively regulates Cyclin D1 and low-density lipoprotein (LDL) receptor gene expression in HepG2 cells (139). A recent report has shown that induction of gluconeogenic genes, PEPCK and glucose-6-phosphatase (G6Pase), in liver upon fasting is mediated via the activation of p38 MAP kinase pathway (27). This activation of p38 MAP kinase upon starvation is mediated via the activation of protein kinase A (PKA). Glucagon, a hormone secretes during fasting and responsible for the activation of the gluconeogenic genes, is also capable of activating p38 MAP kinase in primary rat hepatocytes (27). Like Erk and JNK MAP kinases, activation of p38 MAP kinase also inhibits insulin signaling (Fig. 1, blue lines), which will be discussed in a later section.

\section{$\underline{\text { PKC }}$}

PKC is a Ser/ Thr kinase and found in all eukaryotes. Depending on the enzyme's cofactor requirements, there are three major subgroups of $\mathrm{PKC}$, conventional or $\mathrm{CPKC}$, novel or nPKC and atypical or aPKC (91). The cPKCs contain $\square$, $\square$, and $\square$ isoforms. The

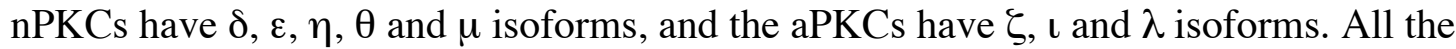
PKC isoforms contain a conserved catalytic domain, (also known as the kinase domain), and a regulatory domain. The conventional isozymes contain a $\mathrm{C} 1$ domain that binds to the diacyl glycerol (DAG) and phorbol esters and a $\mathrm{C} 2$ domain that binds to phosphatidyl serine, which mediates calcium responsiveness at the regulatory site. Thus $\mathrm{cPKCs}$ are 
both DAG and calcium sensitive. The $\mathrm{nPKCs}$ contain a $\mathrm{C} 1$ but a non-functional $\mathrm{C} 2$ or C2-like domain, thus are responsive to DAG but not to calcium. The aPKCs contain neither a $\mathrm{C} 1$, nor a $\mathrm{C} 2$ domain and thus are insensitive to both DAG and calcium (91, $125)$.

The cPKCs and nPKCs are activated by various signaling pathways that activate phospholipase C (PLC) and produce DAG. For the cPKCs but not the nPKCs, the recruitment of DAG is calcium dependent. For the aPKCs, the activation takes place in part via interactions with cdc42-GTP-Par6 complex, which binds to the PB1 domain of aPKC. Binding to these substrates releases the kinase domain from a pseudo substratebinding domain and activates PKC $(135,136)$. Phosphorylation of $\mathrm{PKC}$ is required for its activation. The phosphorylation takes place at the activation loop that contains TFCGT motif. Another known phosphorylation site is present near the $\mathrm{C}$ terminal hydrophobic region. PDK 1 catalyzes the phosphorylation event (145).

Activation of various isoforms of PKC can both positively and negatively regulate insulin-signaling pathway either directly or via activating various MAP kinases (Fig. 1, red arrows). A discussion in this regard in more detail could be found in a later section.

\section{$\underline{\text { TOR }}$}

Target of rapamycin (TOR) is a Ser/Thr kinase that controls cell growth and metabolism. Every eukaryotic genome contains a TOR gene. Eukaryotic TORs have a Cterminal Ser/Thr protein kinase domain, which resembles the catalytic domain of PI3 kinase (216). The mammalian version of TOR is known as mTOR, which forms two protein complexes mTORC1 and mTORC2. mTORC1 is associated with mTOR, raptor and G $\square \mathrm{L}$ (also known as mLST8), whereas mTORC2 is composed of mTOR, rictor and G $\square$ L. An intracellular cofactor peptidyl-prolyl cis/trans isomerase named FKBP12 binds to rapamycin and inhibits the kinase activity of mTORC1 but not mTORC2; however, the exact mechanism of this inhibition is not known $(73,103,163)$. A small GTPase protein 
Rheb binds directly to the kinase domain of mTOR in mTORC1 and activates the complex in a GTP-dependent manner. The tuberous sclerosis proteins TSC1 and TSC2 form a heterodimer and inhibit Rheb activation as TSC2 acts as a GAP (GTPase activating protein), which stimulates GTP hydrolysis of Rheb (Fig. 1), however, the function of Rheb towards mTORC2 has yet not been established (116).

TOR integrates various signals to regulate cell growth. Insulin and other growth factors, nutrients, cellular AMP/ATP ratio and stress modulate the mTOR-signaling pathway. Activation of the PI3 kinase pathway by insulin or growth factors activates Akt. Akt serves as a negative regulator of TSC1/TSC2 complex (Fig. 1, green lines). Inactivation of TSC1/TSC2 complex by Akt eventually activates the mTORC1 (Fig. 1) (119). Excess nutrients, especially amino acids, also can positively regulate this pathway either indirectly via inhibiting the TSC1/TSC2 complex or directly via activating Rheb $(61,172)$. Low cellular energy level increases AMP/ATP ratio that activates AMPK (will be discussed in detail later). Activated AMPK positively regulates TSC1/TSC2 by directly phosphorylating and enhancing the GAP activity of TSC2 (Fig. 1, orange line) (88). Activation of TSC2 in turn inhibits the mTORC1. Cellular stress and hypoxia also inhibit the mTORC1 complex via activating the TSC1/TSC2 complex (22).

Upon activation, mTORC1 enhances protein translation via activating p70 S6 kinase-1 (S6K-1) and eukaryotic initiation factor binding protein-1 (4EBP-1). S6K-1 requires phosphorylation at two sites for full activation. Thr 389 phosphorylation of the C-terminal hydrophobic motif by mTORC1 and Thr 229 phosphorylation of the kinase domain by PDK1 is absolutely required for the activation of S6K-1. Activated S6K-1 in turn activates $40 \mathrm{~S}$ ribosomal protein S6 and enhances translation. On the other hand, mTORC1 enhances cap-dependent translation via phosphorylating 4EBP-1. Upon phosphorylation, 4EBP-1 releases eIF4E, a eukaryotic translation initiation factor, and translation initiation takes place. Interaction of mTORC1 with S6K-1 and 4EBP-1 is mediated through raptor $(78,194)$.

The mTORC2 complex has only recently been identified and thus is less well 
characterized. This complex contains a protein called rictor instead of raptor. mTORC2 activates Akt, by phosphorylating it at the Ser-473 residue (164). The identity of the kinase, which is responsible for the Ser-473 phosphorylation of Akt was largely elusive. Phosphorylation of Akt at this residue, besides at Thr-308, is absolutely necessary for the activation of this protein, which gives an indirect measurement of insulin stimulation on PI3 kinase activation (3). RNA-interference study as well as in vitro kinase assay confirmed that mTOR and rictor but not raptor phosphorylates full length Akt at Ser-473 and also facilitates phosphorylation at Thr-308 by PDK-1. The mTOR-rictor complex is therefore suggested as a potential drug target for cancer and diabetes (164). However, how insulin signaling activates this complex, which in turn mediates the activation of Akt, has not been demonstrated yet. Both TORC1 and TORC2 in different species form multimeric complexes via a TOR-TOR interaction $(90,163)$.

Mammalian TOR complexes, especially mTORC1, integrate various signaling pathways and establish crosstalk between them. Activation of PI3 kinase pathway activates mTORC1 (Fig. 1, green lines). Treatment with rapamycin, an inhibitor of mTORC1, abolishes the insulin-mediated induction of G6PD expression in primary rat hepatocytes (202), which strongly suggests that the activation of this pathway downstream to PI3 kinase is required to mediate the insulin induction of G6PD. However, prolonged activation of this complex inhibits the PI3 kinase pathway by a feedback mechanism (Fig. 1, pink line). A more detailed discussion in this regard will be followed.

\footnotetext{
$\underline{\text { AMPK }}$

AMPK is a sensor of cellular energy level. Increasing the cellular AMP/ATP ratio activates this kinase, which in turn, switches off ATP consuming processes, such as, the anabolic metabolism pathways, and switches on ATP generating processes or the catabolic pathways (97).
} 
AMPK is a heterotrimer and composed of a catalytic $\square$ subunit and regulatory $\square$ and $\square$ subunits. In mammals, each of these subunits is encoded by multiple genes. In mammalian cells, AMP activates AMPK in three different ways: by allosterically activating the AMPK complex formation, by promoting phosphorylation at Thr-172 of the kinase domain of the $\square$ subunit and by inhibiting dephosphorylation at Thr-172 by making AMPK a poor substrate of protein phosphatase 2C (76). The AMP-mediated activation of AMPK is antagonized by high concentration of ATP.

The upstream kinase that activates AMPK by phosphorylating it at Thr-172 is only recently identified as LKB1 (74). Like AMPK, LKB1 forms a heterotrimer with two other proteins, MO25 and STRAD. Formation of the heterotrimer is required for the catalytic activity of LKB1 as well as for its cytoplasmic localization. Activators of AMPK do not seem to activate LKB1. Thus, it has been suggested that LKB1 is constitutively active, and the regulation of AMPK phosphorylation is mediated via regulation of AMPK but not LKB1. LKB1 activates 11 AMPK-related kinases by phosphorylating them at Thr residues equivalent to Thr-172 of AMPK. Thus, LKB1 is suggested to act as a master upstream kinase, which mediates its function by AMPK and AMPK-related kinases $(74,77)$. The role of this kinase in cellular AMPK regulation is still unknown.

Various cellular stresses, which deplete ATP, and increase the AMP/ATP ratio, like metabolic poisoning and pathological stress will activate AMPK. Metabolic poisons include inhibitors of tricarboxylic acid cycle (arsenite), respiratory chain (azide), mitochondrial ATP synthase (oligomycin) and uncouplers of oxidative phosphorylation (dinitrophenol, DNP), whereas pathological stresses include glucose deprivation, ischemia, hypoxia, oxidative and hyperosmotic stress. Exercise or contraction also enhances AMPK activation due to increasing ATP consumption in skeletal muscle (28, 74, 76). Two widely used antidiabetic drugs, metformin (233) and thiazolidinediones (59), have recently been shown to activate AMPK. While thiazolidinediones appear to enhance cellular AMP/ATP ratio, the mechanism of action by which metformin activates AMPK has not been demonstrated. 


\section{AMPK and metabolic gene regulation:}

A central role for AMPK in regulating intracellular metabolism is emerging. Activated AMPK phosphorylates acetyl-CoA carboxylase (ACC) at Ser-79, Ser-1200 and Ser-1215 (45, 130). AMPK is the only known kinase that phosphorylates at Ser-79 of ACC (75). Phosphorylation of this serine inhibits ACC activity. ACC converts acetyl CoA into malonyl CoA and is known as the rate limiting enzyme of the fatty acid biosynthetic pathway. Malonyl CoA is not only involved in de novo fatty acid biosynthesis, but also inhibits carnitine: palmitoyl-CoA transferase-1 (CPT1), the ratelimiting enzyme for fatty acid oxidation in mitochondria. Inhibition of ACC activity by phosphorylation will inhibit fatty acid biosynthesis and increase fatty acid oxidation. AMPK also plays a role in regulating metabolic capacity by regulating the expression of genes for the metabolic enzymes. Activation of AMPK down regulates lipogenic genes including FAS and ACC $(29,53,74)$. Inhibition of lipogenic genes is mediated through down regulation of the transcription factors required for the lipogenic gene expression. These transcription factors are the sterol regulatory element binding protein (SREBP) -1c (233) and the hepatic nuclear factor-4 $\square$ (HNF4 $\square)(86,112)$. Activation of AMPK enhances glucose uptake by increasing glucose transporter (GLUT4) levels in muscle. Activated AMPK enhances DNA binding ability of the transcription factor MEF2 in muscle, which is the possible mechanism of increase in GLUT 4 level upon AMPK activation (232). A recent report revealed that the activators of AMPK, such as 5aminoimidazole-4-carboxamide ribonucleotide (AICAR) and DNP enhance GLUT4 translocation and glucose uptake in adipocytes in a p38 MAP kinase-dependent pathway (223). Activation of AMPK reduces the activity of HMG CoA reductase, the rate limiting enzyme for cholesterol biosynthesis in liver $(36,65)$. AMPK activation is also associated with increased activation of glycolytic enzymes such as 6-phosphofructo kinase, although the exact mechanism is not known (120). AMPK, thus, plays a major role in the cellular metabolism regarding glucose and lipid homeostasis. Involvement of AMPK in regulation of insulin signaling (Fig. 1, orange lines) will be discussed in a later section. 


\section{$\underline{\text { PUFA }}$}

Fatty acids with more than one double bond are called polyunsaturated fatty acids or PUFAs. Most of the PUFAs belong to the essential fatty acid family, as they cannot be synthesized de novo and a dietary supplement from plant oil is necessary. There are two major groups of essential fatty acid families, known as the $\square-6$ and $\square-3$ family. The precursors of these two families are linoleic acid (18:2) and alpha linolenic acid (18:3), respectively. The omega carbon is the carbon in the methyl group and since the last double bond of linoleic and alpha linolenic acids are 6 and 3 carbons away from the methyl group, they are named as $\square-6$ and $\square-3$ fatty acid, respectively. The first double bond in these two fatty acids is 9 carbons away from the carboxylic or delta end. Mammals cannot add double bonds any further away from the carboxylic end than nine carbons and thus $\square-6$ and $\square-3$ fatty acids cannot be synthesized de novo.

Linoleic acid is converted into Glinolenic acid (GLA, 18:3) by $\square-6$ desaturase, which is elongated into dihomo- -linolenic acid (DGLA, 20:3) by the action of elongase. DGLA is converted into arachidonic acid (20:4) by $\square-5$ desaturase. GLA, DGLA and arachidonic acid all belong to the $\square-6$ fatty acid family. On the other hand, $\square$-linolenic acid is converted into eicosapentanoic acid (EPA, 20:5) by sequential desaturation, elongation and desaturation by $\square-6$ desaturase, elongase, and $\square-5$ desaturase, respectively. EPA is converted into docosahexaenoic acid (DHA, 22:6) by elongation, followed by desaturation by $\square-4$ desaturase. Both EPA and DHA belong to the $\square-3$ fatty acid family. PUFAs are involved in making membrane structures as part of phospholipids. Activation of phospholipase A2 releases PUFAs (especially arachidonic acid) from the sn-2 position. In our body PUFAs are found in their cis-conformation in the lipid bilayer, which enhances membrane fluidity.

Three of the twenty carbon PUFAs, DGLA, arachidonic acid and EPA, can be metabolized into eicosanoids. The enzyme cyclooxygenase (COX) catalyzes the production of the prostanoid families of prostaglandins and thromboxanes, whereas, the enzyme lipooxygenase (LOX) catalyzes the production of leukotrienes. A family of 
cytochrome p450 dependent epoxygenases has been shown to act on arachidonic acid to produce epoxyeicosatrienoic acids (EET), which have anti-inflammatory action. The prostanoids are known to act via $\mathrm{G}$ protein-coupled receptors. Depending on the Gprotein linkage, prostanoids can activate adenylate cyclase (makes cAMP and activates PKA), PLC (activates PKC and increases cellular $\mathrm{Ca}^{2+}$ concentration), or the inhibitory $\mathrm{G}$ protein, $\mathrm{Gi}$ (inhibits cAMP production or activates PLC $\square$ and elevates intracellular $\mathrm{Ca}^{2+}$ level) $(10,44,133,173)$. Arachidonic acid inhibits lipogenic gene expression in 3T3-L1 adipocytes via prostanoids by activating Gi (123). However; this mechanism differs from the PUFA-mediated inhibition of hepatic lipogenic gene expression (95).

\section{PUFA-mediated regulation of gene expression:}

PUFAs are known to inhibit expression of hepatic glycolytic and lipogenic genes both in vivo and in hepatocytes in culture. Addition of $\square-6$ or $\square-3$ fatty acids, but not saturated (like palmitate, 16:0, or stearate, 18:0) or monounsaturated fatty acids (like oleate, 18:1), to a high-carbohydrate diet inhibits lipogenic gene expression $(37,96)$. Several transcription factors are regulated by PUFA that in turn, regulate genes involved in fatty acid metabolism. In this context, regulation of the nuclear receptors such as PPAR, liver x receptor (LXR), HNF-4 $\square$ and SREBP, by PUFA have been reported.

PPAR family proteins bind to the promoter region of many genes involved in fatty acid transport, desaturation and oxidation as a heterodimer with retinoid $\mathrm{x}$ receptor (RXR) (93). Direct binding of eicosapentanoic acid, 20:5, to PPAR makes a stable conformation, which helps to recruit co-activators to this receptor (219). LXRs ( $\square$ and $\square$ ) bind to oxysterols and directly regulate hepatic cholesterol biosynthesis. LXRs, upon binding to the oxysterols, at the same time, indirectly up regulate hepatic lipogenic gene expression by increasing the expression of SREBP1c (157). PUFAs, especially arachidonic acid and with a lower effect linoleic acid, interferes with the binding of oxysterols to LXR and thus inhibit LXR-mediated gene regulation (142). HNF4 $\square$ activates genes involved in bile acid synthesis, carbohydrate metabolism and apolipoprotein synthesis by binding to the promoter region of the corresponding genes as 
homodimers. Fatty acyl-CoAs can directly bind to HNF4 $\square$ at its ligand-binding domain and regulate its activity. While binding of saturated fatty acyl CoAs (14:0-CoA or 16:0 CoA) activate HNF4 $\square$, binding of 18:3-CoA, 20:5 CoA and 22:6-CoA to HNF4 $\square$ inhibit its effect on gene expression $(94,211)$.

The best-characterized transcription factor involved in PUFA-mediated inhibition of gene transcription is SREBP-1c. SREBPs are transcription factors involved in regulation of cholesterol and lipid synthesis. SREBP-1 (1a and 1c) is involved in regulation of lipogenic genes and triglyceride synthesis, whereas SREBP-2 regulates cholesterol synthesis. SREBPs are transcribed as precursor proteins (pSREBP), which upon cellular stimulations such as sterol depletion, are cleaved into the transcriptionally active (nSREBP) form and travel to the nucleus. Unlike nuclear receptors, SREBPs do not bind fatty acids directly, however fatty acids regulate the nuclear abundance of nSREBP. Intracellular cholesterol distribution is affected by PUFAs. Cholesterol is associated with spingomyelin while bound to plasma membrane. Treatment of cells with PUFAs stimulates the activity of sphingomyelinase, which redistributes cholesterol from plasma membrane to the endoplasmic reticulum. This event of cholesterol redistribution inhibits formation of nSREBP and attenuates transcriptional activation of SREBP regulated genes (214). PUFA inhibits the accumulation of SREBP-1 but not SREBP-2 mRNA in the liver of intact animals and in primary rat hepatocytes. In this regard, the most effective PUFAs are the ones with 20 or longer carbon chain, however, the monounsaturated fatty acid oleate, shows some effect (220). A recent report has demonstrated that docosahexaenoic acid, inhibits SREBP-1c mRNA as well as nSREBP1c abundance in primary rat hepatocytes via the Erk MAP kinase and 26S proteosomedependent pathways (19). Thus, PUFA plays a major role in gene expression at the transcriptional level via various mechanisms.

PUFAs regulate gene expression at posttranscriptional level, as well, at multiple steps. In the case of G6PD, PUFAs inhibit the gene expression at the pre-mRNA splicing step both in intact animals and in rat hepatocytes $(5,175,191)$, whereas, PUFAs decrease the stability of GLUT 4 (193) and SCD I (168) mRNAs in the cytoplasm of 3T3 L1 adipocytes. Deficiency of 
--3 PUFA content in diet inhibits GLUT 1 expression in rat brain without affecting the mRNA synthesis, which indicates a posttranscriptional regulation of GLUT1 expression by $\square-3$ PUFA (152). Dietary PUFA-mediated inhibition of transcription of the SREBP-1 gene does not solely account for the decrease in the abundance of SREBP-1c mRNA by PUFA $(221,222)$. This observation suggests that SREBP-1 gene regulation at least in part, is mediated via posttranscriptional regulation by PUFA. The details of the mechanisms by which PUFAs regulate these genes at the posttranscriptional steps remain largely unexplored.

\section{Interference of insulin signal transduction pathway by various signaling molecules:}

Insulin signal transduction pathway, as discussed earlier, is activated when insulin binds to its receptor at the cell surface. The insulin receptor, which is a tyrosine kinase, upon activation, phosphorylates its own tyrosine residues (Fig. 1). These phosphotyrosine residues of insulin receptor are recognized and bound by IRS proteins and in turn IRS is phosphorylated at its own tyrosine residues by the insulin receptor. Tyrosinephosphorylated IRS is then recognized and bound by the adapter subunit of PI3 kinase. A stable complex formation between the IRS and the PI3 kinase activates the later protein, which in turn activates the downstream effector protein Akt and various cellular processes are turned on (169).

The insulin signal transduction pathway can be inhibited by Ser-phosphorylation of IRS-1. Various Ser residues (Ser-307, -612, -632) of IRS-1 have been identified, whose phosphorylation inhibits the PI3 kinase pathway and thus insulin signal transduction (Fig. 1) $(62,143,160)$. The exact mechanism by which Ser phosphorylation of IRS-1 interferes with the PI3 kinase pathway is not clear; however, several plausible mechanisms have been suggested. Ser-307 is located near the PTB domain of IRS-1, which binds the phosphorylated insulin receptor. It has been hypothesized that Ser-307 phosphorylation of IRS-1 could cause a conformational change, which in turn could reduce the affinity of IRS-1 for the insulin receptor and thus terminate the signaling 
pathway $(1,2)$. On the other hand, Ser 612 and 632 are located near the tyrosine residues of the PI3 kinase-binding site. Phosphorylation of these Tyr residues is necessary for the binding to the adapter subunit of PI3 kinase. Ser-phosphorylations at this site might interfere with the Tyr-phosphorylation and in turn might inhibit the binding to the PI3 kinase (155). Interestingly, prolonged insulin treatment induces Ser-phosphorylation of various residues of IRS-1, which suggests the existence of a feedback mechanism, which uncouples IRS-1 from its upstream or downstream binding partners. In the next few paragraphs I am going to discuss the involvement of various signaling molecules that interfere with the PI3 kinase pathway and thus modulate insulin signaling. These signaling molecules are: various MAP kinases, PKCs, mTOR, fatty acids and AMPK. These pathways either independently or in concert interfere with the insulin signaling.

MAP kinases: Activation of various MAP kinases (Erk, Jnk and p38) increases Ser phosphorylation of IRS-1 followed by inhibition of Akt phosphorylation and PI3 kinase activity in various cell types (Fig. 1, blue lines) $(46,47,60,83,153)$. A central role of JNK MAP kinase in obesity and insulin resistance via activation of Ser-307 phosphorylation and inhibition of tyrosine phosphorylation of IRS-1 has been established in ob/ob mice (83). TNF-alpha-mediated inhibition of the PI3 kinase pathway involves the activation of the Erk, JNK and/or p38 MAP kinase pathways (46, 60, 160). Over expression of the upstream kinases (MKKs) of these pathways also interferes with the PI3 kinase activation. Enhanced basal level accumulation of p38 MAP kinase has been reported in adipocytes of type 2 diabetic patients, which correlates with the down regulation of GLUT4 expression, an indication of insulin resistance in these patients (30). Thus, activation of various MAP kinases by different stimuli causes impairment of insulin signaling.

PKCs: Various isoforms of PKCs can inhibit insulin signaling in different cell types. Activation or over expression of conventional, novel or atypical PKC isoforms interfere with the PI3 kinase pathway. In this regard, hyperglycemia enhances the activation of a conventional $\mathrm{PKC}, \mathrm{PKC} \square$, which is responsible for insulin resistance; however, the exact mechanism has not been demonstrated (104). Over expression of 
conventional PKC isoforms have been reported to inhibit the kinase activity of the insulin receptor (18). Activation of novel PKCs ( $\square$ and $\square$ ) also inhibit the PI3 kinase pathway by inducing Ser-307 phosphorylation of IRS-1 or by inhibiting the kinase activity of the insulin receptor $(33,101,167)$. Over expression of PKC $\square$, an atypical PKC, causes Ser phosphorylation of IRS-1 and inhibits the PI3 kinase pathway in NIH3T3 and Fao cells $(115,155)$. To the contrary, various isoforms of $\mathrm{PKC}$, upon activation, can positively modulate the PI3 kinase pathway. For example, activation of various isoforms of PKC ( $\square, \square$ and $\square$ has been shown to enhance insulin-stimulated glucose transport in NIH 3T3 cells $(34,42)$. Insulin enhances PKC $\square$ activity in muscle cells and in hepatoma cell lines $(21,32)$. The atypical PKCs $\square$ and $\square$ are activated by PDK-1 and enhance GLUT4 translocation in adipocytes and muscle cells. Over expression of these isoforms enhance both the basal and the insulin-stimulated glucose transport $(12,51)$. Thus, it seems that, depending on cell types, activation of various isoforms of PKC can either stimulate or inhibit insulin signaling. This provides an example where a complex cross talk between two signaling pathways exists and creates a balance between activation and/or inhibition of one of these pathways by the other.

mTOR: mTOR acts as a downstream effector protein of the PI3 kinase pathway. As described earlier, activated Akt inhibits the GAP activity of TSC1/TSC2 complex and thus, activates mTOR by recruiting Rheb to its kinase domain (Fig. 1, green lines). Insulin-mediated induction of lipogenic gene expression depends on activated mTOR. In this regard, inhibition of mTOR by rapamycin abolishes the insulin-induction of G6PD mRNA in primary rat hepatocytes (202). However, sustained activation of mTOR, which occurs in pathological conditions such as obesity induced by dietary intake of $40 \%$ or more fat (Fig. 1, the thick purple line), causes insulin resistance via Ser-phosphorylation of IRS-1 by mTOR/S6K-1 pathway (Fig. 1, pink line) (197). This suggests that over activation of mTOR creates an imbalance in insulin signaling and generates a feed back inhibition of the PI3 kinase pathway.

Fatty acids: High-fat diet or presence of fatty acid in culture medium interferes with insulin signaling by activating various inhibitory pathways. Activation of mTOR, 
MAP kinases, various isoforms of PKCs, PKA and inhibitor $\square \mathrm{B}$ kinase (IKK- $\square$ ) by fatty acids have been implicated in this regard (Fig. 1). A few examples of activation of each of these pathways by dietary fat or free fatty acids and an impairment of insulin signaling are as follows. A diet containing $40 \%$ or more fat enhances mTOR pathway in intact animals, which in turn elevates Ser-307 phosphorylation of IRS-1 and decreases Akt phosphorylation (197). Various MAP kinases are activated in obese animal models. In ob/ob mice activation of JNK has been reported leading to insulin resistance (83). Presence of arachidonic acid in culture media activates p38 MAP kinase pathway in HeLa cells, HL60 promyelocytic leukemic cells, and human neutrophils (81). Free fatty acids mediate insulin resistance in 3T3-L1 adipocytes via activating JNK and TNF-alpha (137). PUFAs increase adenylate cyclase activation, which in turn enhances cAMP and activates PKA $(7,8,131,132)$. This effect is specific to the brain and probably not of consequence in liver. However, a recent report shows that p38 MAP kinase is a downstream effector of PKA (27), which can lead to attenuation of insulin signal transduction. Free fatty acids can also induce activation of PKC $\square$ and $\square$ leading to insulin resistance both in muscle and liver $(110,229)$. Inhibitor $\square$ B kinase (IKK- $\square$ ) could also be involved in free fatty acids-mediated insulin resistance. IKK- $\square$ is activated by PKC $\square(62)$ and p38 MAP kinase (46), both of which could be activated by free fatty acids. As IRS-1 is a direct in vitro substrate of IKK- $\square$, it is likely that IKK- $\square$ can phosphorylate IRS-1 and regulate insulin sensitivity (62). Dietary or free fatty acids have also been implicated in attenuation of insulin signaling where the involvement of the inhibitory pathways has not been shown. For example, diet containing $\square-3$ and $\square-6$ fatty acids reduce the number of insulin receptors, decrease the tyrosine phosphorylation of insulin receptor and IRS-1 and decrease the PI3 kinase activity in liver (192). The 22:6 PUFA, docosahexaenoic acid, has recently been reported to inhibit insulin-mediated induction of Akt phosphorylation in primary rat hepatocytes (19). The exact regulatory mechanisms involved in attenuation of insulin signaling by PUFA in these cases have not been reported yet.

AMPK: PUFAs present in diet or culture medium activate AMPK (Fig. 1, cyan line), both in the liver of intact animals and in primary hepatocytes. Activation of AMPK 
can both positively and negatively regulate insulin signaling. The positive mechanisms are as follows: 1) Activation of AMPK leads to down regulation of lipogenic genes in liver and inhibits lipolysis and thus, inhibits production of free fatty acids $(29,53,185)$. As discussed earlier, an increase in the cellular free fatty acid content impairs insulin signaling by various mechanisms, prolonged inhibition of which results in induction of insulin sensitivity. 2) Activation of AMPK leads to down regulation of the mTOR/S6K-1 pathway (Fig. 1, solid orange line) (78). Prolonged activation of mTOR, which takes place under pathological condition, attenuates insulin signaling (Fig. 1, pink line). Thus, inhibition of this pathway by AMPK under such conditions enhances insulin sensitivity. The inhibitory mechanisms by which AMPK attenuates insulin signaling are as follows: 1) Activation of PI3 kinase activates mTOR/S6K-1 (Fig. 1, green lines), which is located downstream of Akt. Inhibition of mTOR/S6K-1 under non-pathological condition by activated AMPK thus, attenuates insulin signaling. 2) AMPK activation can lead to the activation of p38 MAP kinase $(113,114,204)$, a known inhibitor of the PI3 kinase, and thus, AMPK can indirectly inhibit insulin-signaling (Fig. 1, broken orange line). 


\section{Summary and hypothesis:}

The summary of this section is shown in figure 1. Insulin upon binding to its receptor activates the insulin-signaling pathway by recruiting IRS proteins to the receptor. IRS becomes tyrosine-phosphorylated by the insulin receptor and in turn recruits PI3 kinase and activates it. PI3 kinase in turn activates the downstream effector protein Akt by facilitating its phosphorylation at Thr-308 and Ser-473. Activation of Akt enhances the mTOR pathway by inhibiting the GTPase activity of TSC1/TSC2, which in turn facilitates binding of small GTP-binding protein Rheb to mTOR. Activation of mTOR phosphorylates and activates S6K-1. Activation of this signaling cascade turns on various cellular responses, which eventually stimulates cell growth, glycolytic and lipogenic gene expression, protein translation etc.

A primary mechanism of inhibition of insulin signaling is by Ser-phosphorylation of IRS proteins. Ser-phosphorylation of IRS either interferes with its binding to the insulin receptor or to the PI3 kinase which causes a down regulation of insulin signaling pathway. Activation of various MAP kinases, PKC, TNF-alpha and mTOR either alone or in combination can cause Ser-phosphorylation of IRS proteins. Ser-phosphorylation of IRS by mTOR suggests a feedback loop of insulin signaling. Activation of AMPK inhibits mTOR activation, which can have both positive and negative impact on insulin signaling.

High-fat diets, free fatty acids and/or various PUFAs activate MAP kinase pathways, either directly or via activating PKC and/or TNF-alpha (Fig. 1, brown lines). High-fat diet can also activate mTOR, which generates a pathological condition (Fig. 1, the thick purple line). Activation of these pathways results in Ser-phosphorylation of IRS-1 (Fig. 1, blue and pink lines). PUFAs also activate AMPK (Fig. 1, cyan line), which interferes with the PI3 kinase/mTOR pathway (Fig. 1, orange lines) and at the same time inhibits lipogenic gene expression. Starvation, which causes inhibition of lipogenic gene 
expression, also activates MAP kinase (via activating PKA) and AMPK (Fig. 1, shaded yellow lines) and thus can have negative impact on insulin signaling.

G6PD is a lipogenic enzyme, which is induced by insulin both in intact animals and in primary hepatocytes. Insulin-mediated induction of G6PD in primary rat hepatocytes follows the PI3 kinase pathway. Induction of this gene expression by insulin is attenuated upon starvation or high-fat diet in intact animals or by PUFA in culture medium. PUFAs do not inhibit the basal level expression of G6PD, suggesting that it only attenuates the insulin-mediated induction of this gene. From this background and information from the literature, I hypothesized that arachidonic acid, a PUFA, when present in the medium along with insulin, interferes with the PI3 kinase pathway, and thus, attenuates the effect of insulin on G6PD gene expression. Prolonged inhibition of this pathway can cause insulin resistance but in a non-pathological condition will decrease the expression of the lipogenic genes. We further hypothesized that arachidonic acid causes activation of inhibitory pathways, such as, MAP kinases, PKC and/or mTOR, which can interfere with the insulin signaling probably by increasing Ser-phosphorylation of IRS-1. We also hypothesized that arachidonic acid activates the AMPK pathway, which attenuates G6PD gene expression, either directly, or via activating other inhibitory pathways, which interfere with insulin signaling. 


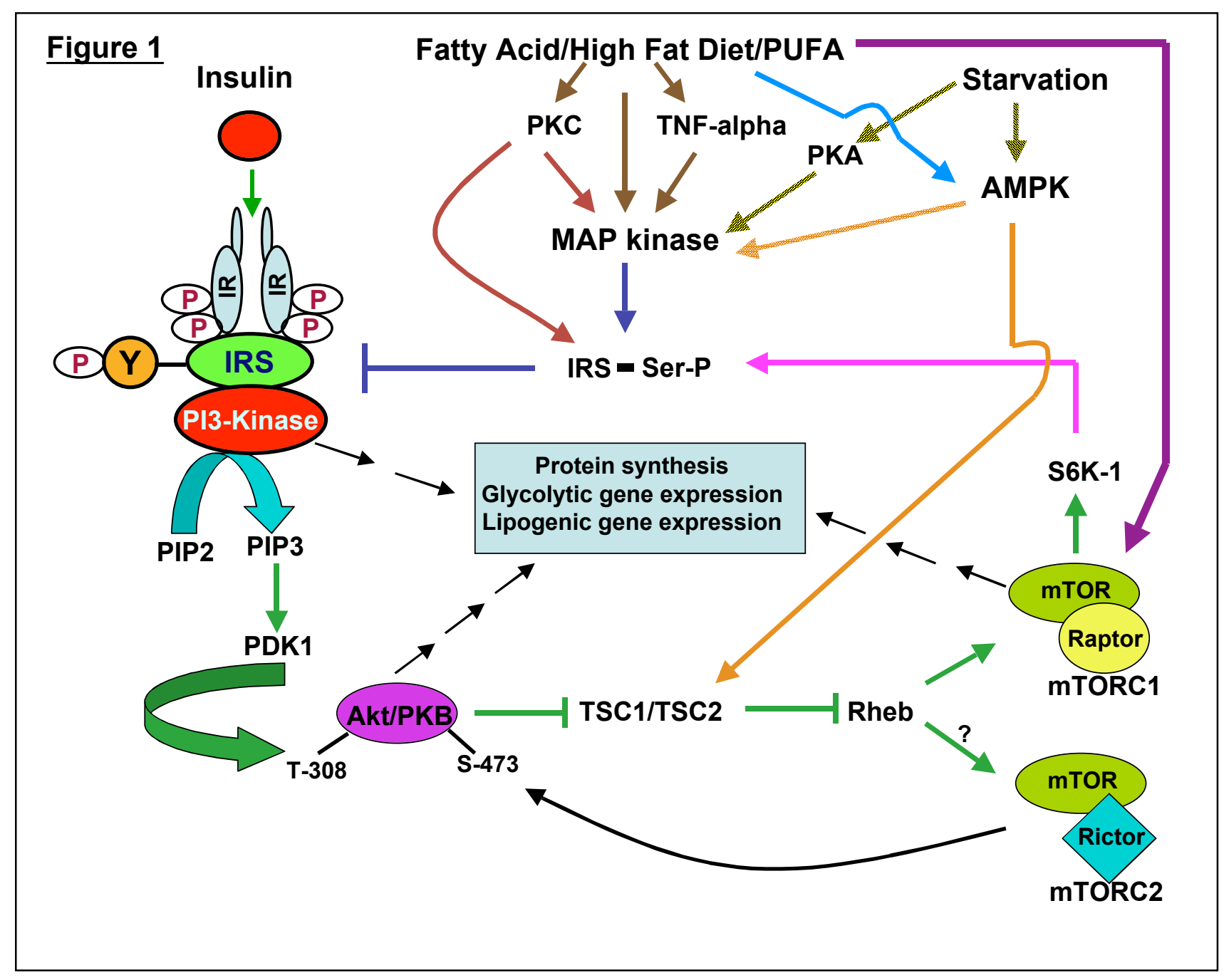


Figure 1. Integration of various signaling pathways in metabolic gene regulation. The color code of the figure is as follows: Green lines, activation of mTORC1 as a down stream target of PI3 kinase. Thick purple line: over activation of mTORC1 by high fat diet. Pink line: Ser-phosphorylation of IRS via activation of S6K-1. Brown lines: activation of MAP kinase, as a direct or indirect effect of PUFA. Red lines: activation of MAP kinase by PKC and Ser-phosphorylation of IRS by PKC. Thin cyan line: activation of AMPK by PUFA. Shaded yellow lines, activation of MAP kinase and AMPK due to starvation. Broken orange line: activation of MAP kinase by AMPK. Solid orange line: down regulation mTORC1 by AMPK. Blue lines, Ser-phosphorylation of IRS by MAP kinases and inhibition of PI3 kinase pathway. Short black arrows, involvement of PI3 kinase, Akt and mTOR in regulation of various processes. Long black arrow: involvement of mTORC2 in phosphorylation of Akt at Ser-473. 


\section{$\underline{\text { References }}$}

1. Aguirre, V., T. Uchida, L. Yenush, R. Davis, and M. F. White. 2000. The cJun NH(2)-terminal kinase promotes insulin resistance during association with insulin receptor substrate-1 and phosphorylation of Ser(307). J Biol Chem 275:9047-54.

2. Aguirre, V., E. D. Werner, J. Giraud, Y. H. Lee, S. E. Shoelson, and M. F. White. 2002. Phosphorylation of Ser307 in insulin receptor substrate-1 blocks interactions with the insulin receptor and inhibits insulin action. J Biol Chem 277:1531-7.

3. Alessi, D. R., M. Andjelkovic, B. Caudwell, P. Cron, N. Morrice, P. Cohen, and B. A. Hemmings. 1996. Mechanism of activation of protein kinase B by insulin and IGF-1. Embo J 15:6541-51.

4. Alessi, D. R., S. R. James, C. P. Downes, A. B. Holmes, P. R. Gaffney, C. B. Reese, and P. Cohen. 1997. Characterization of a 3-phosphoinositide-dependent protein kinase which phosphorylates and activates protein kinase Balpha. Curr Biol 7:261-9.

5. Amir-Ahmady, B., and L. Salati. 2001. Regulation of the processing of glucose6-phosphate dehydrogenase mRNA by nutritional status. J. Biol Chem 276:10514-23

6. Andjelkovic, M., D. R. Alessi, R. Meier, A. Fernandez, N. J. Lamb, M. Frech, P. Cron, P. Cohen, J. M. Lucocq, and B. A. Hemmings. 1997. Role of translocation in the activation and function of protein kinase B. J Biol Chem 272:31515-24.

7. Angulo-Guerrero, O., and R. R. Oliart. 1998. Effects of dietary polyunsaturated fatty acids on adenylate cyclase, 5 'nucleotidase and $\mathrm{Na}+\mathrm{K}(+)-$ ATPase activities in rat brain-plasma membrane. Arch Latinoam Nutr 48:293-8.

8. Angulo-Guerrero, O., and R. R. Oliart. 1998. Effects of dietary polyunsaturated fatty acids on rat brain plasma membrane fatty acid composition. Arch Latinoam Nutr 48:287-92.

9. Antonetti, D. A., P. Algenstaedt, and C. R. Kahn. 1996. Insulin receptor substrate 1 binds two novel splice variants of the regulatory subunit of phosphatidylinositol 3-kinase in muscle and brain. Mol Cell Biol 16:2195-203.

10. Asboth, G., S. Phaneuf, G. N. Europe-Finner, M. Toth, and A. L. Bernal. 1996. Prostaglandin E2 activates phospholipase $C$ and elevates intracellular calcium in cultured myometrial cells: involvement of EP1 and EP3 receptor subtypes. Endocrinology 137:2572-9.

11. Bagrodia, S., B. Derijard, R. J. Davis, and R. A. Cerione. 1995. Cdc42 and PAK-mediated signaling leads to Jun kinase and p38 mitogen-activated protein kinase activation. J Biol Chem 270:27995-8.

12. Bandyopadhyay, G., M. L. Standaert, U. Kikkawa, Y. Ono, J. Moscat, and R. V. Farese. 1999. Effects of transiently expressed atypical (zeta, lambda), conventional (alpha, beta) and novel (delta, epsilon) protein kinase $\mathrm{C}$ isoforms on insulin-stimulated translocation of epitope-tagged GLUT4 glucose transporters in rat adipocytes: specific interchangeable effects of protein kinases C-zeta and Clambda. Biochem J 337 ( Pt 3):461-70. 
13. Beelman, C. A., and R. Parker. 1995. Degradation of mRNA in eukaryotes. Cell 81:179-83.

14. Berdanier, C. D., and D. Shubeck. 1979. Interaction of glucocorticoid and insulin in the responses of rats to starvation-refeeding. J Nutr 109:1766-71.

15. Berg, E. A., J. Y. Wu, L. Campbell, M. Kagey, and S. R. Stapleton. 1995. Insulin-like effects of vanadate and selenate on the expression of glucose-6phosphate dehydrogenase and fatty acid synthase in diabetic rats. Biochimie 77:919-24.

16. Bevilacqua, A., M. C. Ceriani, S. Capaccioli, and A. Nicolin. 2003. Posttranscriptional regulation of gene expression by degradation of messenger RNAs. J Cell Physiol 195:356-72.

17. Blencowe, B. J. 2000. Exonic splicing enhancers: mechanism of action, diversity and role in human genetic diseases. Trends Biochem Sci 25:106-10.

18. Bollag, G. E., R. A. Roth, J. Beaudoin, D. Mochly-Rosen, and D. E.

Koshland, Jr. 1986. Protein kinase C directly phosphorylates the insulin receptor in vitro and reduces its protein-tyrosine kinase activity. Proc Natl Acad Sci U S A 83:5822-4.

19. Botolin, D., Y. Wang, B. Christian, and D. B. Jump. 2006. Docosahexaneoic acid (22:6,n-3) regulates rat hepatocyte SREBP-1 nuclear abundance by Erk- and 26S proteasome-dependent pathways. J Lipid Res 47:181-92.

20. Boulton, T. G., S. H. Nye, D. J. Robbins, N. Y. Ip, E. Radziejewska, S. D. Morgenbesser, R. A. DePinho, N. Panayotatos, M. H. Cobb, and G. D. Yancopoulos. 1991. ERKs: a family of protein-serine/threonine kinases that are activated and tyrosine phosphorylated in response to insulin and NGF. Cell 65:663-75.

21. Braiman, L., A. Alt, T. Kuroki, M. Ohba, A. Bak, T. Tennenbaum, and S. R. Sampson. 1999. Protein kinase Cdelta mediates insulin-induced glucose transport in primary cultures of rat skeletal muscle. Mol Endocrinol 13:2002-12.

22. Brugarolas, J., K. Lei, R. L. Hurley, B. D. Manning, J. H. Reiling, E. Hafen, L. A. Witters, L. W. Ellisen, and W. G. Kaelin, Jr. 2004. Regulation of mTOR function in response to hypoxia by REDD1 and the TSC1/TSC2 tumor suppressor complex. Genes Dev 18:2893-904.

23. Brunet, A., A. Bonni, M. J. Zigmond, M. Z. Lin, P. Juo, L. S. Hu, M. J. Anderson, K. C. Arden, J. Blenis, and M. E. Greenberg. 1999. Akt promotes cell survival by phosphorylating and inhibiting a Forkhead transcription factor. Cell 96:857-68.

24. Bruning, J. C., J. Winnay, B. Cheatham, and C. R. Kahn. 1997. Differential signaling by insulin receptor substrate 1 (IRS-1) and IRS-2 in IRS-1-deficient cells. Mol Cell Biol 17:1513-21.

25. Burgering, B. M., and P. J. Coffer. 1995. Protein kinase B (c-Akt) in phosphatidylinositol-3-OH kinase signal transduction. Nature 376:599-602.

26. Burmeister, L. A., and C. N. Mariash. 1991. Dietary sucrose enhances processing of mRNA-S14 nuclear precursor. J Biol Chem 266:22905-11.

27. Cao, W., Q. F. Collins, T. C. Becker, J. Robidoux, E. G. Lupo, Jr., Y. Xiong, K. W. Daniel, L. Floering, and S. Collins. 2005. p38 Mitogen-activated protein 
kinase plays a stimulatory role in hepatic gluconeogenesis. J Biol Chem 280:42731-7.

28. Carling, D. 2004. The AMP-activated protein kinase cascade--a unifying system for energy control. Trends Biochem Sci 29:18-24.

29. Carling, D., V. A. Zammit, and D. G. Hardie. 1987. A common bicyclic protein kinase cascade inactivates the regulatory enzymes of fatty acid and cholesterol biosynthesis. FEBS Lett 223:217-22.

30. Carlson, C. J., S. Koterski, R. J. Sciotti, G. B. Poccard, and C. M. Rondinone. 2003. Enhanced basal activation of mitogen-activated protein kinases in adipocytes from type 2 diabetes: potential role of p38 in the downregulation of GLUT4 expression. Diabetes 52:634-41.

31. Cartegni, L., S. L. Chew, and A. R. Krainer. 2002. Listening to silence and understanding nonsense: exonic mutations that affect splicing. Nat Rev Genet 3:285-98.

32. Caruso, M., M. A. Maitan, G. Bifulco, C. Miele, G. Vigliotta, F. Oriente, P. Formisano, and F. Beguinot. 2001. Activation and mitochondrial translocation of protein kinase Cdelta are necessary for insulin stimulation of pyruvate dehydrogenase complex activity in muscle and liver cells. J Biol Chem 276:45088-97.

33. Chalfant, C. E., T. P. Ciaraldi, J. E. Watson, S. Nikoulina, R. R. Henry, and D. R. Cooper. 2000. Protein kinase Ctheta expression is increased upon differentiation of human skeletal muscle cells: dysregulation in type 2 diabetic patients and a possible role for protein kinase Ctheta in insulin-stimulated glycogen synthase activity. Endocrinology 141:2773-8.

34. Chalfant, C. E., H. Mischak, J. E. Watson, B. C. Winkler, J. Goodnight, R. V. Farese, and D. R. Cooper. 1995. Regulation of alternative splicing of protein kinase C beta by insulin. J Biol Chem 270:13326-32.

35. Ciejek, E. M., J. L. Nordstrom, M. J. Tsai, and B. W. O'Malley. 1982. Ribonucleic acid precursors are associated with the chick oviduct nuclear matrix. Biochemistry 21:4945-53.

36. Clarke, P. R., and D. G. Hardie. 1990. Regulation of HMG-CoA reductase: identification of the site phosphorylated by the AMP-activated protein kinase in vitro and in intact rat liver. Embo J 9:2439-46.

37. Clarke, S. D., and D. B. Jump. 1994. Dietary polyunsaturated fatty acid regulation of gene transcription. Annu Rev Nutr 14:83-98.

38. Clarke, S. D., D. R. Romsos, and G. A. Leveille. 1977. Differential effects of dietary methyl esters of long-chain saturated and polyunsaturated fatty acids on rat liver and adipose tissue lipogenesis. J Nutr 107:1170-81.

39. Clarke, S. D., D. R. Romsos, and G. A. Leveille. 1977. Influence of dietary fatty acids on liver and adipose tissue lipogenesis and on liver metabolites in meal-fed rats. J Nutr 107:1277-87.

40. Clarke, S. D., D. R. Romsos, and G. A. Leveille. 1976. Specific inhibition of hepatic fatty acid synthesis exerted by dietary linoleate and linolenate in essential fatty acid adequate rats. Lipids 11:485-90. 
41. Conricode, K. M. 1995. Involvement of phosphatidylinositol 3-kinase in stimulation of glucose transport by growth factors in 3T3-L1 adipocytes. Biochem Mol Biol Int 36:835-43.

42. Cooper, D. R., J. E. Watson, N. Patel, P. Illingworth, M. Acevedo-Duncan, J. Goodnight, C. E. Chalfant, and H. Mischak. 1999. Ectopic expression of protein kinase CbetaII, -delta, and -epsilon, but not -betaI or -zeta, provide for insulin stimulation of glucose uptake in NIH-3T3 cells. Arch Biochem Biophys 372:69-79.

43. Cross, D. A., D. R. Alessi, P. Cohen, M. Andjelkovich, and B. A. Hemmings. 1995. Inhibition of glycogen synthase kinase- 3 by insulin mediated by protein kinase B. Nature 378:785-9.

44. Danesch, U., P. C. Weber, and A. Sellmayer. 1994. Arachidonic acid increases c-fos and Egr-1 mRNA in 3T3 fibroblasts by formation of prostaglandin E2 and activation of protein kinase C. J Biol Chem 269:27258-63.

45. Davies, S. P., A. T. Sim, and D. G. Hardie. 1990. Location and function of three sites phosphorylated on rat acetyl-CoA carboxylase by the AMP-activated protein kinase. Eur J Biochem 187:183-90.

46. de Alvaro, C., T. Teruel, R. Hernandez, and M. Lorenzo. 2004. Tumor necrosis factor alpha produces insulin resistance in skeletal muscle by activation of inhibitor kappaB kinase in a p38 MAPK-dependent manner. J Biol Chem 279:17070-8.

47. De Fea, K., and R. A. Roth. 1997. Modulation of insulin receptor substrate-1 tyrosine phosphorylation and function by mitogen-activated protein kinase. J Biol Chem 272:31400-6.

48. Domin, J., R. Dhand, and M. D. Waterfield. 1996. Binding to the plateletderived growth factor receptor transiently activates the p85alpha-p110alpha phosphoinositide 3-kinase complex in vivo. J Biol Chem 271:21614-21.

49. Engelman, J. A., M. P. Lisanti, and P. E. Scherer. 1998. Specific inhibitors of p38 mitogen-activated protein kinase block 3T3-L1 adipogenesis. J Biol Chem 273:32111-20.

50. Enslen, H., D. M. Brancho, and R. J. Davis. 2000. Molecular determinants that mediate selective activation of p38 MAP kinase isoforms. Embo J 19:1301-11.

51. Etgen, G. J., K. M. Valasek, C. L. Broderick, and A. R. Miller. 1999. In vivo adenoviral delivery of recombinant human protein kinase $\mathrm{C}$-zeta stimulates glucose transport activity in rat skeletal muscle. J Biol Chem 274:22139-42.

52. Fey, E. G., G. Krochmalnic, and S. Penman. 1986. The nonchromatin substructures of the nucleus: the ribonucleoprotein (RNP)-containing and RNPdepleted matrices analyzed by sequential fractionation and resinless section electron microscopy. J Cell Biol 102:1654-65.

53. Foretz, M., D. Carling, C. Guichard, P. Ferre, and F. Foufelle. 1998. AMPactivated protein kinase inhibits the glucose-activated expression of fatty acid synthase gene in rat hepatocytes. J Biol Chem 273:14767-71.

54. Franke, T. F., S. I. Yang, T. O. Chan, K. Datta, A. Kazlauskas, D. K. Morrison, D. R. Kaplan, and P. N. Tsichlis. 1995. The protein kinase encoded by the Akt proto-oncogene is a target of the PDGF-activated phosphatidylinositol 3-kinase. Cell 81:727-36. 
55. Franze, A., M. I. Ferrante, F. Fusco, A. Santoro, E. Sanzari, G. Martini, and M. V. Ursini. 1998. Molecular anatomy of the human glucose 6-phosphate dehydrogenase core promoter. FEBS Lett 437:313-8.

56. Freedland, R. A., S. Murad, and A. I. Hurvitz. 1968. Relationship of nutritional and hormonal influences on liver enzyme activity. Fed Proc 27:1217-22.

57. Freshney, N. W., L. Rawlinson, F. Guesdon, E. Jones, S. Cowley, J. Hsuan, and J. Saklatvala. 1994. Interleukin-1 activates a novel protein kinase cascade that results in the phosphorylation of Hsp27. Cell 78:1039-49.

58. Fritz, R. S., and R. F. Kletzien. 1987. Regulation of glucose-6-phosphate dehydrogenase by diet and thyroid hormone. Mol Cell Endocrinol 51:13-7.

59. Fryer, L. G., A. Parbu-Patel, and D. Carling. 2002. The Anti-diabetic drugs rosiglitazone and metformin stimulate AMP-activated protein kinase through distinct signaling pathways. J Biol Chem 277:25226-32.

60. Fujishiro, M., Y. Gotoh, H. Katagiri, H. Sakoda, T. Ogihara, M. Anai, Y. Onishi, H. Ono, M. Abe, N. Shojima, Y. Fukushima, M. Kikuchi, Y. Oka, and T. Asano. 2003. Three mitogen-activated protein kinases inhibit insulin signaling by different mechanisms in 3T3-L1 adipocytes. Mol Endocrinol 17:48797.

61. Gao, X., Y. Zhang, P. Arrazola, O. Hino, T. Kobayashi, R. S. Yeung, B. Ru, and D. Pan. 2002. Tsc tumour suppressor proteins antagonize amino-acid-TOR signalling. Nat Cell Biol 4:699-704.

62. Gao, Z., D. Hwang, F. Bataille, M. Lefevre, D. York, M. J. Quon, and J. Ye. 2002. Serine phosphorylation of insulin receptor substrate 1 by inhibitor kappa B kinase complex. J Biol Chem 277:48115-21.

63. Garcia, D. R., and D. Holten. 1975. Inhibition of rat liver glucose-6-phosphate dehydrogenase synthesis by glucagon. J Biol Chem 250:3960-5.

64. Garcia, J., B. Lemercier, S. Roman-Roman, and G. Rawadi. 1998. A Mycoplasma fermentans-derived synthetic lipopeptide induces AP-1 and NFkappaB activity and cytokine secretion in macrophages via the activation of mitogen-activated protein kinase pathways. J Biol Chem 273:34391-8.

65. Garton, A. J., D. G. Campbell, D. Carling, D. G. Hardie, R. J. Colbran, and S. J. Yeaman. 1989. Phosphorylation of bovine hormone-sensitive lipase by the AMP-activated protein kinase. A possible antilipolytic mechanism. Eur J Biochem 179:249-54.

66. Ge, H., and J. L. Manley. 1990. A protein factor, ASF, controls cell-specific alternative splicing of SV40 early pre-mRNA in vitro. Cell 62:25-34.

67. Geisler, R. W., A. E. Roggeveen, and R. J. Hansen. 1978. The effects of insulin on the turnover of glucose-6-phosphate dehydrogenase in epididymal adipose tissue of the rat. Biochim Biophys Acta 544:284-93.

68. Girard, J., P. Ferre, and F. Foufelle. 1997. Mechanisms by which carbohydrates regulate expression of genes for glycolytic and lipogenic enzymes. Annu Rev Nutr 17:325-52.

69. Glock, G. E., and P. McLean. 1954. Levels of enzymes of the direct oxidative pathway of carbohydrate metabolism in mammalian tissues and tumors. Biochem J 56:171-175. 
70. Gout, I., R. Dhand, G. Panayotou, M. J. Fry, I. Hiles, M. Otsu, and M. D. Waterfield. 1992. Expression and characterization of the p85 subunit of the phosphatidylinositol 3-kinase complex and a related p85 beta protein by using the baculovirus expression system. Biochem J 288 ( Pt 2):395-405.

71. Graveley, B. R. 2000. Sorting out the complexity of SR protein functions. Rna 6:1197-211.

72. Hanks, S. K., and T. Hunter. 1995. Protein kinases 6. The eukaryotic protein kinase superfamily: kinase (catalytic) domain structure and classification. Faseb J 9:576-96.

73. Hara, K., Y. Maruki, X. Long, K. Yoshino, N. Oshiro, S. Hidayat, C. Tokunaga, J. Avruch, and K. Yonezawa. 2002. Raptor, a binding partner of target of rapamycin (TOR), mediates TOR action. Cell 110:177-89.

74. Hardie, D. G. 2004. The AMP-activated protein kinase pathway--new players upstream and downstream. J Cell Sci 117:5479-87.

75. Hardie, D. G., and D. A. Pan. 2002. Regulation of fatty acid synthesis and oxidation by the AMP-activated protein kinase. Biochem Soc Trans 30:1064-70.

76. Hardie, D. G., J. W. Scott, D. A. Pan, and E. R. Hudson. 2003. Management of cellular energy by the AMP-activated protein kinase system. FEBS Lett 546:11320.

77. Hawley, S. A., J. Boudeau, J. L. Reid, K. J. Mustard, L. Udd, T. P. Makela, D. R. Alessi, and D. G. Hardie. 2003. Complexes between the LKB1 tumor suppressor, STRAD alpha/beta and MO25 alpha/beta are upstream kinases in the AMP-activated protein kinase cascade. J Biol 2:28.

78. Hay, N., and N. Sonenberg. 2004. Upstream and downstream of mTOR. Genes Dev 18:1926-45.

79. Herlaar, E., and Z. Brown. 1999. p38 MAPK signalling cascades in inflammatory disease. Mol Med Today 5:439-47.

80. Hibi, M., A. Lin, T. Smeal, A. Minden, and M. Karin. 1993. Identification of an oncoprotein- and UV-responsive protein kinase that binds and potentiates the c-Jun activation domain. Genes Dev 7:2135-48.

81. Hii, C. S., Z. H. Huang, A. Bilney, M. Costabile, A. W. Murray, D. A. Rathjen, C. J. Der, and A. Ferrante. 1998. Stimulation of p38 phosphorylation and activity by arachidonic acid in HeLa cells, HL60 promyelocytic leukemic cells, and human neutrophils. Evidence for cell type-specific activation of mitogen-activated protein kinases. J Biol Chem 273:19277-82.

82. Hiles, I. D., M. Otsu, S. Volinia, M. J. Fry, I. Gout, R. Dhand, G. Panayotou, F. Ruiz-Larrea, A. Thompson, N. F. Totty, and et al. 1992.

Phosphatidylinositol 3-kinase: structure and expression of the $110 \mathrm{kd}$ catalytic subunit. Cell 70:419-29.

83. Hirosumi, J., G. Tuncman, L. Chang, C. Z. Gorgun, K. T. Uysal, K. Maeda, M. Karin, and G. S. Hotamisligil. 2002. A central role for JNK in obesity and insulin resistance. Nature 420:333-6.

84. Ho, Y. S., A. J. Howard, and J. D. Crapo. 1988. Cloning and sequence of a cDNA encoding rat glucose-6-phosphate dehydrogenase [published erratum appears in Nucleic Acids Res 1989 Jan 25;17(2):831]. Nucleic Acids Res 16:7746. 
85. Hodge, D. L., and L. M. Salati. 1997. Nutritional regulation of the glucose-6phosphate dehydrogenase gene is mediated by a nuclear posttranscriptional mechanism. Arch Biochem Biophys 348:303-12.

86. Hong, Y. H., U. S. Varanasi, W. Yang, and T. Leff. 2003. AMP-activated protein kinase regulates HNF4alpha transcriptional activity by inhibiting dimer formation and decreasing protein stability. J Biol Chem 278:27495-501.

87. Hu, P., A. Mondino, E. Y. Skolnik, and J. Schlessinger. 1993. Cloning of a novel, ubiquitously expressed human phosphatidylinositol 3-kinase and identification of its binding site on p85. Mol Cell Biol 13:7677-88.

88. Inoki, K., T. Zhu, and K. L. Guan. 2003. TSC2 mediates cellular energy response to control cell growth and survival. Cell 115:577-90.

89. Inukai, K., M. Funaki, T. Ogihara, H. Katagiri, A. Kanda, M. Anai, Y. Fukushima, T. Hosaka, M. Suzuki, B. C. Shin, K. Takata, Y. Yazaki, M. Kikuchi, Y. Oka, and T. Asano. 1997. p85alpha gene generates three isoforms of regulatory subunit for phosphatidylinositol 3-kinase (PI 3-Kinase), p50alpha, p55alpha, and p85alpha, with different PI 3-kinase activity elevating responses to insulin. J Biol Chem 272:7873-82.

90. Jacinto, E., R. Loewith, A. Schmidt, S. Lin, M. A. Ruegg, A. Hall, and M. N. Hall. 2004. Mammalian TOR complex 2 controls the actin cytoskeleton and is rapamycin insensitive. Nat Cell Biol 6:1122-8.

91. Jaken, S. 1996. Protein kinase C isozymes and substrates. Curr Opin Cell Biol 8:168-73.

92. Johnson, G. L., and R. Lapadat. 2002. Mitogen-activated protein kinase pathways mediated by ERK, JNK, and p38 protein kinases. Science 298:1911-2.

93. Jump, D. B. 2002. Dietary polyunsaturated fatty acids and regulation of gene transcription. Curr Opin Lipidol 13:155-64.

94. Jump, D. B., and S. D. Clarke. 1999. Regulation of gene expression by dietary fat. Annu Rev Nutr 19:63-90.

95. Jump, D. B., S. D. Clarke, O. MacDougald, and A. Thelen. 1993. Polyunsaturated fatty acids inhibit S14 gene transcription in rat liver and cultured hepatocytes. Proc Natl Acad Sci U S A 90:8454-8.

96. Jump, D. B., S. D. Clarke, A. Thelen, and M. Liimatta. 1994. Coordinate regulation of glycolytic and lipogenic gene expression by polyunsaturated fatty acids. J Lipid Res 35:1076-84.

97. Kahn, B. B., T. Alquier, D. Carling, and D. G. Hardie. 2005. AMP-activated protein kinase: ancient energy gauge provides clues to modern understanding of metabolism. Cell Metab 1:15-25.

98. Kastrouni, E., T. Pegiou, P. Gardiki, and A. Trakatellis. 1984. Activity changes of glucose-6-phosphate dehydrogenase in response to diet and insulin. Int J Biochem 16:1353-8.

99. Katsurada, A., N. Iritani, H. Fukuda, Y. Matsumura, N. Nishimoto, T. Noguchi, and T. Tanaka. 1990. Effects of nutrients and hormones on transcriptional and post- transcriptional regulation of fatty acid synthase in rat liver. Eur J Biochem 190:427-33. 
100. Ke, Y., J. Ash, and L. F. Johnson. 1996. Splicing signals are required for Sphase regulation of the mouse thymidylate synthase gene. Mol Cell Biol 16:37683.

101. Kellerer, M., J. Mushack, E. Seffer, H. Mischak, A. Ullrich, and H. U. Haring. 1998. Protein kinase $\mathrm{C}$ isoforms alpha, delta and theta require insulin receptor substrate-1 to inhibit the tyrosine kinase activity of the insulin receptor in human kidney embryonic cells (HEK 293 cells). Diabetologia 41:833-8.

102. Kelley, D. S., and R. F. Kletzien. 1984. Ethanol modulation of the hormonal and nutritional regulation of glucose 6-phosphate dehydrogenase activity in primary cultures of rat hepatocytes. Biochem J 217:543-9.

103. Kim, D. H., D. D. Sarbassov, S. M. Ali, J. E. King, R. R. Latek, H. Erdjument-Bromage, P. Tempst, and D. M. Sabatini. 2002. mTOR interacts with raptor to form a nutrient-sensitive complex that signals to the cell growth machinery. Cell 110:163-75.

104. King, G. L. 1996. The role of hyperglycaemia and hyperinsulinaemia in causing vascular dysfunction in diabetes. Ann Med 28:427-32.

105. Konig, H., H. Ponta, and P. Herrlich. 1998. Coupling of signal transduction to alternative pre-mRNA splicing by a composite splice regulator. Embo J 17:290413.

106. Krainer, A. R., G. C. Conway, and D. Kozak. 1990. Purification and characterization of pre-mRNA splicing factor SF2 from HeLa cells. Genes Dev 4:1158-71.

107. Kramer, A. 1996. The structure and function of proteins involved in mammalian pre-mRNA splicing. Annu Rev Biochem 65:367-409.

108. Kurtz, J. W., and W. W. Wells. 1981. Induction of glucose-6-phosphate dehydrogenase in primary cultures of adult rat hepatocytes. Requirement for insulin and dexamethasone. J Biol Chem 256:10870-5.

109. Kyriakis, J. M., and J. Avruch. 2001. Mammalian mitogen-activated protein kinase signal transduction pathways activated by stress and inflammation. Physiol Rev 81:807-69.

110. Lam, T. K., H. Yoshii, C. A. Haber, E. Bogdanovic, L. Lam, I. G. Fantus, and A. Giacca. 2002. Free fatty acid-induced hepatic insulin resistance: a potential role for protein kinase C-delta. Am J Physiol Endocrinol Metab 283:E682-91.

111. Lawler, S., Y. Fleming, M. Goedert, and P. Cohen. 1998. Synergistic activation of SAPK1/JNK1 by two MAP kinase kinases in vitro. Curr Biol 8:1387-90.

112. Leclerc, I., C. Lenzner, L. Gourdon, S. Vaulont, A. Kahn, and B. Viollet. 2001. Hepatocyte nuclear factor-4alpha involved in type 1 maturity-onset diabetes of the young is a novel target of AMP-activated protein kinase. Diabetes 50:151521.

113. Lemieux, K., D. Konrad, A. Klip, and A. Marette. 2003. The AMP-activated protein kinase activator AICAR does not induce GLUT4 translocation to transverse tubules but stimulates glucose uptake and p38 mitogen-activated protein kinases alpha and beta in skeletal muscle. Faseb J 17:1658-65.

114. Li, J., E. J. Miller, J. Ninomiya-Tsuji, R. R. Russell, 3rd, and L. H. Young. 2005. AMP-activated protein kinase activates p38 mitogen-activated protein 
kinase by increasing recruitment of p38 MAPK to TAB 1 in the ischemic heart. Circ Res 97:872-9.

115. Liu, Y. F., K. Paz, A. Herschkovitz, A. Alt, T. Tennenbaum, S. R. Sampson, M. Ohba, T. Kuroki, D. LeRoith, and Y. Zick. 2001. Insulin stimulates PKCzeta -mediated phosphorylation of insulin receptor substrate-1 (IRS-1). A self-attenuated mechanism to negatively regulate the function of IRS proteins. J Biol Chem 276:14459-65.

116. Long, X., Y. Lin, S. Ortiz-Vega, K. Yonezawa, and J. Avruch. 2005. Rheb binds and regulates the mTOR kinase. Curr Biol 15:702-13.

117. Lopez, A. J. 1998. Alternative splicing of pre-mRNA: developmental consequences and mechanisms of regulation. Annu Rev Genet 32:279-305.

118. Luzzatto, L., and A. Mehta. 1989. Glucose-6-phosphate dehydrogenase deficiency, p. 2237-2266. In C. R. Scriver, A. Beaudet, W. Sly, and D. Valle (ed.), The Metabolic Basis of Inherited Disease, 6th ed. McGraw-Hill, New York.

119. Manning, B. D. 2004. Balancing Akt with S6K: implications for both metabolic diseases and tumorigenesis. J Cell Biol 167:399-403.

120. Marsin, A. S., C. Bouzin, L. Bertrand, and L. Hue. 2002. The stimulation of glycolysis by hypoxia in activated monocytes is mediated by AMP-activated protein kinase and inducible 6-phosphofructo-2-kinase. J Biol Chem 277:3077883.

121. Martini, G., D. Toniolo, T. Vulliamy, L. Luzzatto, R. Dono, G. Viglietto, G. Paonessa, M. D'Urso, and M. G. Persico. 1986. Structural analysis of the Xlinked gene encoding human glucose 6-phosphate dehydrogenase. Embo J 5:1849-55.

122. Martins, R. N., G. B. Stokes, and C. L. Masters. 1985. Regulation of the multiple molecular forms of rat liver glucose 6-phosphate dehydrogenase by insulin and dietary restriction. Biochem Biophys Res Commun 127:136-42.

123. Mater, M. K., D. Pan, W. G. Bergen, and D. B. Jump. 1998. Arachidonic acid inhibits lipogenic gene expression in 3T3-L1 adipocytes through a prostanoid pathway. J Lipid Res 39:1327-34.

124. McDermott, E. P., and L. A. O'Neill. 2002. Ras participates in the activation of p38 MAPK by interleukin-1 by associating with IRAK, IRAK2, TRAF6, and TAK-1. J Biol Chem 277:7808-15.

125. Mellor, H., and P. J. Parker. 1998. The extended protein kinase C superfamily. Biochem J 332 ( Pt 2):281-92.

126. Miksicek, R. J., and H. C. Towle. 1982. Changes in the rates of synthesis and messenger RNA levels of hepatic glucose-6-phosphate and 6-phosphogluconate dehydrogenases following induction by diet or thyroid hormone. J Biol Chem 257:11829-35.

127. Mitchell, P., and D. Tollervey. 2000. mRNA stability in eukaryotes. Curr Opin Genet Dev 10:193-8.

128. Mitchell, P., and D. Tollervey. 2000. Musing on the structural organization of the exosome complex. Nat Struct Biol 7:843-6.

129. Morrison, D. K., and R. E. Cutler. 1997. The complexity of Raf-1 regulation. Curr Opin Cell Biol 9:174-9. 
130. Munday, M. R., D. G. Campbell, D. Carling, and D. G. Hardie. 1988.

Identification by amino acid sequencing of three major regulatory

phosphorylation sites on rat acetyl-CoA carboxylase. Eur J Biochem 175:331-8.

131. Murphy, M. G., and Z. Byczko. 1992. Further studies of the mechanism(s) of polyunsaturated-fatty-acid-mediated increases in intracellular cAMP formation in N1E-115 neuroblastoma cells. Neurochem Res 17:1069-77.

132. Murphy, M. G., and Z. Byczko. 1992. Non-eicosanoid functions of essential fatty acids: regulation of adenosine-related functions in cultured neuroblastoma cells. Adv Exp Med Biol 318:91-102.

133. Nagai, M., K. Tuchiya, and H. Kojima. 1996. Prostaglandin E2 increases the calcium concentration in rat brown adipocytes and their consumption of oxygen. Prostaglandins 51:377-86.

134. Nakamura, T., K. Yoshimoto, K. Aoyama, and A. Ichihara. 1982. Hormonal regulations of glucose-6-phosphate dehydrogenase and lipogenesis in primary cultures of rat hepatocytes. J Biochem (Tokyo) 91:681-93.

135. Newton, A. C. 1995. Protein kinase C: structure, function, and regulation. J Biol Chem 270:28495-8.

136. Newton, A. C. 1997. Regulation of protein kinase C. Curr Opin Cell Biol 9:1617.

137. Nguyen, M. T., H. Satoh, S. Favelyukis, J. L. Babendure, T. Imamura, J. I. Sbodio, J. Zalevsky, B. I. Dahiyat, N. W. Chi, and J. M. Olefsky. 2005. JNK and tumor necrosis factor-alpha mediate free fatty acid-induced insulin resistance in 3T3-L1 adipocytes. J Biol Chem 280:35361-71.

138. Obata, T., M. B. Yaffe, G. G. Leparc, E. T. Piro, H. Maegawa, A. Kashiwagi, R. Kikkawa, and L. C. Cantley. 2000. Peptide and protein library screening defines optimal substrate motifs for AKT/PKB. J Biol Chem 275:36108-15.

139. Ono, K., and J. Han. 2000. The p38 signal transduction pathway: activation and function. Cell Signal 12:1-13.

140. Osman, F., N. Jarrous, Y. Ben-Asouli, and R. Kaempfer. 1999. A cis-acting element in the 3'-untranslated region of human TNF-alpha mRNA renders splicing dependent on the activation of protein kinase PKR. Genes Dev 13:328093.

141. Ottinger, E. A., M. C. Botfield, and S. E. Shoelson. 1998. Tandem SH2 domains confer high specificity in tyrosine kinase signaling. J Biol Chem 273:729-35.

142. Ou, J., H. Tu, B. Shan, A. Luk, R. A. DeBose-Boyd, Y. Bashmakov, J. L. Goldstein, and M. S. Brown. 2001. Unsaturated fatty acids inhibit transcription of the sterol regulatory element-binding protein-1c (SREBP-1c) gene by antagonizing ligand-dependent activation of the LXR. Proc Natl Acad Sci U S A 98:6027-32.

143. Ozes, O. N., H. Akca, L. D. Mayo, J. A. Gustin, T. Maehama, J. E. Dixon, and D. B. Donner. 2001. A phosphatidylinositol 3-kinase/Akt/mTOR pathway mediates and PTEN antagonizes tumor necrosis factor inhibition of insulin signaling through insulin receptor substrate-1. Proc Natl Acad Sci U S A 98:4640-5. 
144. Palsson, E. M., M. Popoff, M. Thelestam, and L. A. O'Neill. 2000. Divergent roles for Ras and Rap in the activation of p38 mitogen-activated protein kinase by interleukin-1. J Biol Chem 275:7818-25.

145. Parekh, D. B., W. Ziegler, and P. J. Parker. 2000. Multiple pathways control protein kinase C phosphorylation. Embo J 19:496-503.

146. Patel, N. A., C. E. Chalfant, J. E. Watson, J. R. Wyatt, N. M. Dean, D. C. Eichler, and D. R. Cooper. 2001. Insulin regulates alternative splicing of protein kinase $\mathrm{C}$ beta II through a phosphatidylinositol 3-kinase-dependent pathway involving the nuclear serine/arginine-rich splicing factor, SRp40, in skeletal muscle cells. J Biol Chem 276:22648-54.

147. Patel, N. A., D. C. Eichler, D. S. Chappell, P. A. Illingworth, C. E. Chalfant, M. Yamamoto, N. M. Dean, J. R. Wyatt, K. Mebert, J. E. Watson, and D. R. Cooper. 2003. The protein kinase $\mathrm{C}$ beta II exon confers mRNA instability in the presence of high glucose concentrations. J Biol Chem 278:1149-57.

148. Payne, D. M., A. J. Rossomando, P. Martino, A. K. Erickson, J. H. Her, J. Shabanowitz, D. F. Hunt, M. J. Weber, and T. W. Sturgill. 1991. Identification of the regulatory phosphorylation sites in pp42/mitogen-activated protein kinase (MAP kinase). Embo J 10:885-92.

149. Pearson, G., F. Robinson, T. Beers Gibson, B. E. Xu, M. Karandikar, K. Berman, and M. H. Cobb. 2001. Mitogen-activated protein (MAP) kinase pathways: regulation and physiological functions. Endocr Rev 22:153-83.

150. Persico, M. G., G. Viglietto, G. Martini, D. Toniolo, G. Paonessa, C. Moscatelli, R. Dono, T. Vulliamy, L. Luzzatto, and M. D'Urso. 1986. Isolation of human glucose-6-phosphate dehydrogenase (G6PD) cDNA clones: primary structure of the protein and unusual 5' non-coding region. Nucleic Acids Res 14:2511-22.

151. Philippe, M., Y. Larondelle, F. Lemaigre, B. Mariame, H. Delhez, P. Mason, L. Luzzatto, and G. G. Rousseau. 1994. Promoter function of the human glucose-6-phosphate dehydrogenase gene depends on two GC boxes that are cell specifically controlled. Eur J Biochem 226:377-84.

152. Pifferi, F., F. Roux, B. Langelier, J. M. Alessandri, S. Vancassel, M. Jouin, M. Lavialle, and P. Guesnet. 2005. (n-3) polyunsaturated fatty acid deficiency reduces the expression of both isoforms of the brain glucose transporter GLUT1 in rats. J Nutr 135:2241-6.

153. Pirola, L., S. Bonnafous, A. M. Johnston, C. Chaussade, F. Portis, and E. Van Obberghen. 2003. Phosphoinositide 3-kinase-mediated reduction of insulin receptor substrate- $1 / 2$ protein expression via different mechanisms contributes to the insulin-induced desensitization of its signaling pathways in L6 muscle cells. J Biol Chem 278: $15641-51$.

154. Rank, K. B., P. K. Harris, L. C. Ginsberg, and S. R. Stapleton. 1994. Isolation and sequence of a rat glucose-6-phosphate dehydrogenase promoter. Biochim Biophys Acta 1217:90-2.

155. Ravichandran, L. V., D. L. Esposito, J. Chen, and M. J. Quon. 2001. Protein kinase C-zeta phosphorylates insulin receptor substrate-1 and impairs its ability to activate phosphatidylinositol 3-kinase in response to insulin. J Biol Chem 276:3543-9. 
156. Ray, L. B., and T. W. Sturgill. 1988. Insulin-stimulated microtubule-associated protein kinase is phosphorylated on tyrosine and threonine in vivo. Proc Natl Acad Sci U S A 85:3753-7.

157. Repa, J. J., G. Liang, J. Ou, Y. Bashmakov, J. M. Lobaccaro, I. Shimomura, B. Shan, M. S. Brown, J. L. Goldstein, and D. J. Mangelsdorf. 2000. Regulation of mouse sterol regulatory element-binding protein-1c gene (SREBP1c) by oxysterol receptors, LXRalpha and LXRbeta. Genes Dev 14:2819-30.

158. Rocchi, S., S. Tartare-Deckert, I. Mothe, and E. Van Obberghen. 1995. Identification by mutation of the tyrosine residues in the insulin receptor substrate- 1 affecting association with the tyrosine phosphatase $2 \mathrm{C}$ and phosphatidylinositol 3-kinase. Endocrinology 136:5291-7.

159. Ross, J. 1995. mRNA stability in mammalian cells. Microbiol Rev 59:423-50.

160. Rui, L., V. Aguirre, J. K. Kim, G. I. Shulman, A. Lee, A. Corbould, A. Dunaif, and M. F. White. 2001. Insulin/IGF-1 and TNF-alpha stimulate phosphorylation of IRS-1 at inhibitory Ser307 via distinct pathways. J Clin Invest 107:181-9.

161. Salati, L. M., B. Adkins-Finke, and S. D. Clarke. 1988. Free fatty acid inhibition of the insulin induction of glucose-6-phosphate dehydrogenase in rat hepatocyte monolayers. Lipids 23:36-41.

162. Salvemini, F., A. Franze, A. Iervolino, S. Filosa, S. Salzano, and M. V. Ursini. 1999. Enhanced glutathione levels and oxidoresistance mediated by increased glucose-6-phosphate dehydrogenase expression. J Biol Chem 274:2750-7.

163. Sarbassov, D. D., S. M. Ali, D. H. Kim, D. A. Guertin, R. R. Latek, H. Erdjument-Bromage, P. Tempst, and D. M. Sabatini. 2004. Rictor, a novel binding partner of mTOR, defines a rapamycin-insensitive and raptor-independent pathway that regulates the cytoskeleton. Curr Biol 14:1296-302.

164. Sarbassov, D. D., D. A. Guertin, S. M. Ali, and D. M. Sabatini. 2005. Phosphorylation and regulation of Akt/PKB by the rictor-mTOR complex. Science 307:1098-101.

165. Scheid, M. P., and J. R. Woodgett. 2001. PKB/AKT: functional insights from genetic models. Nat Rev Mol Cell Biol 2:760-8.

166. Schmitz, G., H. Hohage, and K. Ullrich. 1993. Glucose-6-phosphate: a key compound in glycogenosis I and favism leading to hyper- or hypolipidaemia. Eur J Pediatr 152:S77-84.

167. Schmitz-Peiffer, C., C. L. Browne, N. D. Oakes, A. Watkinson, D. J. Chisholm, E. W. Kraegen, and T. J. Biden. 1997. Alterations in the expression and cellular localization of protein kinase $\mathrm{C}$ isozymes epsilon and theta are associated with insulin resistance in skeletal muscle of the high-fat-fed rat. Diabetes 46:169-78.

168. Sessler, A. M., N. Kaur, J. P. Palta, and J. M. Ntambi. 1996. Regulation of stearoyl-CoA desaturase $1 \mathrm{mRNA}$ stability by polyunsaturated fatty acids in 3T3L1 adipocytes. J Biol Chem 271:29854-8.

169. Shepherd, P. R., D. J. Withers, and K. Siddle. 1998. Phosphoinositide 3-kinase: the key switch mechanism in insulin signalling. Biochem J 333 ( Pt 3):471-90. 
170. Shoelson, S. E., S. Chatterjee, M. Chaudhuri, and M. F. White. 1992. YMXM motifs of IRS-1 define substrate specificity of the insulin receptor kinase. Proc Natl Acad Sci U S A 89:2027-31.

171. Smith, C. W., and J. Valcarcel. 2000. Alternative pre-mRNA splicing: the logic of combinatorial control. Trends Biochem Sci 25:381-8.

172. Smith, E. M., S. G. Finn, A. R. Tee, G. J. Browne, and C. G. Proud. 2005. The tuberous sclerosis protein TSC2 is not required for the regulation of the mammalian target of rapamycin by amino acids and certain cellular stresses. J Biol Chem 280:18717-27.

173. Smith, W. L. 1989. The eicosanoids and their biochemical mechanisms of action. Biochem J 259:315-24.

174. Songyang, Z., S. E. Shoelson, M. Chaudhuri, G. Gish, T. Pawson, W. G. Haser, F. King, T. Roberts, S. Ratnofsky, R. J. Lechleider, and et al. 1993. SH2 domains recognize specific phosphopeptide sequences. Cell 72:767-78.

175. Stabile, L. P., D. L. Hodge, S. A. Klautky, and L. M. Salati. 1996. Posttranscriptional regulation of glucose-6-phosphate dehydrogenase by dietary polyunsaturated fat. Arch Biochem Biophys 332:269-79.

176. Stabile, L. P., S. A. Klautky, S. M. Minor, and L. M. Salati. 1998. Polyunsaturated fatty acids inhibit the expression of the glucose-6-phosphate dehydrogenase gene in primary rat hepatocytes by a nuclear posttranscriptional mechanism. J Lipid Res 39:1951-63.

177. Stapleton, S. R., G. J. Stevens, J. F. Teel, K. B. Rank, E. A. Berg, J. Y. Wu, L. C. Ginsberg, and R. F. Kletzien. 1993. Effects of acetaldehyde on glucose-6phosphate dehydrogenase activity and mRNA levels in primary rat hepatocytes in culture. Biochimie 75:971-6.

178. Stephens, L., K. Anderson, D. Stokoe, H. Erdjument-Bromage, G. F. Painter, A. B. Holmes, P. R. Gaffney, C. B. Reese, F. McCormick, P. Tempst, J. Coadwell, and P. T. Hawkins. 1998. Protein kinase B kinases that mediate phosphatidylinositol 3,4,5-trisphosphate-dependent activation of protein kinase B. Science 279:710-4.

179. Stephens, L., A. Eguinoa, S. Corey, T. Jackson, and P. T. Hawkins. 1993. Receptor stimulated accumulation of phosphatidylinositol (3,4,5)-trisphosphate by G-protein mediated pathways in human myeloid derived cells. Embo J 12:226573.

180. Stephens, L. R., A. Eguinoa, H. Erdjument-Bromage, M. Lui, F. Cooke, J. Coadwell, A. S. Smrcka, M. Thelen, K. Cadwallader, P. Tempst, and P. T. Hawkins. 1997. The G beta gamma sensitivity of a PI3K is dependent upon a tightly associated adaptor, p101. Cell 89:105-14.

181. Stephens, L. R., K. T. Hughes, and R. F. Irvine. 1991. Pathway of phosphatidylinositol $(3,4,5)$-trisphosphate synthesis in activated neutrophils. Nature 351:33-9.

182. Stokoe, D., K. Engel, D. G. Campbell, P. Cohen, and M. Gaestel. 1992. Identification of MAPKAP kinase 2 as a major enzyme responsible for the phosphorylation of the small mammalian heat shock proteins. FEBS Lett 313:307-13. 
183. Stumpo, D. J., and R. F. Kletzien. 1984. Regulation of glucose-6-phosphate dehydrogenase mRNA by insulin and the glucocorticoids in primary cultures of rat hepatocytes. Eur J Biochem 144:497-502.

184. Subbaramaiah, K., W. J. Chung, and A. J. Dannenberg. 1998. Ceramide regulates the transcription of cyclooxygenase-2. Evidence for involvement of extracellular signal-regulated kinase/c-Jun N-terminal kinase and p38 mitogenactivated protein kinase pathways. J Biol Chem 273:32943-9.

185. Suchankova, G., M. Tekle, A. K. Saha, N. B. Ruderman, S. D. Clarke, and T. W. Gettys. 2005. Dietary polyunsaturated fatty acids enhance hepatic AMPactivated protein kinase activity in rats. Biochem Biophys Res Commun 326:8518.

186. Sun, X. J., D. L. Crimmins, M. G. Myers, Jr., M. Miralpeix, and M. F. White. 1993. Pleiotropic insulin signals are engaged by multisite phosphorylation of IRS1. Mol Cell Biol 13:7418-28.

187. Sun, X. J., P. Rothenberg, C. R. Kahn, J. M. Backer, E. Araki, P. A. Wilden, D. A. Cahill, B. J. Goldstein, and M. F. White. 1991. Structure of the insulin receptor substrate IRS-1 defines a unique signal transduction protein. Nature 352:73-7.

188. Sun, X. J., L. M. Wang, Y. Zhang, L. Yenush, M. G. Myers, Jr., E. Glasheen, W. S. Lane, J. H. Pierce, and M. F. White. 1995. Role of IRS-2 in insulin and cytokine signalling. Nature 377:173-7.

189. Takizawa, T., I. Y. Huang, T. Ikuta, and A. Yoshida. 1986. Human glucose-6phosphate dehydrogenase: primary structure and cDNA cloning. Proc Natl Acad Sci U S A 83:4157-61.

190. Tan, Y., J. Rouse, A. Zhang, S. Cariati, P. Cohen, and M. J. Comb. 1996. FGF and stress regulate CREB and ATF-1 via a pathway involving p38 MAP kinase and MAPKAP kinase-2. Embo J 15:4629-42.

191. Tao, H., W. Szeszel-Fedorowicz, B. Amir-Ahmady, M. A. Gibson, L. P. Stabile, and L. M. Salati. 2002. Inhibition of the splicing of glucose-6-phosphate dehydrogenase precursor mRNA by polyunsaturated fatty acids. J Biol Chem 277:31270-8.

192. Taouis, M., C. Dagou, C. Ster, G. Durand, M. Pinault, and J. Delarue. 2002. $\mathrm{N}-3$ polyunsaturated fatty acids prevent the defect of insulin receptor signaling in muscle. Am J Physiol Endocrinol Metab 282:E664-71.

193. Tebbey, P. W., K. M. McGowan, J. M. Stephens, T. M. Buttke, and P. H. Pekala. 1994. Arachidonic acid down-regulates the insulin-dependent glucose transporter gene (GLUT4) in 3T3-L1 adipocytes by inhibiting transcription and enhancing mRNA turnover. J Biol Chem 269:639-44.

194. Tee, A. R., and J. Blenis. 2005. mTOR, translational control and human disease. Semin Cell Dev Biol 16:29-37.

195. Toniolo, D., M. Filippi, R. Dono, T. Lettieri, and G. Martini. 1991. The CpG island in the 5' region of the G6PD gene of man and mouse. Gene 102: 197-203.

196. Towle, H. C., E. N. Kaytor, and H. M. Shih. 1997. Regulation of the expression of lipogenic enzyme genes by carbohydrate. Annu Rev Nutr 17:405-33.

197. Um, S. H., F. Frigerio, M. Watanabe, F. Picard, M. Joaquin, M. Sticker, S. Fumagalli, P. R. Allegrini, S. C. Kozma, J. Auwerx, and G. Thomas. 2004. 
Absence of S6K1 protects against age- and diet-induced obesity while enhancing insulin sensitivity. Nature 431:200-5.

198. Ursini, M. V., A. Parrella, G. Rosa, S. Salzano, and G. Martini. 1997. Enhanced expression of glucose-6-phosphate dehydrogenase in human cells sustaining oxidative stress. Biochem J 323:801-6.

199. van der Houven van Oordt, W., M. T. Diaz-Meco, J. Lozano, A. R. Krainer, J. Moscat, and J. F. Caceres. 2000. The MKK(3/6)-p38-signaling cascade alters the subcellular distribution of hnRNP A1 and modulates alternative splicing regulation. J Cell Biol 149:307-16.

200. Virbasius, J. V., A. Guilherme, and M. P. Czech. 1996. Mouse p170 is a novel phosphatidylinositol 3-kinase containing a C2 domain. J Biol Chem 271:13304-7.

201. Vulliamy, T., P. Mason, and L. Luzzatto. 1992. The molecular basis of glucose6-phosphate dehydrogenase deficiency. Trends Genet 8:138-43.

202. Wagle, A., S. Jivraj, G. L. Garlock, and S. R. Stapleton. 1998. Insulin regulation of glucose-6-phosphate dehydrogenase gene expression is rapamycinsensitive and requires phosphatidylinositol 3-kinase. J Biol Chem 273:14968-74.

203. Wagner, E. J., and M. A. Garcia-Blanco. 2001. Polypyrimidine tract binding protein antagonizes exon definition. Mol Cell Biol 21:3281-8.

204. Walker, J., H. B. Jijon, H. Diaz, P. Salehi, T. Churchill, and K. L. Madsen. 2005. 5-aminoimidazole-4-carboxamide riboside (AICAR) enhances GLUT2dependent jejunal glucose transport: a possible role for AMPK. Biochem J 385:485-91.

205. Walker, K. S., M. Deak, A. Paterson, K. Hudson, P. Cohen, and D. R. Alessi. 1998. Activation of protein kinase B beta and gamma isoforms by insulin in vivo and by 3-phosphoinositide-dependent protein kinase-1 in vitro: comparison with protein kinase B alpha. Biochem J 331 ( Pt 1):299-308.

206. Wang, J., V. M. Vock, S. Li, O. R. Olivas, and M. F. Wilkinson. 2002. A quality-control pathway that downregulates aberrant TCR transcripts by a mechanism requiring UPF2 and translation. J Biol Chem 11:11.

207. Wang, L. M., P. Michieli, W. R. Lie, F. Liu, C. C. Lee, A. Minty, X. J. Sun, A. Levine, M. F. White, and J. H. Pierce. 1995. The insulin receptor substrate-1related 4PS substrate but not the interleukin-2R gamma chain is involved in interleukin-13-mediated signal transduction. Blood 86:4218-27.

208. Weg-Remers, S., H. Ponta, P. Herrlich, and H. Konig. 2001. Regulation of alternative pre-mRNA splicing by the ERK MAP-kinase pathway. Embo J 20:4194-203.

209. Westermarck, J., T. Holmstrom, M. Ahonen, J. E. Eriksson, and V. M. Kahari. 1998. Enhancement of fibroblast collagenase-1 (MMP-1) gene expression by tumor promoter okadaic acid is mediated by stress-activated protein kinases Jun N-terminal kinase and p38. Matrix Biol 17:547-57.

210. Widmann, C., S. Gibson, M. B. Jarpe, and G. L. Johnson. 1999. Mitogenactivated protein kinase: conservation of a three-kinase module from yeast to human. Physiol Rev 79:143-80.

211. Wisely, G. B., A. B. Miller, R. G. Davis, A. D. Thornquest, Jr., R. Johnson, T. Spitzer, A. Sefler, B. Shearer, J. T. Moore, T. M. Willson, and S. P. Williams. 
2002. Hepatocyte nuclear factor 4 is a transcription factor that constitutively binds fatty acids. Structure 10:1225-34.

212. Withers, D. J., J. S. Gutierrez, H. Towery, D. J. Burks, J. M. Ren, S. Previs, Y. Zhang, D. Bernal, S. Pons, G. I. Shulman, S. Bonner-Weir, and M. F. White. 1998. Disruption of IRS-2 causes type 2 diabetes in mice. Nature 391:900-4.

213. Wolfe, R. G., and D. Holten. 1978. The effect of dietary fat or cholesterol and cholic acid on the rate of synthesis of rat liver glucose-6-P dehydrogenase. J Nutr 108:1708-17.

214. Worgall, T. S., R. A. Johnson, T. Seo, H. Gierens, and R. J. Deckelbaum. 2002. Unsaturated fatty acid-mediated decreases in sterol regulatory elementmediated gene transcription are linked to cellular sphingolipid metabolism. J Biol Chem 277:3878-85.

215. Wu, Z., P. J. Woodring, K. S. Bhakta, K. Tamura, F. Wen, J. R. Feramisco, M. Karin, J. Y. Wang, and P. L. Puri. 2000. p38 and extracellular signalregulated kinases regulate the myogenic program at multiple steps. Mol Cell Biol 20:3951-64.

216. Wullschleger, S., R. Loewith, and M. N. Hall. 2006. TOR signaling in growth and metabolism. Cell 124:471-84.

217. Xiao, S. H., and J. L. Manley. 1997. Phosphorylation of the ASF/SF2 RS domain affects both protein-protein and protein-RNA interactions and is necessary for splicing. Genes Dev 11:334-44.

218. Xing, J., J. M. Kornhauser, Z. Xia, E. A. Thiele, and M. E. Greenberg. 1998. Nerve growth factor activates extracellular signal-regulated kinase and p38 mitogen-activated protein kinase pathways to stimulate CREB serine 133 phosphorylation. Mol Cell Biol 18:1946-55.

219. Xu, H. E., M. H. Lambert, V. G. Montana, D. J. Parks, S. G. Blanchard, P. J. Brown, D. D. Sternbach, J. M. Lehmann, G. B. Wisely, T. M. Willson, S. A. Kliewer, and M. V. Milburn. 1999. Molecular recognition of fatty acids by peroxisome proliferator-activated receptors. Mol Cell 3:397-403.

220. Xu, J., H. Cho, S. O'Malley, J. H. Park, and S. D. Clarke. 2002. Dietary polyunsaturated fats regulate rat liver sterol regulatory element binding proteins-1 and -2 in three distinct stages and by different mechanisms. J Nutr 132:3333-9.

221. Xu, J., M. T. Nakamura, H. P. Cho, and S. D. Clarke. 1999. Sterol regulatory element binding protein-1 expression is suppressed by dietary polyunsaturated fatty acids. A mechanism for the coordinate suppression of lipogenic genes by polyunsaturated fats. J Biol Chem 274:23577-83.

222. Xu, J., M. Teran-Garcia, J. H. Park, M. T. Nakamura, and S. D. Clarke. 2001. Polyunsaturated fatty acids suppress hepatic sterol regulatory elementbinding protein-1 expression by accelerating transcript decay. J Biol Chem 276:9800-7.

223. Yamaguchi, S., H. Katahira, S. Ozawa, Y. Nakamichi, T. Tanaka, T. Shimoyama, K. Takahashi, K. Yoshimoto, M. O. Imaizumi, S. Nagamatsu, and H. Ishida. 2005. Activators of AMP-activated protein kinase enhance GLUT4 translocation and its glucose transport activity in 3T3-L1 adipocytes. Am J Physiol Endocrinol Metab 289:E643-9. 
224. Yamauchi, J., Y. Kaziro, and H. Itoh. 1999. Differential regulation of mitogenactivated protein kinase kinase 4 (MKK4) and 7 (MKK7) by signaling from $\mathrm{G}$ protein beta gamma subunit in human embryonal kidney 293 cells. J Biol Chem 274:1957-65.

225. Yeakley, J. M., H. Tronchere, J. Olesen, J. A. Dyck, H. Y. Wang, and X. D. Fu. 1999. Phosphorylation regulates in vivo interaction and molecular targeting of serine/arginine-rich pre-mRNA splicing factors. J Cell Biol 145:447-55.

226. Yenush, L., K. J. Makati, J. Smith-Hall, O. Ishibashi, M. G. Myers, Jr., and M. F. White. 1996. The pleckstrin homology domain is the principal link between the insulin receptor and IRS-1. J Biol Chem 271:24300-6.

227. Yenush, L., and M. F. White. 1997. The IRS-signalling system during insulin and cytokine action. Bioessays 19:491-500.

228. Yoshimoto, K., T. Nakamura, S. Niimi, and A. Ichihara. 1983. Hormonal regulation of translatable mRNA of glucose-6-phosphate dehydrogenase in primary cultures of adult rat hepatocytes. Biochim Biophys Acta 741:143-9.

229. Yu, C., Y. Chen, G. W. Cline, D. Zhang, H. Zong, Y. Wang, R. Bergeron, J. K. Kim, S. W. Cushman, G. J. Cooney, B. Atcheson, M. F. White, E. W. Kraegen, and G. I. Shulman. 2002. Mechanism by which fatty acids inhibit insulin activation of insulin receptor substrate-1 (IRS-1)-associated phosphatidylinositol 3-kinase activity in muscle. J Biol Chem 277:50230-6.

230. Zahler, A. M., W. S. Lane, J. A. Stolk, and M. B. Roth. 1992. SR proteins: a conserved family of pre-mRNA splicing factors. Genes Dev 6:837-47.

231. Zheng, C. F., and K. L. Guan. 1993. Cloning and characterization of two distinct human extracellular signal-regulated kinase activator kinases, MEK1 and MEK2. J Biol Chem 268:11435-9.

232. Zheng, D., P. S. MacLean, S. C. Pohnert, J. B. Knight, A. L. Olson, W. W. Winder, and G. L. Dohm. 2001. Regulation of muscle GLUT-4 transcription by AMP-activated protein kinase. J Appl Physiol 91:1073-83.

233. Zhou, G., R. Myers, Y. Li, Y. Chen, X. Shen, J. Fenyk-Melody, M. Wu, J. Ventre, T. Doebber, N. Fujii, N. Musi, M. F. Hirshman, L. J. Goodyear, and D. E. Moller. 2001. Role of AMP-activated protein kinase in mechanism of metformin action. J Clin Invest 108:1167-74.

234. Zimmermann, S., and K. Moelling. 1999. Phosphorylation and regulation of Raf by Akt (protein kinase B). Science 286:1741-4. 


\section{Chapter 2}

\section{Title: Arachidonic acid inhibits the insulin induction of glucose-6-phosphate dehydrogenase via p38 MAP kinase.}

This chapter has been published in

THE JOURNAL OF BIOLOGICAL CHEMISTRY VOL. 280, NO. 49, pp.

40660-40667, December 9, 2005

(C) 2005 by The American Society for Biochemistry and Molecular Biology, Inc. Printed in the U.S.A. by Indrani Talukdar, Wioletta Szeszel-Fedorowicz, and Lisa M. Salati from the Department of Biochemistry and Molecular Pharmacology, West Virginia University, Morgantown, West Virginia 26506

The co-author of this publication Wioletta Szeszel-Fedorowicz helped in preparation of the manuscript and in repetition of some experiments.

The reproduction of this publication is under the copyright permission policy by ASBMB journals. (http://www.jbc.org/misc/Copyright Permission.shtml) 


\section{ARACHIDONIC ACID INHIBITS THE INSULIN INDUCTION OF GLUCOSE-6- PHOSPHATE DEHYDROGENASE VIA p38 MAP KINASE* \\ Indrani Talukdar, Wioletta Szeszel-Fedorowicz, and Lisa M. Salati ${ }^{\#}$ \\ From the Department of Biochemistry and Molecular Pharmacology, West Virginia University, Morgantown, $W V, 26506$ \\ Running title: Arachidonic acid inhibits insulin signaling \\ ${ }^{\#}$ To whom correspondence should be addressed: Department of Biochemistry and Molecular Pharmacology, WVU Health Sciences Center, PO Box 9142, Morgantown, WV 26506, Phone: 304-293-7759, E-mail: Lsalati@hsc.wvu.edu}

Polyunsaturated fatty acids are potent inhibitors of lipogenic gene expression in liver. The lipogenic enzyme, glucose-6-phosphate dehydrogenase (G6PD) is unique in this gene family in that fatty acids inhibit at a posttranscriptional step. In this study, we provide evidence for a signaling pathway for the arachidonic acid inhibition of G6PD mRNA abundance. Arachidonic acid decreases the insulin induction of G6PD expression; by itself, arachidonic acid does not inhibit basal G6PD mRNA accumulation. The insulinstimulation of G6PD involves the phosphoinositide-3-kinase (PI3-kinase) pathway (Wagle A., Jivraj, S., Garlock, G.L., and Stapleton, S.R. (1998) J. Biol. Chem. 273, 14968-14974). Incubation of hepatocytes with arachidonic acid blocks the activation of PI3-kinase by insulin as observed by a decrease in $\mathrm{Ser}^{473}$ phosphorylation of Akt, the downstream effector of PI3-kinase. The decrease in PI3-kinase activity was associated with an increase in $\mathrm{Ser}^{307}$ phosphorylation of IRS-1. Western analysis demonstrated increased phosphorylation of p38 MAPK in arachidonic acid treated cells, while ERK and JNK activity was not changed. Incubating the hepatocytes with the p38 MAPK inhibitor, SB203580, blocked the arachidonic acid inhibition of G6PD mRNA accumulation. Furthermore, SB203580 decreased the arachidonic acid-mediated Ser $^{307}$ phosphorylation of IRS-1 and rescued Akt activation that was otherwise decreased by arachidonic acid. Thus, arachidonic acid inhibits the insulin stimulation of G6PD mRNA accumulation by stimulating the p38 MAPK pathway thereby inhibiting insulin signal transduction.

Insulin is the central hormone required for the activation of lipogenic genes in the liver. Feeding animals a high carbohydrate diet enhances the expression of the lipogenic genes. This effect involves the stimulatory actions of both dietary glucose and insulin $(1,2)$. In contrast, dietary polyunsaturated fats attenuate the stimulatory effect of feeding a high carbohydrate diet $(3,4)$. We have used glucose-6-phosphate dehydrogenase (G6PD)1, a member of the lipogenic gene family as a model system for studying the mechanism of action of fatty acids. The advantage of this model is that insulin is the primary inducer of G6PD expression and fatty acids such as arachidonic acid are the primary inhibitors of G6PD expression; this regulation is independent of other hormonal requirements $(5,6)$. The intracellular mechanisms by which polyunsaturated fats inhibit G6PD or other lipogenic genes are not completely understood. Inhibition by polyunsaturated fatty acid may represent a direct action of fatty acids on factors involved in gene expression. Alternatively, fatty acids may act indirectly via the inhibition of stimulatory signal transduction pathways of glucose or insulin. We hypothesized that fatty acids inhibit G6PD expression by inhibition of the insulin induction.

Insulin transduces its signal upon binding to the insulin receptor. Transduction of this signal in liver involves phosphorylation of two intracellular substrates, insulin receptor substrate (IRS)-1 and IRS-2 (7). These proteins play complementary roles in insulin signaling (8). Activation of PI3-kinase is associated with the stimulatory effects of insulin on metabolic pathways including lipogenesis (9-11). 
The IRS proteins can be phosphorylated on both tyrosines and serines. A known mechanism for the inhibition of IRS-1 activation is by phosphorylation at serines 307, 612 and 632 (12). These serine residues, when phosphorylated might interfere with the interaction between IRS-1 and the insulin receptor or PI3-kinase $(13,14)$. Among the factors known to cause serine phosphorylation of IRS-1 are the mitogen-activated protein kinases (MAP kinases). Activation of the MAP kinases, extracellular regulated kinase (Erk) $(15,16)$, c-Jun amino-terminal kinase (JNK) (17-19), or p38 MAP kinase (p38 MAPK) $(17,20)$ is associated with the development of insulin resistance in muscle and adipose tissue.

Known activators of MAP kinases include tumor necrosis factor $\square$ (TNF $\square$ ) and very high fat diets. TNFG, a potent mediator of insulin resistance, activates all three of the MAP kinases. Phosphorylation and activation of p38 MAPK by TNF $\square$ correlates with IRS-1 serine phosphorylation and a decrease in PI3-kinase activity $(17,20)$. In muscle and adipose tissue, this results in the decrease in glucose uptake associated with insulin resistance. Likewise, diets containing $40 \%$ or more of the energy content as fat, also decrease PI3-kinase activation and result in an insulin resistant phenotype in intact animals (21-23). This may involve activation of MAP kinases $(18,19)$. In contrast to the pathological effects of large amounts of dietary fat, addition of smaller amounts of polyunsaturated fat (less than $20 \%$ of energy) to a high carbohydrate diet has a potent but reversible inhibitory effect on lipogenic gene expression (3). The question remains if modulation of insulin signaling by low levels of dietary fat is involved in the non-pathological regulation of metabolic pathways and in particular the de novo synthesis of fatty acids.

In this paper, we report a signaling pathway by which polyunsaturated fatty acids inhibit G6PD expression. We demonstrate that arachidonic acid inhibits the insulin-mediated induction of G6PD mRNA abundance in primary rat hepatocytes. This inhibition of insulin action occurs by $\mathrm{Ser}^{307}$ phosphorylation of IRS-1. Incubation of hepatocytes with arachidonic acid results in an activation of p38 MAPK, thereby inducing IRS-1 serine phosphorylation, and reducing PI3kinase activation. Inhibition of p38 MAPK results in a loss of the arachidonic acid-mediated inhibition of G6PD expression. This is the first report of p38 MAPK involvement in the regulation of a lipogenic gene by polyunsaturated fatty acids.

\section{EXPERIMENTAL PROCEDURES}

Animal Care and Cell Culture - Male Sprague-Dawley rats (175-225g) were starved $16 \mathrm{~h}$ prior to surgery. Hepatocytes were isolated by a modification of the technique of Seglen (24) as previously described (6). Hepatocytes $\left(3.1 \times 10^{6}\right)$ were placed in $60-\mathrm{mm}$ dishes coated with rattail collagen and incubated in $\mathrm{Hi} / \mathrm{Wo} / \mathrm{Ba}$ medium (Waymouth MB752/1 plus $20 \mathrm{mM} \mathrm{HEPES,} \mathrm{pH}$ 7.4, $0.5 \mathrm{mM}$ serine, $0.5 \mathrm{mM}$ alanine, $0.2 \%$ bovine serum albumin). Medium containing the treatments indicated in the figure legends was added after $24 \mathrm{~h}$ in culture. Fatty acids (Nu-Check Prep) were added as a complex bound to bovine serum albumin (25). The fatty acid (4 mM), albumin $(1 \mathrm{mM})$ stocks contained butylated hydroxytoluene $(0.1 \%)$, and the medium contained $\square$-tocopherol phosphate, disodium $(10 \mu \mathrm{g} /$ liter $)$, to minimize oxidation of fatty acids. The concentration of arachidonic acid used $(175 \mu \mathrm{M})$ results in the maximum inhibition of G6PD expression $(6,26)$. Hepatocytes not receiving arachidonic acid are treated with an equivalent amount of albumin and butylated hydroxytoluene. Because arachidonic acid is metabolized rapidly by the hepatocytes, the medium was replenished every $12 \mathrm{~h}$. The Erk inhibitor (PD98059) was purchased from Cell Signaling Technology; the inhibitors of PI3kinase (LY294002), and p38 MAPK (SB203580) were purchased from Calbiochem.

Isolation of Total RNA and Ribonuclease Protection Assay - Total RNA from 2-3 plates per treatment was isolated by the method of Chomczynski and Sacchi (27). Quantitation of RNA was 
performed using RNase protection assays (Ambion, Inc.). Rat G6PD exon 13 template was synthesized as described previously (26). The templates for the rat $\square$-actin and $18 \mathrm{~s}$ probes were purchased from Ambion, Inc. Probe synthesis, hybridizations and RNase digestion were as previously described (28). The resulting hybridization products protected from RNase digestion were separated in a 5\% denaturing polyacrylamide gel. Images were visualized by storage phosphor technology and quantified using ImageQuaNT software by Molecular Dynamics (Amersham Biosciences).

Preparation of Cell Extract and Western Blot Analysis - The hepatocytes were lysed in buffer containing $10 \mathrm{mM}$ Tris, $\mathrm{pH} 7.4,1 \%$ SDS and total protein was quantified using a BCA protein assay (Pierce). Equal amounts of denatured protein (40 \g per lane) were loaded onto a 7.5\% polyacrylamide gel and transferred to Immun-Blot $\square$ PVDF membrane (Bio-Rad) at $100 \mathrm{~V}$ for $1.5 \mathrm{~h}$. The membranes were blocked in $5 \%$ nonfat dry milk for $1 \mathrm{~h}$ and incubated with primary antibody diluted in $5 \%$ bovine serum albumin overnight at $4{ }^{\circ} \mathrm{C}$. The primary antibodies against phosphorylated Akt (Ser ${ }^{473}$ ), phosphorylated IRS-1 $\left(\operatorname{Ser}^{307}\right.$ and $\operatorname{Ser}^{612}$ ), phosphorylated p38 MAPK $\left(\mathrm{Thr}^{180} / \mathrm{Tyr}^{182}\right)$, phosphorylated Erk $\left(\mathrm{Tyr}^{183 / 185}\right)$, phosphorylated JNK $\left(\mathrm{Thr}^{183} / \mathrm{Tyr}^{185}\right)$ and total Akt, IRS-1, p38 MAPK, Erk, and JNK were obtained from Cell Signaling Technology. Anti rabbit IgG conjugated with horseradish peroxidase (Cell Signaling Technology) was used as the secondary antibody, and the immunocomplexes were detected by enhanced chemiluminescence (Pierce). Images were visualized with film (Pierce) and quantified by densitometry using ImageQuaNT software (Molecular Dynamics).

PI3-kinase assay - Rat hepatocytes were harvested with lysis buffer containing $50 \mathrm{mM} \mathrm{NaCl}$, $100 \mathrm{mM}$ Tris, $\mathrm{pH} 8,1 \%$ Triton $\mathrm{X}-100,5 \mathrm{mM}$ EDTA, $10 \mathrm{mM} \mathrm{NaF}, 0.5 \mathrm{M} \mathrm{NaVO}_{4}, 1 \mathrm{M}$ DTT, and protease inhibitors. Equal amounts of protein $(500 \mathrm{Dg})$ from each treatment group were immunoprecipitated with anti p85 antibody (Upstate) and protein A sepharose beads. The bead pellets were washed twice with lysis buffer, once each with TNE buffer $(200 \mathrm{mM}$ Tris, $\mathrm{pH} 7.5$, $100 \mathrm{mM} \mathrm{NaCl}, 1 \mathrm{mM}$ EDTA) and 20mM HEPES, pH 7.5 and suspended in assay buffer $(20 \mathrm{mM}$ HEPES, pH 7.5, 10mM MgCl $2,0.2 \mathrm{mg} / \mathrm{ml}$ phosphoinositol, $60 \square \mathrm{M}$ ATP, $20 \square \mathrm{Ci}\left[\square^{32} \mathrm{P}\right] \mathrm{ATP}$ ). After 15 minutes in assay buffer, the reaction was terminated by addition of $1 \mathrm{M} \mathrm{HCl}$, and the lipids were extracted with chloroform:methanol (1:1). The organic phase was loaded on silica gel TLC plates (10). The lipids were visualized using autoradiography.

\section{RESULTS}

Insulin induces the expression of G6PD $m R N A$, whereas arachidonic acid attenuates this effect - Primary rat hepatocytes were used for these studies because they are the only cell culture system that mimics the effects of dietary polyunsaturated fat on the regulation hepatic G6PD expression. In hepatocytes, insulin increases G6PD mRNA abundance and arachidonic acid inhibits G6PD mRNA amount, similar to the changes in G6PD expression observed in intact liver, in animals fed a high carbohydrate diet and a diet supplemented with polyunsaturated fat (6\% safflower oil), respectively $(6,29)$. Furthermore, regulation of G6PD expression occurs at a nuclear posttranscriptional step in both intact liver and primary hepatocyte cultures $(6,28,29)$. We first asked if arachidonic acid per se regulated G6PD expression. Because G6PD activity is essential for cell viability, the amount of G6PD mRNA remains readily detectable in the absence of insulin (Fig. 1). The addition of arachidonic acid alone did not decrease the expression of G6PD mRNA. In contrast, insulin induced G6PD mRNA expression 7-fold, and arachidonic acid 
inhibited this induction by $50 \%$ or more. Thus, arachidonic acid appears to inhibit the insulinmediated induction of G6PD expression.

Arachidonic acid inhibits Akt-phosphorylation and induces $\mathrm{Ser}^{307}$-phosphorylation of IRS-1 Because the arachidonate inhibition is only observed in cells with intact insulin action, we hypothesized that arachidonic acid interferes with the PI3-kinase pathway and thus prevents the induction of G6PD mRNA by insulin. The induction of G6PD mRNA by insulin has been demonstrated to require the PI3-kinase signal transduction pathway (ref. 30 and data not shown). The form or metabolite of arachidonic acid that inhibits gene expression is not known. Thus, the hepatocytes were preincubated with arachidonic acid to allow time for incorporation of this fatty acid into membrane phospholipid and/or generation of the relevant intracellular metabolite. The rapid signal transduction by the insulin receptor could otherwise have preceded the generation of the relevant inhibitory form of arachidonic acid. Insulin induced Akt-phosphorylation 24 to 75fold across time points (Figs. $2 A$ and $2 B$ ). This induction was rapid and persisted through 60 minutes. Pre-incubation of hepatocytes with arachidonic acid attenuated the insulin-mediated induction of Akt phosphorylation by 50 to $72 \%$ across the time points (Figs. $2 A$ and $2 B$ ). The amount of total Akt was not affected by these treatments (Fig. 2A). Similarly, arachidonic acid inhibited PI3-kinase activity by $50 \%$ consistent with it being an upstream activator of Akt (data not shown).

The decrease in Akt phosphorylation in cells incubated with arachidonic acid suggests that arachidonic acid is inhibiting a step at or prior to PI-3 kinase activation. Since phosphorylation of IRS-1 at serines can interfere with its interaction with either the insulin receptor or PI-3 kinase and thereby inhibits insulin signal transduction (12), we measured changes in the amount of IRS1 phosphorylation on 2 different serine residues. Incubation of hepatocytes with arachidonic acid prior to and during insulin addition increased IRS-1 Ser ${ }^{307}$ phosphorylation 4- to 6-fold at each time point (Figs. $2 A$ and $2 C$ ). Insulin alone caused a smaller but reproducible increase $\mathrm{Ser}^{307}$ phosphorylation. Arachidonic acid does not cause an increase in the phosphorylation of all regulatory serines in IRS-1. In this regard, arachidonic acid did not stimulate an increase in phosphorylation at $\operatorname{Ser}^{612}$ of IRS-1 (Fig. $2 A$ ). While phosphorylation of $\operatorname{Ser}^{612}$ can also abolish tyrosine phosphorylation of IRS-1 (7), arachidonic acid inhibition of insulin signaling in hepatocytes does not appear to involve this serine residue. These results suggest that arachidonic acid increases $\mathrm{Ser}^{307}$ phosphorylation of IRS-1; this in turn interferes with the PI3-kinase activity and Akt phosphorylation, which are required for the insulin induction of G6PD mRNA.

Arachidonic acid induces p38 MAPK phosphorylation - To explore the mechanism for the increase in IRS-1 Ser ${ }^{307}$ phosphorylation, we determined if arachidonic acid in the presence of insulin activates serine/threonine kinases involved in serine phosphorylation of IRS-1. Members of the MAP kinases family are known to stimulate serine phosphorylation of IRS-1 (15-20). The amounts of phosphorylated and activated, as well as, the total amounts of the three MAP kinases, Erk, JNK and p38 were measured by western blot analyses (Figs. $3 A$ and $3 B$ ). Insulin stimulated a small but consistent increase in p38 MAPK phosphorylation. A similar increase was detected with arachidonic acid, alone (Fig. $3 C$ ). The greatest increase in the phosphorylation of $\mathrm{p} 38$ MAPK (4- to 6-fold) was observed with arachidonic acid in the presence of insulin as compared to no additions. Furthermore, the increase in p38 MAPK phosphorylation occurred within the same time frame as the changes in Akt and IRS-1 Ser ${ }^{307}$ phosphorylation. The total amount p38 MAPK was not regulated by these treatments (Fig. 3C). In contrast, arachidonic acid did not increase the amounts of activated Erk and JNK. Fluctuations in Erk and JNK activation were observed across treatments and likely reflect stimulation due to the manipulation of the cells for the addition of the treatments. There was no consistent effect of the treatments per se on Erk or JNK activation. This result suggests that arachidonic acid stimulates $\operatorname{Ser}^{307}$ phosphorylation of IRS-1 by activation of $\mathrm{p} 38$ MAPK 
Inhibition of the p38 MAPK pathway decreases the arachidonic acid-mediated inhibition of G6PD mRNA expression - We next tested if the activation of p38 MAPK by arachidonic acid is responsible for the inhibition of G6PD mRNA accumulation. The p38 MAP kinase pathway was inhibited by SB203580. SB203580 had little or no effect on the insulin-mediated induction of G6PD mRNA abundance; but abrogated the inhibition by arachidonic acid (Fig. 4). In contrast, inhibition of Erk signaling with the inhibitor, PD98059, had no detectable effect on G6PD regulation by insulin or arachidonic acid (data not shown); consistent with the lack of Erk activation by arachidonic acid. To verify that activation of p38 MAPK was involved in the Ser ${ }^{307}$ phosphorylation of IRS-1, the effects of arachidonic acid on Ser $^{307}$ phosphorylation of IRS-1 and Akt phosphorylation were measured in hepatocytes incubated with SB203580. Arachidonic acid in the presence of the p38 MAPK inhibitor did not increase the $\operatorname{Ser}^{307}$ phosphorylation of IRS-1 as compared to insulin and SB203580 treated hepatocytes (Fig. 5, compare lanes $4 \& 5$ vs. $2 \& 3$ for P-IRS1). At the same time, Akt phosphorylation in hepatocytes incubated with arachidonic acid and SB203580 did not decrease with respect to hepatocytes incubated with insulin and SB203580 (Fig. 5, lanes $4 \& 5$ vs. $2 \& 3$ for P-Akt). These results are consistent with the idea that activation of p38 MAP kinase by arachidonic acid impairs the activation of the PI3-kinase by inducing Ser ${ }^{307}$ phosphorylation of IRS-1, which in turn inhibits the induction of G6PD mRNA by insulin.

Multiple unsaturated fatty acids inhibit insulin signal transduction. Polyunsaturated fatty acids of both the $\square 6$ and $\square 3$ families inhibit G6PD expression (6). We asked if other polyunsaturated fatty acids also inhibit insulin signal transduction. Eicosapentaenoic acid

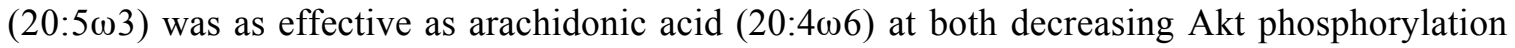
and increasing p38 MAPK phosphorylation (Table 1). The eighteen carbon precursors of these fatty acids, especially linoleate (18:2) caused similar changes in Akt and p38 MAPK phosphorylation but were somewhat less effective similar to the lower inhibitory effect of these fatty acids on G6PD mRNA accumulation both historically (6) and in this experiment (data not shown).

TNF $\square$ induces p38 MAP kinase, inhibits activation of Akt and also diminishes induction of G6PD by insulin - To corroborate that arachidonic acid activation of p38 MAPK was involved in its inhibition of G6PD expression, we tested the effect of another activator of p38 MAPK. TNFD inhibits insulin-mediated Akt phosphorylation in 3T3-L1 adipocytes myotubes $(17,20)$. In addition, TNF $\square$ activates $\mathrm{p} 38$ and other MAP kinases in various cell-lines, resulting in inhibition of the PI3-kinase pathway (20). Incubation of rat hepatocytes with insulin and TNF $\square$ resulted in a concomitant 5-fold increase in phosphorylated p38 MAPK and a 53 to $76 \%$ decrease in phosphorylated Akt across time points (Figs. $6 A$ and $6 B$, respectively). These changes in $\mathrm{p} 38$ MAPK and Akt phosphorylation occurred within the same time frame as the changes caused by arachidonic acid. In addition, TNF $\square$ also decreased the insulin induction of G6PD mRNA by $50 \%$ (Fig. 6C). Thus, activation of MAP kinases by multiple effectors is associated with a decrease in Akt activation and a decrease in the accumulation of G6PD mRNA.

\section{DISCUSSION}

In previous work, we have defined a unique posttranscriptional mechanism whereby polyunsaturated fatty acids inhibit G6PD expression - a decrease in pre-mRNA splicing $(26,31)$. In the present study, we sought to determine the signaling pathway involved in this inhibition. We demonstrate that the polyunsaturated fatty acid inhibition of G6PD expression involves inhibition of the insulin-mediated induction of G6PD (Fig. 1). This inhibition is a consequence of 
arachidonic acid inhibition of insulin signal transduction via PI3-kinase (Fig. 2). Incubation of hepatocytes with insulin and arachidonic acid activated p38 MAPK resulting in $\mathrm{Ser}^{307}$ phosphorylation of IRS-1 (Figs. 2 and 3), a modification which inhibits insulin activation of PI3kinase (7). In confirmation of this, inhibition of p38 MAPK activity, blocks the arachidonic acid inhibition of G6PD expression, decreases Ser $^{307}$ phosphorylation of IRS-1, and increases PI3kinase activity as measured by Akt phosphorylation (Figs. 4 and 5). This is the first report of inhibition of a lipogenic gene in liver via activation of the p38 MAPK pathway.

Polyunsaturated fatty acids have been demonstrated to activate MAP kinases in various cell types (c.f., (32-34). In primary rat hepatocytes, the action of arachidonic acid is specific for p38 MAPK; ERK and Jun kinases are not activated by arachidonic acid (Fig. 3). Activation of p38 MAPK is generally thought to be part of the stress activated signal transduction pathway $(35,36)$ and in this regard, arachidonic acid is a known generator of toxic peroxides $(37,38)$. Several lines of evidence suggest that oxidative stress is not the mechanism by which arachidonic acid in primary rat hepatocytes is activating p38 MAPK. First, the extent of p38 MAPK activation is the same with either arachidonic acid or insulin alone (Fig. $3 C$ ). In addition, arachidonic acid in the absence of insulin does not inhibit G6PD expression despite readily detectable levels of G6PD mRNA (Fig. 1). Second, oxidation of arachidonic acid in the culture system is minimized by preparation of fatty acid stocks with butylated hydroxytoluene, and the culture medium is supplemented with additional $\square$-tocopherol. While these will not completely eliminate oxidation, peroxidation is not detectable using a thiobarbituric acid assay (6). More importantly, enhanced oxidation induces G6PD expression $(39,40)$. Thus, if arachidonic acid is causing oxidative stress, an increase in G6PD expression would have been observed.

The mechanism by which arachidonic acid activates p38 MAPK is not clear. Multiple steps exist upstream of p38 MAPK and regulate its phosphorylation. Stress and cytokines generally induce p38 MAPK via Tak1 or Ask1 $(41,42)$. Still other reports suggest that protein kinase C is an important upstream kinase. Preliminary studies using the inhibitor of protein kinase $\mathrm{C}$, GF109203X, demonstrated that inhibition of protein kinase C does not block the inhibition of G6PD expression by arachidonic acid. ${ }^{2}$ Alternatively, polyunsaturated fatty acids can also activate AMP activated protein kinase in rat liver and hepatocytes $(43,44)$. Activation of AMPK is associated with an increase in p38 MAPK phosphorylation in skeletal and cardiac muscles and this increase is associated with an increase in glucose uptake $(45,46)$. While p38 MAPK has not been shown to be a substrate for AMPK, these results are consistent with AMPK being upstream in the p38 MAPK signaling pathway.

The mechanism whereby arachidonic acid inhibits insulin signaling in hepatocytes shares some of the characteristics of the mechanism of insulin resistance caused by consumption of a high fat diet. Diets with fat contents of $40 \%$ or more inhibit the activation of PI3-kinase by increasing Ser $^{307}$ phosphorylation of IRS-1 (23). Activation of mTOR followed by subsequent activation of S6 kinase 1 (S6K1) was implicated in this response $(47,48)$ and genetic ablation of the S6K1 gene protects against insulin resistance in the intact mouse (23). In primary hepatocytes, arachidonic acid did not activate S6 kinase and treatment with rapamycin for 1 to 24 $\mathrm{h}$ did not ablate the fatty acid inhibition. ${ }^{2}$ Still others have implicated protein kinase $\mathrm{C} \square$ in the $\mathrm{Ser}^{307}$ phosphorylation of IRS-1 and as a mechanism for fat-induced insulin resistance in skeletal muscle (49). While our preliminary data is inconsistent with protein kinase $\mathrm{C}$ activation, this may reflect a distinct difference between isolated cells and intact tissue. Alternatively, it may reflect distinctly different signal transduction pathways between muscle and liver.

Polyunsaturated fat inhibition of lipogenic gene expression occurs with very low levels of dietary fat $(6 \%$ by weight and $14 \%$ by kcal; $(29)$. Such low levels of dietary fat are not associated with insulin resistance. The signal transduction mechanism, which we describe, may reflect a reversible response to changing nutrient conditions. In this regard, we did not observe a decrease in total IRS-1 amount (Fig. $2 A$ ), even at longer time points, which has been observed during insulin resistance $(16,17)$. Regulation of hepatic metabolism by polyunsaturated fats must 
therefore occur at two levels: first, a reversible regulatory response and second, under prolonged and excessive stimulus, a down regulation of the insulin signal transduction pathway.

What remains to be established is how these signals are translocated to the nucleus and to the site of gene expression. In the case of G6PD, the signals must activate proteins involved in premRNA splicing. Cellular signaling events regulate both positive and negative effectors of splicing. The PI3-kinase and MAP kinase pathways have been implicated in regulation of alternative splicing (50-53). Insulin activates alternative splicing of the protein kinase $\mathrm{C}$ पII mRNA via increased phosphorylation of the splicing activator, SRp40 (51,52). Involvement of p38 MAPK signaling in shuttling of hnRNP A1, a suppressor of alternative splicing has also been reported (54). The mechanisms involved in regulating G6PD pre-mRNA splicing are currently under investigation.

\section{REFERENCES}

1. Hillgartner, F. B., Salati, L. M., and Goodridge, A. G. (1995) Physiol. Rev. 75, 47-76

2. Towle, H. C. (2001) Proc. Natl. Acad. Sci. U S A 98, 13476-13478

3. Clarke, S. D. (2004) Curr. Opin. Lipidol. 15, 13-18

4. Jump, D. B. (2004) Crit. Rev. Clin. Lab. Sci. 41, 41-78

5. $\quad$ Salati, L. M., Adkins-Finke, B., and Clarke, S. D. (1988) Lipids 23, 36-41

6. Stabile, L. P., Klautky, S. A., Minor, S. M., and Salati, L. M. (1998) J. Lipid Res. 39, 1951-1963

7. $\quad$ Shepherd, P. R., Withers, D. J., and Siddle, K. (1998) Biochem. J. 333 ( Pt 3), 471-490

8. Saltiel, A. R., and Kahn, C. R. (2001) Nature 414, 799-806

9. Nadeau, K. J., Leitner, J. W., Gurerich, I., and Draznin, B. (2004) J. Biol. Chem. 279, 34380-34387

10. Ruderman, N. B., Kapeller, R., White, M. F., and Cantley, L. C. (1990) Proc. Natl. Acad. Sci. U S A 87, 1411-1415

11. Wang, D., and Sul, H. S. (1998) J. Biol. Chem. 273, 25420-25426

12. Le Marchand-Brustel, Y., Gual, P., Gremeaux, T., Gonzalez, T., Barres, R., and Tanti, J. F. (2003) Biochem. Soc. Trans. 31, 1152-1156

13. Aguirre, V., Werner, E. D., Giraud, J., Lee, Y. H., Shoelson, S. E., and White, M. F. (2002) J. Biol. Chem. 277, 1531-1537

14. Mothe, I., and Van Obberghen, E. (1996) J. Biol. Chem. 271, 11222-11227

15. De Fea, K., and Roth, R. A. (1997) J. Biol. Chem. 272, 31400-31406

16. Pirola, L., Bonnafous, S., Johnston, A. M., Chaussade, C., Portis, F., and Van Obberghen, E. (2003) J. Biol. Chem. 278, 15641-15651

17. Fujishiro, M., Gotoh, Y., Katagiri, H., Sakoda, H., Ogihara, T., Anai, M., Onishi, Y., Ono, H., Abe, M., Shojima, N., Fukushima, Y., Kikuchi, M., Oka, Y., and Asano, T. (2003) Mol. Endocrinol. 17, 487-497

18. Hirosumi, J., Tuncman, G., Chang, L., Gorgun, C. Z., Uysal, K. T., Maeda, K., Karin, M., and Hotamisligil, G. S. (2002) Nature 420, 333-336

19. Prada, P. O., Zecchin, H. G., Gasparetti, A. L., Torsoni, M. A., Ueno, M., Hirata, A. E., Corezola do Amaral, M. E., Hoer, N. F., Boschero, A. C., and Saad, M. J. (2005)

Endocrinology 146, 1576-1587

20. de Alvaro, C., Teruel, T., Hernandez, R., and Lorenzo, M. (2004) J. Biol. Chem. 279, 17070-17078

21. Taouis, M., Dagou, C., Ster, C., Durand, G., Pinault, M., and Delarue, J. (2002) Am. J. Physiol. Endocrinol. Metab. 282, E664-671 
22. Zierath, J. R., Houseknecht, K. L., Gnudi, L., and Kahn, B. B. (1997) Diabetes 46, 215223

23. Um, S. H., Frigerio, F., Watanabe, M., Picard, F., Joaquin, M., Sticker, M., Fumagalli, S., Allegrini, P. R., Kozma, S. C., Auwerx, J., and Thomas, G. (2004) Nature 431, 200-205

24. Seglen, P. O. (1973) Exp. Cell Res. 82, 391-398

25. Mooney, R. A., and Lane, M. D. (1981) J. Biol. Chem. 256, 11724-11733

26. Tao, H., Szeszel-Fedorowicz, W., Amir-Ahmady, B., Gibson, M. A., Stabile, L. P., and Salati, L. M. (2002) J. Biol. Chem. 277, 31270-31278

27. Chomczynski, P., and Sacchi, N. (1987) Anal. Biochem. 162, 156-159

28. Hodge, D. L., and Salati, L. M. (1997) Arch. Biochem. Biophys. 348, 303-312

29. Stabile, L. P., Hodge, D. L., Klautky, S. A., and Salati, L. M. (1996) Arch. Biochem. Biophy.s 332, 269-279

30. Wagle, A., Jivraj, S., Garlock, G. L., and Stapleton, S. R. (1998) J. Biol. Chem. 273, 14968-14974

31. Amir-Ahmady, B., and Salati, L. M. (2001) J. Biol. Chem. 276, 10514-10523

32. Hii, C. S., Ferrante, A., Edwards, Y. S., Huang, Z. H., Hartfield, P. J., Rathjen, D. A., Poulos, A., and Murray, A. W. (1995) J. Biol. Chem. 270, 4201-4204

33. Hii, C. S., Huang, Z. H., Bilney, A., Costabile, M., Murray, A. W., Rathjen, D. A., Der, C. J., and Ferrante, A. (1998) J. Biol. Chem. 273, 19277-19282

34. Rao, G. N., Baas, A. S., Glasgow, W. C., Eling, T. E., Runge, M. S., and Alexander, R. W. (1994) J. Biol. Chem. 269, 32586-32591

35. Ogura, M., and Kitamura, M. (1998) J. Immunol. 161, 3569-3574

36. Hazzalin, C. A., Cano, E., Cuenda, A., Barratt, M. J., Cohen, P., and Mahadevan, L. C. (1996) Curr. Biol. 6, 1028-1031

37. Kosugi, H., and Kikugawa, K. (1989) Free Radic. Biol. Med. 7, 205-207

38. Wu, D., and Cederbaum, A. I. (2003) J. Biol. Chem. 278, 1115-1124

39. Preville, X., Salvemini, F., Giraud, S., Chaufour, S., Paul, C., Stepien, G., Ursini, M. V., and Arrigo, A. P. (1999) Exp. Cell Res. 247, 61-78

40. Xu, J., Maki, D., and Stapleton, S. R. (2003) J. Biochem. Mol. Toxicol. 17, 67-75

41. Moriguchi, T., Kuroyanagi, N., Yamaguchi, K., Gotoh, Y., Irie, K., Kano, T., Shirakabe, K., Muro, Y., Shibuya, H., Matsumoto, K., Nishida, E., and Hagiwara, M. (1996) J. Biol. Chem. 271, 13675-13679

42. Ichijo, H., Nishida, E., Irie, K., ten Dijke, P., Saitoh, M., Moriguchi, T., Takagi, M., Matsumoto, K., Miyazono, K., and Gotoh, Y. (1997) Science 275, 90-94

43. Kawaguchi, T., Osatomi, K., Yamashita, H., Kabashima, T., and Uyeda, K. (2002) J. Biol. Chem. 277, 3829-3835

44. Suchankova, G., Tekle, M., Saha, A. K., Ruderman, N. B., Clarke, S. D., and Gettys, T. W. (2005) Biochem. Biophys. Res. Commun. 326, 851-858

45. Lemieux, K., Konrad, D., Klip, A., and Marette, A. (2003) FASEB J. 17, 1658-1665

46. Pelletier, A., Joly, E., Prentki, M., and Coderre, L. (2005) Endocrinology 146, 2285-2294

47. Manning, B. D., and Cantley, L. C. (2003) Biochem. Soc. Trans. 31, 573-578

48. Harrington, L. S., Findlay, G. M., Gray, A., Tolkacheva, T., Wigfield, S., Rebholz, H., Barnett, J., Leslie, N. R., Cheng, S., Shepherd, P. R., Gout, I., Downes, C. P., and Lamb, R. F. (2004) J. Cell Biol. 166, 213-223

49. Yu, C., Chen, Y., Cline, G. W., Zhang, D., Zong, H., Wang, Y., Bergeron, R., Kim, J. K., Cushman, S. W., Cooney, G. J., Atcheson, B., White, M. F., Kraegen, E. W., and Shulman, G. I. (2002) J. Biol. Chem. 277, 50230-50236

50. Blaustein, M., Pelisch, F., Coso, O. A., Bissell, M. J., Kornblihtt, A. R., and Srebrow, A. (2004) J. Biol. Chem. 279, 21029-21037

51. Patel, N. A., Chalfant, C. E., Watson, J. E., Wyatt, J. R., Dean, N. M., Eichler, D. C., and Cooper, D. R. (2001) J. Biol. Chem. 276, 22648-22654 
52. Patel, N. A., Kaneko, S., Apostolatos, H. S., Bae, S. S., Watson, J. E., Davidowitz, K., Chappell, D. S., Birnbaum, M. J., Cheng, J. Q., and Cooper, D. R. (2005) J. Biol. Chem. 280, 14302-14309

53. Weg-Remers, S., Ponta, H., Herrlich, P., and Konig, H. (2001) EMBO J. 20, 4194-4203

54. van der Houven van Oordt, W., Diaz-Meco, M. T., Lozano, J., Krainer, A. R., Moscat, J., and Caceres, J. F. (2000) J. Cell Biol. 149, 307-316

\section{FOOTNOTES}

*We thank Stacie Brower for experimental advice; Valerie Walker, Daniel Flynn, and Zhungxion Tao for help with the PI3-kinase assays; and Brian Griffith and Callee McConnell for critical reviews of the manuscript. This work was supported by National Institutes of Health Grant DK46897 to L.M.S.

${ }^{1}$ The abbreviations used are: G6PD, glucose-6-phosphate dehydrogenase; IRS, insulin receptor substrate; PI3-kinase, phosphoinositol-3 kinase; MAP, mitogen activated protein; p38 MAPK, p38 mitogen activated protein kinase; ERK, extracellular regulated kinase; JNK, c-Jun aminoterminal kinase; TNF $\square$, tumor necrosis factor a; S6K1, S6 kinase 1; AMPK, AMP activated protein kinase

${ }^{2}$ Talukdar, I. and Salati, L.M., unpublished observations

\section{FIGURE LEGENDS}

Fig. 1. Arachidonic acid inhibits the insulin-mediated induction of G6PD mRNA in primary rat hepatocytes. Rat hepatocytes were plated onto collagen coated tissue culture dishes in $\mathrm{Hi} / \mathrm{Wo} / \mathrm{Ba}$ medium plus $5 \%$ newborn calf serum. After 3 to $4 \mathrm{~h}$, the medium was changed to serum-free medium and after $10 \mathrm{~h}$ Matrigel $\square$ was added. Twenty-four hours post isolation, the cells ( 3 plates per treatment) were treated with or without $0.04 \square \mathrm{M}$ insulin $\pm 175 \square \mathrm{M}$ arachidonic acid or with arachidonic acid alone. After $24 \mathrm{~h}$ of treatment, the cells were harvested and total RNA was isolated. The top panel is a representative RNase protection assay. The lower panel is the results of two experiments (separate hepatocyte isolations) quantified using phosphorimaging and ImageQuant software. G6PD mRNA was normalized to the amount of $\square$-actin mRNA and the results are expressed relative to the amount of mRNA in no addition. $N A$, no addition; $F A$, arachidonic acid; Ins, insulin

Fig. 2. Arachidonic acid inhibits Akt-activation and induces $\operatorname{Ser}^{307}$ phosphorylation of IRS1. Hepatocytes were treated with or without arachidonic acid $(175 \square \mathrm{M}), 24 \mathrm{~h}$ prior to the addition of insulin $(0.04 \square \mathrm{M})$ and isolated 5, 10, 30 or $60 \mathrm{~min}$ after the addition of insulin. (A) Western blot analysis was performed against total and phosphorylated IRS-1 and Akt. The antibodies specifically detected IRS-1 phosphorylated at $\mathrm{Ser}^{307}$ or $\mathrm{Ser}^{612}$ and Akt phosphorylated at Ser ${ }^{473}$. *The asterisk denotes a nonspecific band detected with the IRS-1 Ser $^{307}$ antibody. (B) The amount of phosphorylated Akt in $n=4$ experiments for the 5, 10, and 30 min time points, and $n=3$ experiments for the $60 \mathrm{~min}$. Each bar is the mean $\pm \mathrm{SE}$ for the indicated number of experiments and the values are expressed as the fold increase in phosphorylated Akt relative to the amount in 
hepatocytes not treated with insulin or arachidonic acid. (C) The amount of phosphorylated IRS$1\left(\mathrm{Ser}^{307}\right)$ for $\mathrm{n}=4$ experiments for the 5,10 , and $30 \mathrm{~min}$ time points, and $\mathrm{n}=2$ experiments for 60 min. The values are expressed relative to the amount of phosphorylated protein in hepatocytes not treated with insulin or arachidonic acid. P-Akt, phosphorylated Akt; $P$-IRS-1, phosphorylated IRS-1; $F A$, arachidonic acid; $I$, insulin.

Fig. 3. Arachidonic acid activates p38 MAPK. Hepatocytes were isolated and plated as described in Fig. 1. Cell lysates was prepared after 2, 5, 10, 30, and 60 min from the untreated, insulin $(0.04 \mu \mathrm{M})$ treated or insulin + arachidonic acid $(175 \mu \mathrm{M})$ treated cells. (A) Western blot analysis was performed against the phosphorylated and total forms of Erk, JNK and p38 MAP kinases. The antibodies for the phosphorylated MAP kinases recognize phosphates at $\mathrm{Tyr}^{183 / 185}$, $\mathrm{Thr}^{183} / \mathrm{Tyr}^{185}$, and $\mathrm{Thr}^{180} / \mathrm{Tyr}^{182}$, respectively. A representative blot of at least 4 separate experiments is shown. (B) Quantitative representation of the fold induction of phosphorylated p38 MAPK in hepatocytes treated with insulin alone or insulin + arachidonic acid. Each bar represents the mean $\pm \mathrm{SE}$ and the values are expressed relative to the absence of treatment. Repetition was as follows: $\mathrm{n}=4$ for $2 \min , \mathrm{n}=6$ for $5 \min , \mathrm{n}=8$ for $10 \min , \mathrm{n}=4$ for $30 \min$ and $\mathrm{n}=2$ for $60 \mathrm{~min}$. (C) Hepatocytes were incubated with insulin $(0.4 \mu \mathrm{M})$ alone, arachidonic acid (175 $\mu \mathrm{M})$ alone or insulin + arachidonic acid. Cell lysates were prepared 5, 10, or 30 min later and western blot analysis was performed against phosphorylated and total p38 MAPK. The blot is representative of $\mathrm{n}=3$ separate experiments. $F A$, arachidonic acid; $P-p 38$, phosphorylated $\mathrm{p} 38 ; P$ Erk, phosphorylated Erk; $P-J N K$, phosphorylated JNK; $I$, insulin.

Fig. 4. A p38 MAPK inhibitor, SB203580, reverses the arachidonic acid-mediated decrease of G6PD mRNA. Hepatocytes were treated with or without $10 \square \mathrm{M} \mathrm{SB} 203580$ for $1 \mathrm{~h}$. After $1 \mathrm{~h}$ arachidonic acid $(175 \mu \mathrm{M})$ was added, and $2 \mathrm{~h}$ later insulin $(0.04 \mu \mathrm{M})$ was added. After $12 \mathrm{~h}$, the medium was replenished with one of the same composition. Total RNA was isolated after $24 \mathrm{~h}$ with insulin. The isolated RNA was analyzed by RNase protection assay and quantified using phosphorimaging and ImageQuant software. The values are the amount of G6PD mRNA normalized to the amount of $\square$-actin mRNA and are plotted relative to the amount of RNA in the absence of treatments or inhibitor. Each bar represents the mean \pm SE of $n=3$ experiments. I, insulin; $F A$, arachidonic acid.

Fig. 5. Inhibition of p38 MAPK blocks the decrease in Akt activation and the increase in IRS-1 Ser $^{307}$ phosphorylation by arachidonic acid. Hepatocytes were treated with or without arachidonic acid $(175 \square \mathrm{M})$ for $23 \mathrm{~h}$. Cells were then incubated with or without $10 \square \mathrm{M} \mathrm{SB} 203580$ for $1 \mathrm{~h}$, prior to the addition of insulin $(0.04 \mu \mathrm{M})$. Total cell lysates were isolated 5 min after the addition of insulin. Western blot analysis was performed with antibodies against total and phosphorylated Akt and IRS-1. The antibody for phosphorylated IRS-1 recognizes phosphate at $\mathrm{Ser}^{307}$ and the antibody for phosphorylated Akt recognizes phosphate at $\mathrm{Ser}^{473} . F A$, arachidonic acid; $P$-IRS-1, phosphorylated IRS-1; $P$-Akt, phosphorylated Akt.

Fig. 6. TNF inhibits activation of Akt, activates p38 MAPK and inhibits induction of G6PD mRNA expression by insulin. (A) Hepatocytes were treated with or without insulin $(0.04 \square \mathrm{M})$ in the presence or absence of TNF $\square(10 \mathrm{ng} / \mathrm{ml})$. Total cell lysates were isolated 5, 10, and $30 \mathrm{~min}$ after the addition of the treatments. Western blot analysis was performed against the phosphorylated and total forms of Erk, JNK and p38 MAP kinases. The antibodies for the phosphorylated MAP kinases recognize phosphates at $\mathrm{Tyr}^{183 / 185}, \mathrm{Thr}^{183} / \mathrm{Tyr}^{185}$, and $\mathrm{Thr}^{180} / \mathrm{Tyr}^{182}$, respectively. (B) Hepatocytes were incubated with or without TNF $(10 \mathrm{ng} / \mathrm{ml})$ for $24 \mathrm{~h}$ prior to the addition of insulin $(0.04 \square \mathrm{M})$. Total cell lysates were isolated 5,10 , and $30 \mathrm{~min}$ following the addition of insulin. Western blot analysis was performed with the antibody against the 
phosphorylated Akt $\left(\mathrm{Ser}^{473}\right)$. The 5 min samples were from the same experiment but on a separate gel from the other time points and were exposed on the same film. (C) Hepatocytes were treated with or without insulin $(0.04 \square \mathrm{M})$ and TNF $(10 \mathrm{ng} / \mathrm{ml})$ as shown. After $24 \mathrm{~h}$, total RNA was isolated and the amounts of G6PD and $\square$-actin mRNA were measured by RNase protection assay and imaged used phosphorimaging. All of figures are representative blots of $\mathrm{n}=3$ experiments. FA, arachidonic acid; $P$-Akt, phosphorylated Akt; $P$ - $p 38$, phosphorylated p38; $P$ Erk, phosphorylated Erk; $P-J N K$, phosphorylated JNK. 
Figure 1
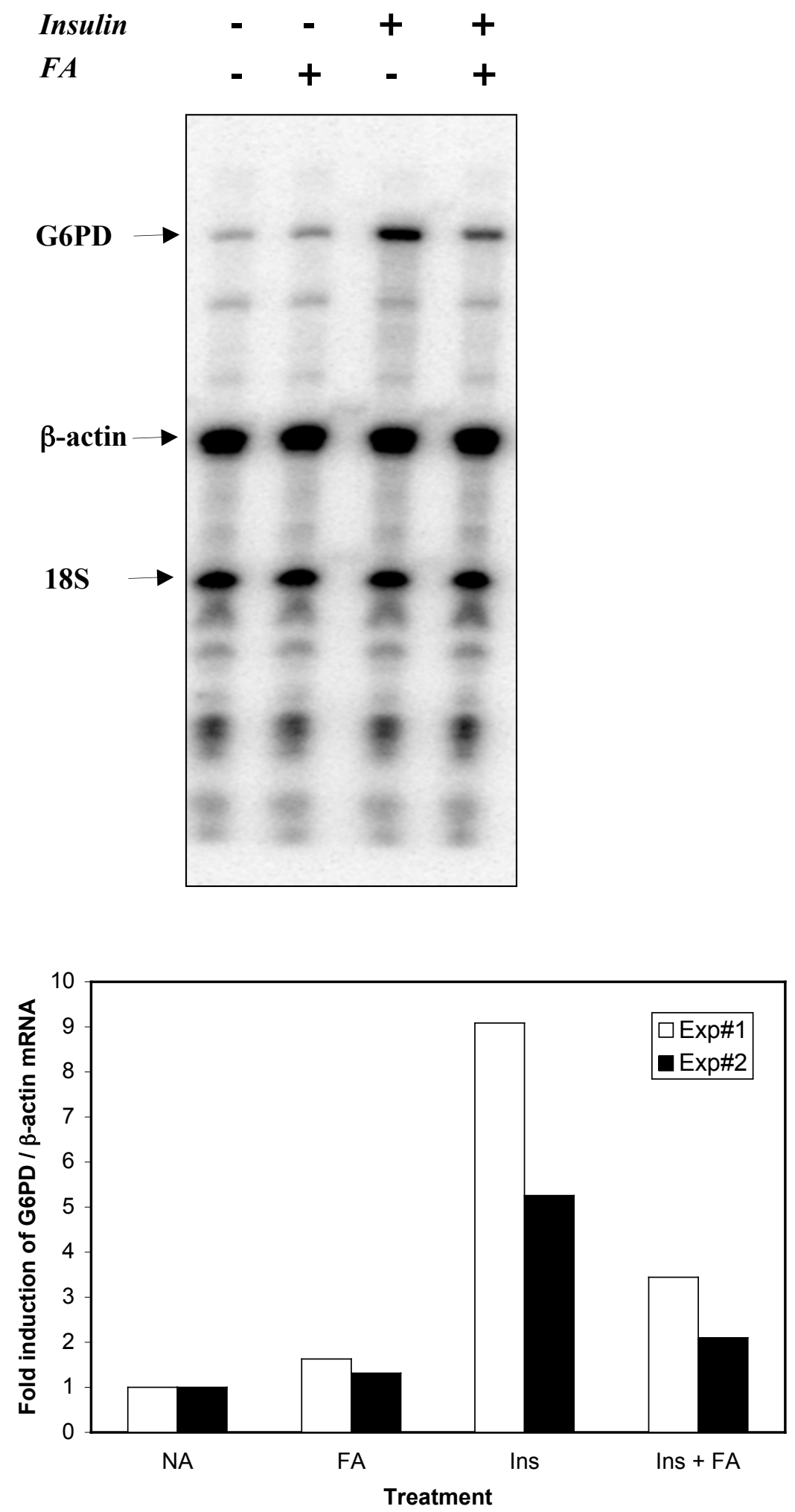


\section{Figure 2}

A
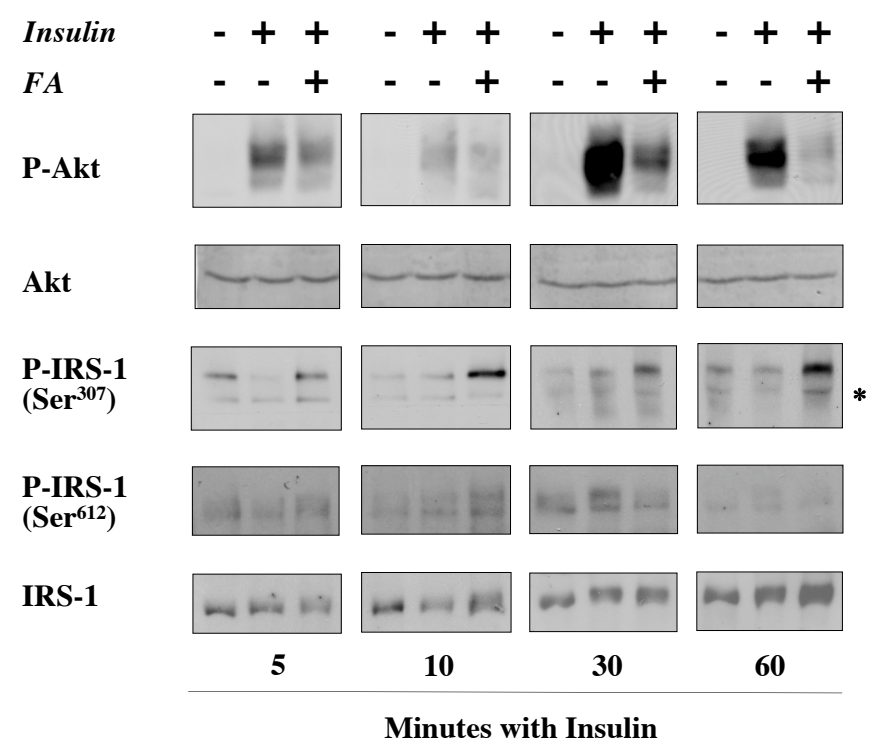

B

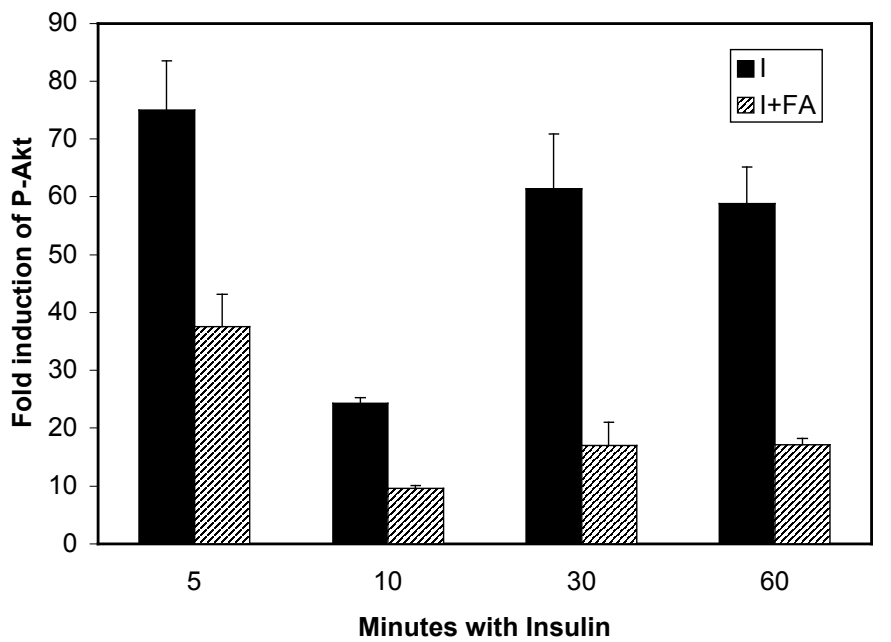

C

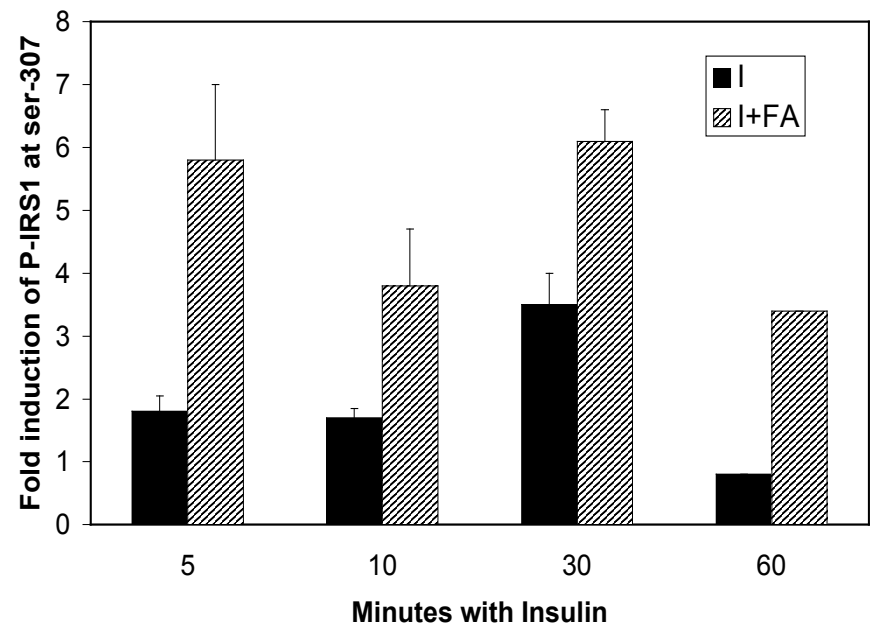




\section{Figure 3}

A

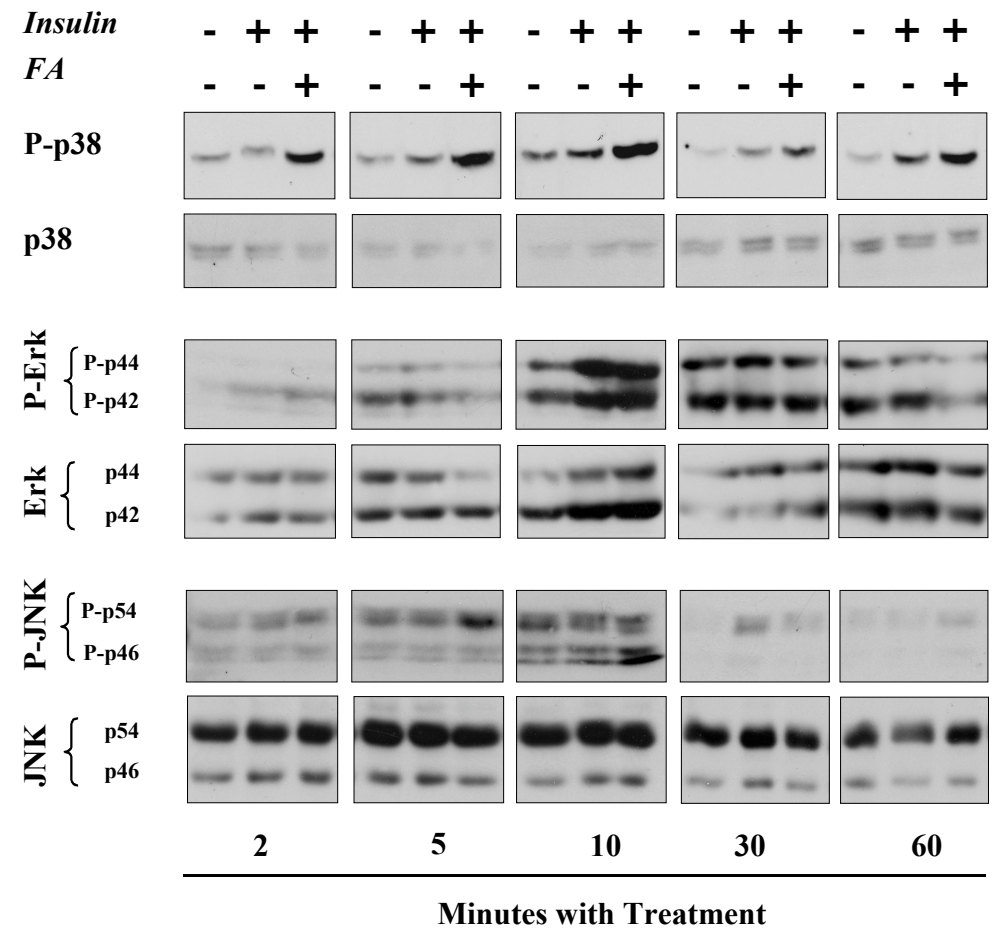

B
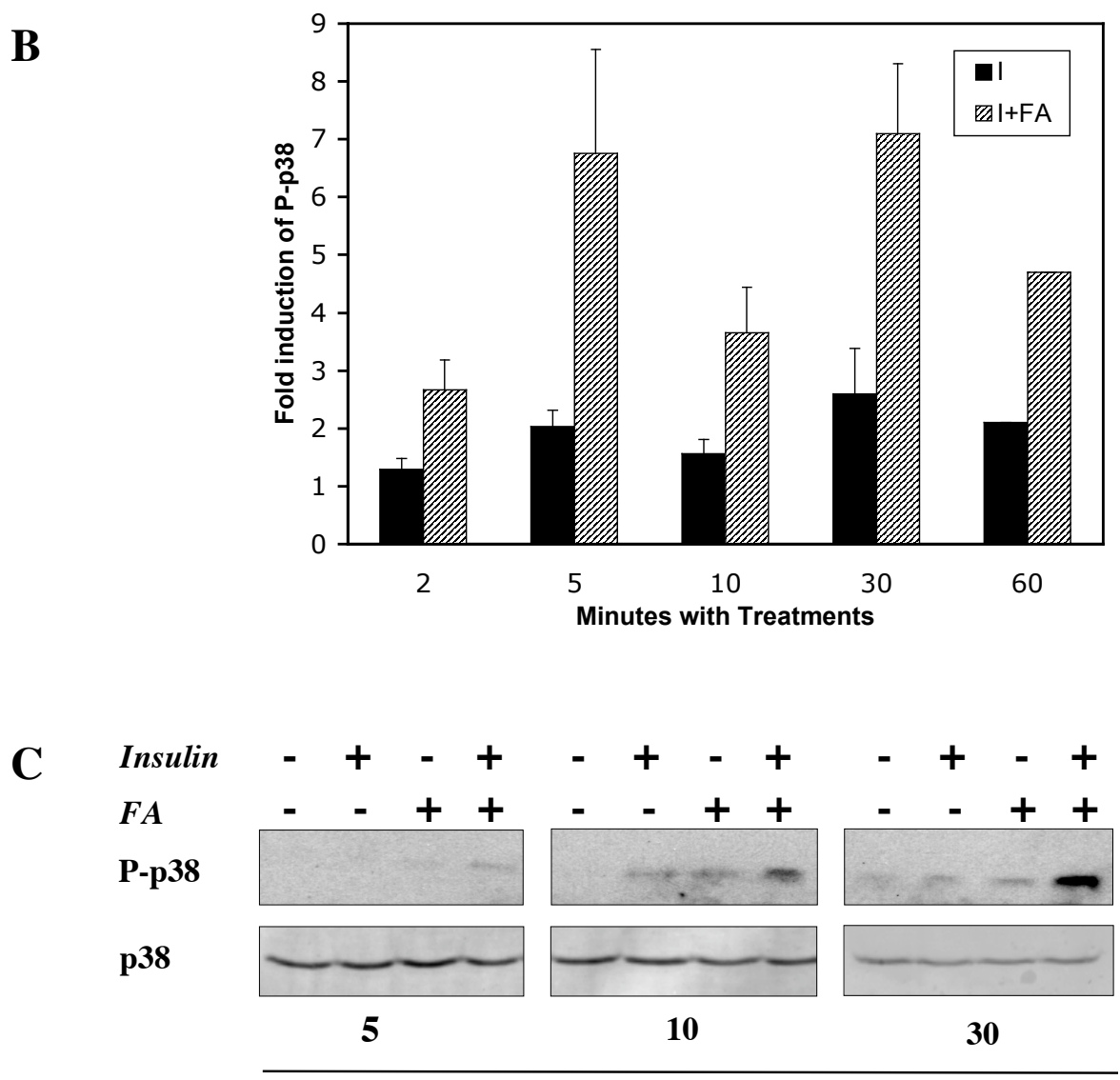

Minutes with Treatment 
Figure 4

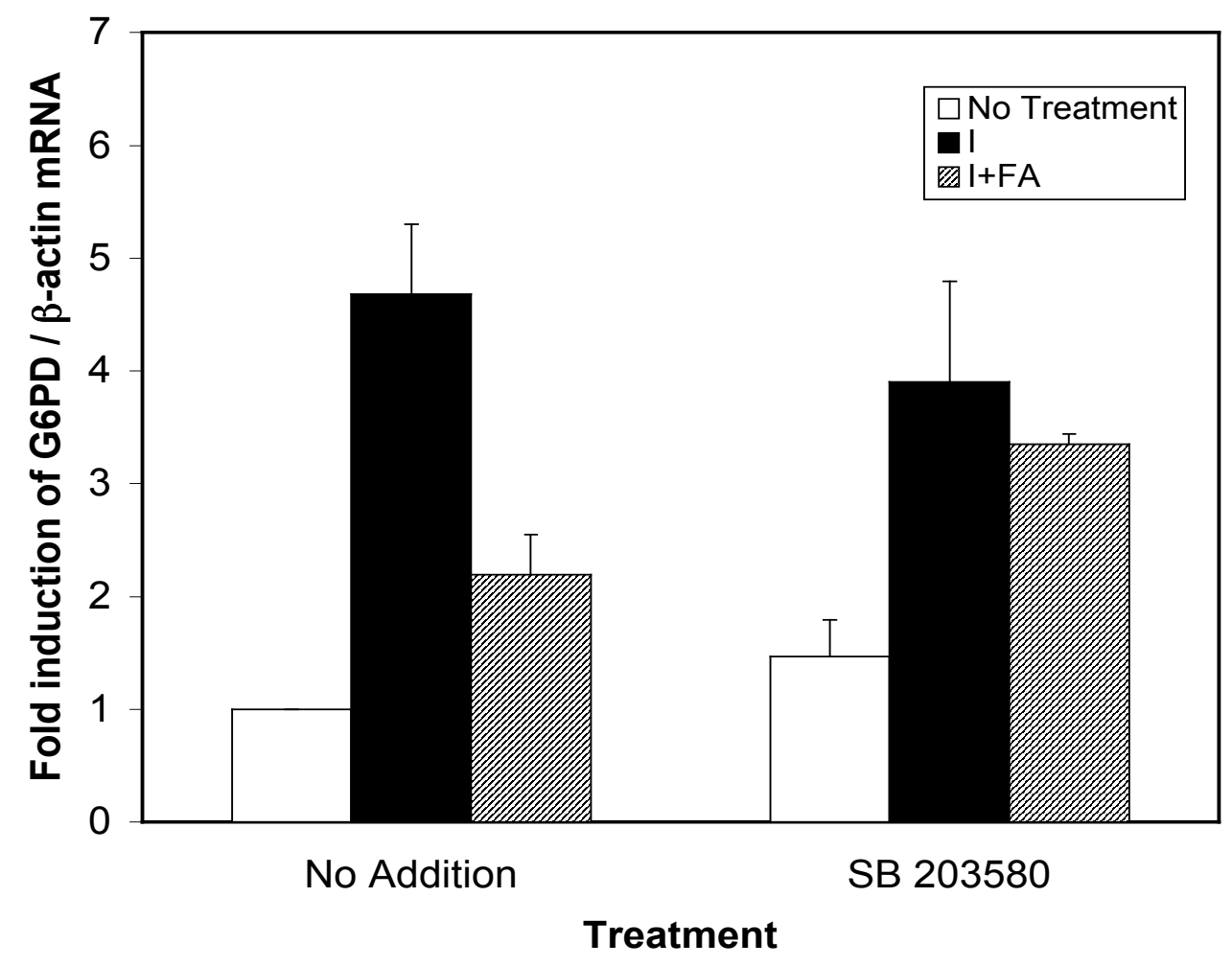




\section{Figure 5}

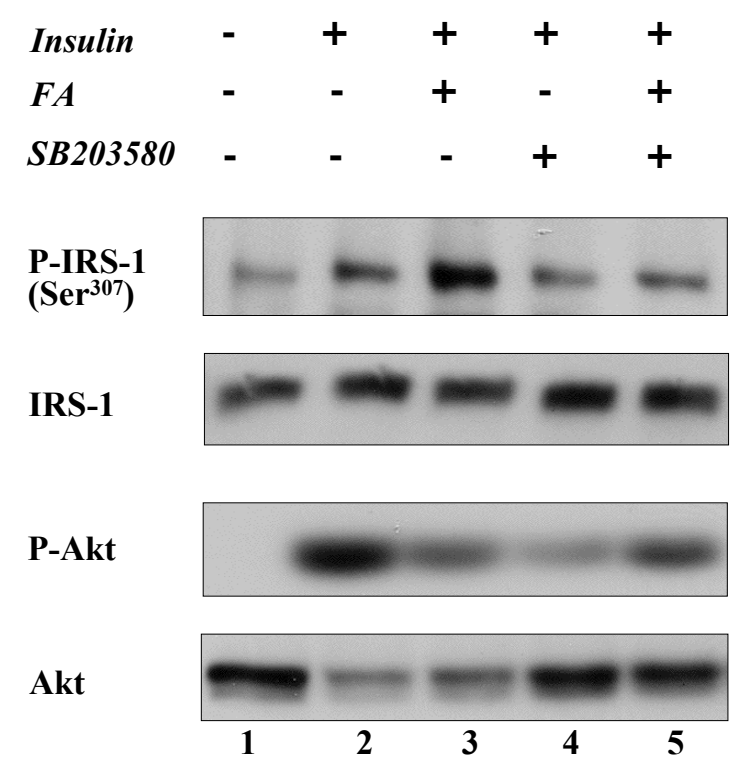




\section{Figure 6}

A
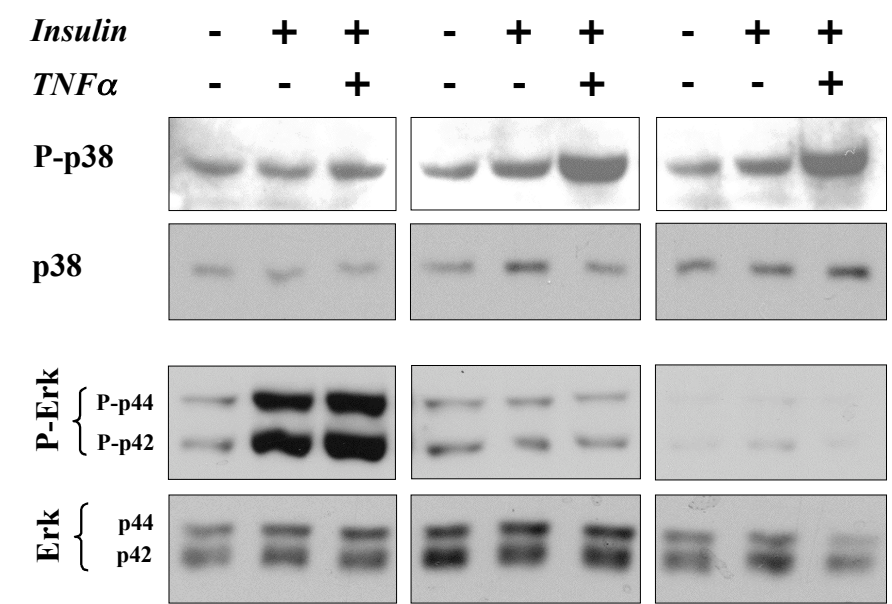

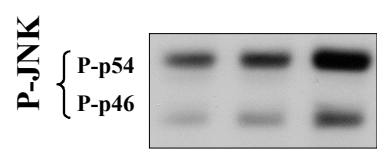

光 $\left\{\begin{array}{l}\text { p54 } \\ \text { p46 }\end{array}\right.$

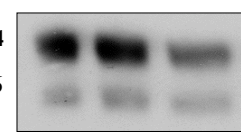

5
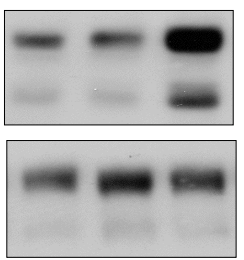

10
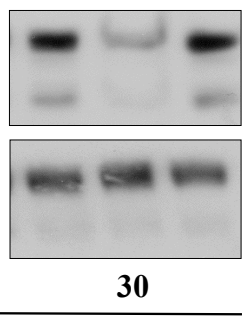

Minutes with Treatment

B

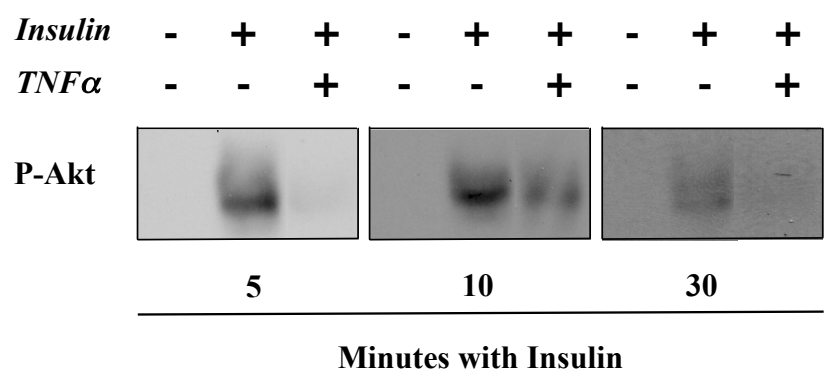

C

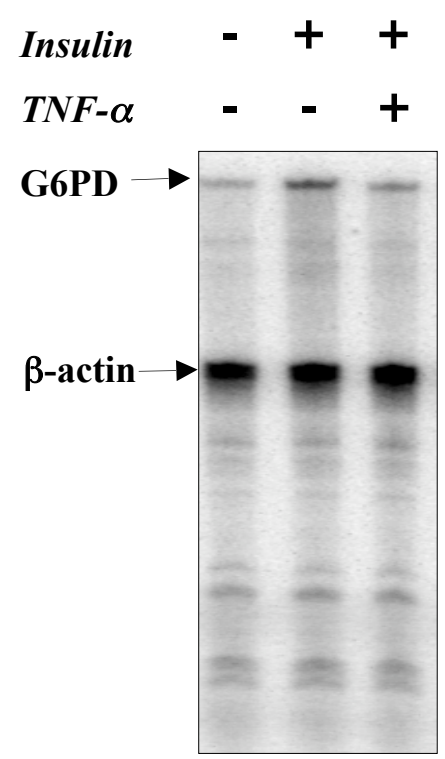


Table 1. Effect of various polyunsaturated fatty acids on Akt and p38 MAPK

phosphorylation. Rat hepatocytes were either preincubated with fatty acid for $24 \mathrm{~h}$ prior to the addition of insulin (Akt-phosphorylation), or treated simultaneously with insulin and $175 \mu \mathrm{M}$ fatty acid (p38 MAPK phosphorylation). Total cell lysates were prepared 10 and 30 min after the addition of insulin. Total and phosphorylated Akt and p38 MAPK were determined by Western blot analysis. The values are the ratio of phosphorylated to total Akt or p38 MAPK and are expressed relative to insulin alone. The data are representative of $n=2$ experiments that showed the same results. 18:2, linoleic acid; 18:3, linolenic acid; 20:5, eicosapentanoic acid; $P$ - $A k t$, phosphorylated Akt; $P$-p38, phosphorylated p38

\begin{tabular}{lll}
\hline Treatments & P-Akt/Akt & P-p38/p38
\end{tabular}

\begin{tabular}{lcc}
\hline 10 minutes & & \\
Insulin & 100 & 1 \\
Insulin $+18: 2$ & 52 & 2.3 \\
Insulin + 18:3 & 33 & 1.6 \\
Insulin + 20:5 & 26 & 11.1
\end{tabular}

\section{$\underline{30 \text { minutes }}$}

$\begin{array}{lcc}\text { Insulin } & 100 & 1 \\ \text { Insulin }+18: 2 & 82 & 6 \\ \text { Insulin + 18:3 } & 36 & 18 \\ \text { Insulin + 20:5 } & 11 & 35\end{array}$




\section{Chapter 3}

\section{Title: Involvement of AMP-activated protein kinase (AMPK) in arachidonic acid- mediated inhibition of G6PD mRNA expression.}

\section{Introduction:}

Glucose-6-phosphate dehydrogenase (G6PD) is the first and the rate-limiting enzyme in the pentose phosphate pathway. It converts glucose-6-phosphate into 6phospho-gluconate and as a byproduct it produces NADPH, a necessary component for fatty acid biosynthesis. Thus, G6PD is known as a lipogenic enzyme.

Like other lipogenic enzymes, G6PD is regulated by hormonal factors and nutritional status. Starvation of intact animals causes a decrease in G6PD expression levels in liver, whereas refeeding a high carbohydrate diet induces this gene's expression. A low-fat diet (1\% safflower oil to prevent essential fatty acid deficiency) induces G6PD expression, while a high-fat diet (6\% safflower oil) inhibits the expression level $(1,2)$. In parallel to the observation in intact animals, incubation of rat hepatocytes with insulin induces G6PD expression several fold, whereas, addition of polyunsaturated fatty acids like arachidonic acid reduces this expression by about $50 \%$ or more $(2,3)$. Regulation of G6PD expression both by high-fat diets in intact animals and by arachidonic acid in rat hepatocytes takes place at a posttranscriptional level $(1,2,4)$.

In our earlier work, we demonstrated that arachidonic acid-mediated inhibition of G6PD mRNA expression involves the activation of the p38 mitogen activated protein kinase (p38 MAP kinase) pathway (5). Activation of this pathway inhibits activation of PI3 kinase in rat hepatocytes, and thereby the insulin-mediated induction of G6PD mRNA $(5,6)$. The mechanism by which the p38 MAP kinase pathway is turned on by arachidonic acid is not known. AMP-activated protein kinase (AMPK), protein kinase $\mathrm{C}$ (PKC) or mammalian target of rapamycin (mTOR) pathways have been demonstrated to be activated by high-fat diet or free fatty acids, which in turn can interfere with the PI3 kinase pathway directly or via activation of MAP kinases. 
AMPK is activated by AMP in three different ways: by allosteric activation of AMPK complex formation, by promoting phosphorylation at Thr-172 residue of AMPK at the kinase domain, or by inhibiting dephosphorylation of Thr-172 via protein phosphatase 2C (PP2C) (7). AMPK is activated by dietary polyunsaturated fatty acids in intact animals (8). Activation of AMPK is necessary for the inhibition of lipogenic genes in primary rat hepatocytes $(9,10)$. Carbohydrate refeeding of starved animals decreases hepatic AMPK activity, which leads to an activation of lipogenic gene expression (11). Activation of AMPK can lead to the activation of p38 MAP kinase in ischemic heart (12), and a commercially available activator of AMPK, 5-aminoimidazole-4-carboxamide riboside (AICAR) is also capable of activating p38 MAP kinase in skeletal muscle and in jejunum $(13,14)$. As AMPK and G6PD are regulated by a similar dietary paradigm and activation of AMPK can lead to the activation of p38 MAP kinase, AMPK seems to be a strong candidate as a mediator for the arachidonic acid effect on G6PD.

Activation of PKC and/or mTOR pathways are the other potential mechanisms for G6PD inhibition by arachidonic acid. Free fatty acids can activate various isoforms of (PKC) and the activation of PKC can activate MAP kinases leading to insulin resistance (15-18). High-fat diets containing $40 \%$ or more fat content inhibit the PI3 kinase pathway by inducing Ser-307 phosphorylation of the insulin receptor substrate-1 (IRS-1). Activation of mTOR and subsequent activation of p70 S6 kinase-1 (S6K-1) by high-fat diets has been shown to be involved in this inhibitory mechanism (19-21). We investigated the possibility of involvement of all these pathways in arachidonic acidmediated inhibition of G6PD expression either directly or by activating the p38 MAP kinase pathway.

In this report we demonstrate that arachidonic acid activates AMPK in primary rat hepatocytes. Activators of AMPK inhibit the insulin-mediated induction of G6PD gene expression, thus mimicking the effect of arachidonic acid. AICAR inhibits the G6PD gene expression by activating the $\mathrm{p} 38$ MAP kinase pathway and at the same time, AICAR inhibits the PI3 kinase pathway, which is necessary for the insulin-mediated induction of G6PD. Neither the PKC nor mTOR pathways are activated to contribute to the inhibitory effect of arachidonic acid on G6PD gene expression. 


\section{Materials and Methods:}

Animal Care and Cell Culture- Male Sprague-Dawley rats (175-225 g) fed a standard chow diet (Harlan Teklad) were used for all experiments. After a 16h starvation, hepatocytes were isolated by collagen perfusion as previously described (2). Hepatocytes $\left(3.1 \times 10^{6}\right)$ were plated onto rat-tail collagen coated dishes $(60 \mathrm{~mm})$ in $\mathrm{Hi} / \mathrm{Wo} / \mathrm{Ba}$ medium (Waymouth's MB752/1 from Sigma, plus $20 \mathrm{mM}$ HEPES, pH 7.4, $0.5 \mathrm{mM}$ serine, $0.5 \mathrm{mM}$ alanine, $0.2 \%$ bovine serum albumin) plus $5 \%$ newborn calf serum at $37^{\circ} \mathrm{C}$ and with $5 \% \mathrm{CO}_{2}$ as growth conditions. Cell viability in all experiments was $90 \%$ or greater as estimated by trypan blue $(0.04 \%)$ exclusion. Three to four hours after plating, the medium was replaced with serum-free medium and a Matrigel overlay $(0.3 \mathrm{mg} / \mathrm{ml})$ was added 4-5 $\mathrm{h}$ later. Twenty-four hours after the original plating, the medium was replaced with one containing the treatments indicated in the figure legends. Subsequently, the medium was replaced every 12-24 $\mathrm{h}$ with one of the same composition. Arachidonic acid (Nu-Check Prep) was bound to bovine serum albumin (22) at the ratio of 4:1. The fatty acid stocks contained butylated hydroxytoluene $(0.01 \%)$, and the medium contained $\square$ tocopherol phosphate, disodium (10 $\mu \mathrm{g} /$ liter), to minimize oxidation of the fatty acids. The AMPK activator, AICAR was purchased from Toronto Research Chemicals Inc. and metformin was purchased from Sigma. The p38 MAP kinase inhibitor, SB203580 and the mTOR pathway inhibitor, rapamycin, were purchased from Calbiochem. The PKC inhibitor bisindolylmaleimide (GF-109203X) was purchased from Alexis Biochemicals, the PKC activator, 12-O-tetradecanoyl-phorbol-13-acetate (TPA), was purchased from Sigma.

Isolation of Total RNA and mRNA measurement- Total RNA from 2-3 plates per treatment was isolated by the method of Chomczynski and Sacchi (23). Determination of the expression of RNA was performed using RNase protection assay (Ambion, Inc.) or real-time reverse transcriptase polymerase chain reaction (RT-PCR). G6PD mRNA was measured using RNase protection assays with a rat exon 13 template (24). A template for rat $\square$-actin was purchased from Ambion, Inc. The templates were linearized before use in 
the in vitro transcription reaction. The probe and RNA were hybridized at $45^{\circ} \mathrm{C}$ overnight, and RNase digestion was done as previously described (4). Following separation of the RNase-protected products in a 5\% denaturing polyacrylamide gel, the images were visualized using storage phosphor technology and quantified using ImageQuant software by Amersham Biosciences.

Real-time RT-PCR assays using TaqMan probes were carried out in 96-well plates using the QuantiTect probe RT-PCR kit (Qiagen). The reaction mixture per well contained $10 \mu \mathrm{l}$ of 2X QuantiTect RT-PCR Master Mix, $0.2 \mu \mathrm{l}$ of QuantiTect probe RT mix, $1 \mu \mathrm{l}$ of $10 \square \mathrm{M}$ forward primer, $1 \mu \mathrm{l}$ of $10 \square \mathrm{M}$ reverse primer, $1 \mu 1$ of $10 \square \mathrm{M}$ fluorogenic dual- labeled G6PD or RPL32 probe (6-FAM), and $200 \mathrm{ng}$ of total RNA to a total volume of $20 \mu \mathrm{l}$. Thermo-cycling conditions were as follows: $45 \mathrm{~min}$ at $50{ }^{\circ} \mathrm{C}$ for reverse transcription; $15 \mathrm{~min}$ at $95^{\circ} \mathrm{C}$ to activate DNA polymerase and to deactivate reverse transcriptase; 35 cycles of $15 \mathrm{~s}$ at $94{ }^{\circ} \mathrm{C}$ to denature and $1 \mathrm{~min}$ at $56{ }^{\circ} \mathrm{C}$ to anneal and extend. Reverse transcription and PCR amplification were performed by using iCycler thermal cycler (Bio-Rad).

Preparation of Cell Extract and Western Blot Analysis-Hepatocytes were scraped using $350 \square 1$ of cell-harvesting buffer (10mM Tris, pH 7.4, 1\% SDS) and the cell lysate was sonicated and centrifuged at 14,000 rpm for $10 \mathrm{~min}$. An aliquot of the supernatant was used for protein quantification using the Bradford (Bio-Rad) assay. Following separation by size on a $7.5 \%$ polyacrylamide gel, the proteins $(20-40 \square \mathrm{g}$ in each lane) were transferred to Immun-BlotTM polyvinylidene difluoride membrane (Bio-Rad) at 100V for $1.5 \mathrm{~h}$ in transfer buffer (25 mM Tris, $200 \mathrm{mM}$ Glycine, 10\% methanol). The membranes were blocked with 5\% nonfat dry milk in $1 \mathrm{X}$ TBS/0.05\% Tween-20 buffer for $1 \mathrm{~h}$ and incubated with primary antibody diluted in $5 \%$ bovine serum albumin overnight at $4{ }^{\circ} \mathrm{C}$. The primary antibodies against phosphorylated Akt (Ser473), phosphorylated IRS-1 (Ser307), phosphorylated p38 MAPK (Thr180/Tyr182), phosphorylated AMPK (Thr172), phosphorylated acetyl-CoA-carboxylase (ACC, Ser79), phosphorylated PKC (pan, —II Ser660), phosphorylated S6K-1, (Thr389), phosphorylated MAP kinase kinase (MKK) 3/6 and total Akt, IRS-1, p38 MAPK, AMPK, ACC were obtained from Cell Signaling Technology. Anti-rabbit IgG conjugated with horseradish 
peroxidase (Cell Signaling Technology) was used as the secondary antibody, and the immunocomplexes were detected by enhanced chemiluminescence (Pierce). Images were visualized with film (Pierce) and quantified by densitometry using ImageQuant software (Amersham Biosciences).

\section{Results:}

Arachidonic acid activates AMPK: Previous work has demonstrated that the inhibition of lipogenic gene (for example acetyl-CoA- carboxylase, (ACC), fatty acid synthase (FAS), and spot 14 expression by polyunsaturated fatty acids involves the activation of hepatic AMPK in rat (8-10). These genes are regulated primarily by a change in the rate of transcription. We asked if regulation of G6PD expression, which is exclusively posttranscriptional, shared this signal transduction pathway. We first determined if arachidonic acid activates AMPK in our primary rat hepatocyte culture. Phosphorylation of AMPK, at Thr-172, gives a measure of the activated form of AMPK (25). Incubation of hepatocytes with arachidonic acid induced AMPK-phosphorylation at Thr-172 as compared to no treated or the insulin treatment alone, whereas total AMPK levels did not change (Fig. 1). This activation of AMPK was rapid and was detected as early as $10 \mathrm{~min}$ and retained through $60 \mathrm{~min}$ (data not shown). AMPK activation leads to Ser-79 phosphorylation of ACC protein (26). Phosphorylation of ACC at this site specifically takes place by activated AMPK $(26,27)$. We used phosphorylation of ACC as a control for functional AMPK activation. ACC-phosphorylation at Ser-79 was highly induced over no treatment or insulin treatment alone, indicating that arachidonic acid indeed activates AMPK in rat hepatocytes. A decrease in total ACC was consistently observed in cells incubated with fatty acids; the reason for this is not clear. Fatty acids are allosteric inhibitors of ACC activity and are associated with the structural transition of the protein from a polymeric to a protomeric form $(28,29)$. Either of these effects may result in a decrease in recognition of ACC by the antibody.

Previous data from our laboratory demonstrated that arachidonic acid activated p38 MAP kinase and the activation was involved in the inhibition of G6PD expression 
(5). Coincident with the activation of AMPK, p38 MAP kinase was activated as evidenced by the phosphorylation of p38 (Fig. 1). In addition, activation of p38 MAP kinase was also accompanied by activation of MKK 3/6 (Fig. 1), which is a MAP kinase kinase immediately upstream of p38 MAP kinase and is responsible for its phosphorylation and activation. The coincident activation of these signaling molecules and resultant inhibition of G6PD mRNA accumulation (data not shown) supports the hypothesis that these pathways may be interrelated.

Activators of AMPK inhibit insulin-mediated induction of G6PD $m R N A$ : We next wanted to test if the activation of AMPK causes an inhibition of G6PD mRNA induction. A known activator of AMPK, AICAR, was used to test if it can mimic the effect of arachidonic acid on G6PD mRNA expression. AICAR, a widely used activator of AMPK is a cell permeable adenosine analogue that can be phosphorylated to ZMP, an AMP analogue and a known activator of AMPK (30). Insulin induced G6PD mRNA five fold over no treatment; however, addition of AICAR in the medium inhibited this induction of G6PD mRNA by $50 \%$ (Fig. 2). This mimics the extent of inhibition of G6PD mRNA by arachidonic acid (5). We also used another known activator of AMPK, metformin (1 $\mathrm{mM}$ ) to test if it can also inhibit G6PD expression. Metformin is a well-known drug for type 2 diabetes and is an AMPK activator; however, the exact mechanism of activation of AMPK by metformin is not known (31). Like AICAR, metformin also inhibited the insulin-induction of G6PD mRNA by $50 \%$ or more (data not shown). From these data we conclude that activators of AMPK can mimic the effect of arachidonic acid on the expression of G6PD mRNA.

AICAR mediated inhibition of G6PD mRNA induction involves p38 MAP kinase pathway: From the data obtained thus far, we hypothesized that activation of AMPK by arachidonic acid causes the inhibition of G6PD mRNA expression by activating p38 MAP kinase. To test our hypothesis, we first determined if activation of AMPK could induce p38 MAP kinase phosphorylation in our system. As shown in figure 3, AICAR 
activates AMPK by phosphorylating it at Thr-172 and at the same time AICAR increases p38 MAP kinase phosphorylation over insulin treatment alone. If this activation of p38 MAP kinase is involved in the inhibition of G6PD expression, then inhibition of p38 MAP kinase should block the effect of AICAR. This was indeed observed. Insulin induced G6PD mRNA expression more than 3.2 fold in the presence of the p38 MAP kinase inhibitor SB203580; however, the AICAR-mediated inhibition of the G6PD mRNA expression was completely abolished (Fig. 4). Expression of RPL32 mRNA, a control for specificity of the treatments did not change (data not shown). Thus, the AICAR-mediated inhibition of G6PD mRNA expression involves the p38 MAP kinase pathway.

AICAR induces Ser-307 phosphorylation of IRS-1 and abolishes Akt-phosphorylation upon pre-incubation: In our previous studies we have established that arachidonic acid activates the p38 MAP kinase pathway, which in turn induces Ser-307 phosphorylation of IRS-1, that thereby down regulates insulin signal transduction (5). Since the data thus far indicated that AICAR, like arachidonic acid, induced p38 MAP kinase phosphorylation and p38 MAP kinase was involved in the inhibition of G6PD mRNA accumulation, we wanted to test if AICAR, like arachidonic acid, could also inhibit the PI3 kinase pathway. As shown in figure 5, pre-incubation with AICAR induced Ser-307 phosphorylation of IRS-1. In addition, the insulin-mediated induction of Akt-phosphorylation was completely abolished in the presence of AICAR. Total IRS-1 and Akt expression were not changed by AICAR. These results suggest that like arachidonic acid, AICAR interferes with the PI3 kinase pathway resulting in a decrease in the expression of G6PD mRNA expression.

Arachidonic acid does not mediate its inhibitory effect on G6PD mRNA expression via activation of $P K C$ : Free fatty acids can activate $\mathrm{PKC}$ in skeletal muscle, which in turn activates MAP kinases and is associated with insulin resistance (16). To test if activation of PKC is involved in the inhibition of G6PD mRNA expression, we measured PKC 
phosphorylation using western blot analysis. Cells treated with arachidonic acid did not increase the phosphorylation of PKC, over insulin treatment alone (Fig. 6A). The phorbol ester, TPA, a known activator of PKC, enhanced phosphorylation of PKC indicating that PKC can be activated in rat hepatocytes (Fig. 6A). We also tested if the activaton of PKC can mimic the effect of arachidonic acid on G6PD mRNA. TPA, instead of inhibiting G6PD mRNA expression, actually enhanced the expression of G6PD mRNA compared to insulin treatment alone (Fig. 6B). Various isoforms of PKC are known to activate the PI3 kinase pathway (32,33). Activation of PI3 kinase by TPA and insulin may be responsible for the enhanced G6PD expression.

To further confirm that PKC was not mediating the effect of arachidonic acid, we tested if a specific inhibitor of PKC, bisindolylmaleimide I, (GF-109203X) can reverse the effect of arachidonic acid on G6PD gene expression (Fig. 6C). The PKC inhibitor could not reverse the effect of arachidonic acid on G6PD mRNA expression. Thus, in primary rat hepatocytes, $\mathrm{PKC}$ is not an intermediate in arachidonic acid inhibition of G6PD expression.

Arachidonic acid-mediated inhibitory effect on G6PD mRNA does not involve the activation of mTOR pathway: mTOR is a downstream effector protein of the PI3 kinase pathway, activation of which leads to protein translation and cellular growth (34). Insulin-mediated induction of Akt stimulates activation of this protein (35). Rapamycin abolishes the activity mTOR by a mechanism yet to be discovered (34). Others (6) and we (Fig. 7A) found that insulin-mediated induction of G6PD mRNA expression is completely abolished when cells are treated with rapamycin. This suggests that activation of mTOR by insulin is required for the insulin-mediated induction of G6PD mRNA expression.

Prolonged and sustained activation of mTOR by feeding intact animals a very high-fat diet inhibits insulin signal transduction and promotes insulin resistance (21). Incubation of rat hepatocytes with low concentrations of arachidonic acid is not the same as long term feeding a high-fat diet. None-the-less, we asked if mTOR was over activated by arachidonic acid and if this activation was involved in inhibition of G6PD mRNA 
expression. Western blot analysis was performed against the phosphorylated/activated form of a downstream effector protein of mTOR, p70 S6K-1. Insulin induces the activation of p70 S6K-1 over no treatment (Fig 7C). Pre-incubation of hepatocytes with arachidonic acid did not increase the phosphorylation of p70 S6K-1 over insulin treatment alone instead, at 5 and 10 min, the phosphorylated form of p70 S6K-1 was inhibited in the presence of arachidonic acid (Fig 7C). Activation of AMPK abolishes the mTOR activity (36). We found the same when we treated cells with the AMPK activator AICAR (Fig. 7B). We already have established that arachidonic acid activates AMPK in primary rat hepatocytes. This data adds another indirect evidence to that observation.

From these experiments it was concluded that activation of mTOR by insulin is required for the insulin-mediated induction of G6PD expression. Inhibition of that by arachidonic acid, most likely via activation of AMPK, results in a decrease in mTOR/p70 S6K-1 activation. This is a probable cause of attenuation of insulin induction on G6PD mRNA expression. From these results it was confirmed however, that neither PKC, nor mTOR pathways are activated by arachidonic acid in our experimental condition, which can attenuate insulin signal transduction and thus can inhibit insulin-induction on G6PD mRNA expression. 


\section{Discussion :}

In our previous study, we have shown that arachidonic acid-mediated inhibition of insulin-induced G6PD mRNA expression involves the activation of p38 MAP kinase pathway, which in turn interferes with the PI3 kinase pathway by phosphorylating IRS-1 at Ser-307, thus inhibiting the insulin-mediated induction of G6PD (5). In this report we have demonstrated that incubation with arachidonic acid results in activation of AMPK (Fig. 1). We present the following lines of evidence that AMPK is a mediator in the arachidonic acid inhibition of G6PD expression. First, activation of AMPK by other agents, such as AICAR, concomitantly activates p38 MAP kinase and Ser-307 phosphorylation of IRS-1, inhibits AKT phosphorylation (Figs. 3 and 5 respectively) and inhibits insulin-induced G6PD mRNA. Second, inhibition of p38 MAP kinase also blocks the effect of AICAR on G6PD mRNA accumulation (Fig. 4). Third, these changes in the activity of signaling pathways and G6PD expression occur within the same time frame as arachidonic acid activation of AMPK and arachidonic acid inhibition of G6PD expression. Our data do not support the notion of the activation of PKC or mTOR pathways by arachidonic acid in our experimental condition and their involvement is unlikely in the inhibition of insulin-induction on G6PD expression (Fig. 6 and 7). Thus, our data are consistent with the hypothesis that activation of AMPK by arachidonic acid enhances p38 MAP kinase activity resulting in the inhibition of insulin signal transduction and thereby G6PD expression.

The activities of the lipogenic enzymes, including G6PD, are coordinately regulated. In this regard, feeding a high-carbohydrate diet increases their activity and starvation or feeding polyunsaturated fatty acids decreases their activity. Activation of AMPK, which mediates the regulation of many of these lipogenic genes, is inversely regulated under the same dietary paradigm (8-11). The details by which these lipogenic genes are regulated have substantial differences. Those genes regulated by transcriptional mechanisms use a different combination of the transcriptional factors (37) and G6PD differs in that the regulation occurs by changes in the rate of mRNA splicing $(1,4,24,38)$. Yet it appears that the signaling pathways affecting these changes may have more in common and AMPK may act as a common upstream signaling molecule that accounts for the coordinate regulation of the lipogenic genes. 
High concentrations of dietary fat cause pathological conditions such as insulin resistance, which leads to type 2 diabetes and obesity in intact animals. We, however, are looking at the normal dietary regulation of a lipogenic gene involving low amounts of dietary polyunsaturated fat ( $6 \%$ by weight). Dietary intake of high-fat ( $40 \%$ or more) leads to the prolonged activation of mTOR pathway causing insulin resistance. In our system, however, arachidonic acid fails to increase phosphorylation of S6K-1, and on the contrary, it decreases phosphorylation of S6K-1 at earlier time points (Fig. 7C).

Activation of AMPK leads to down regulation of mTOR/S6K-1 pathway $(7,34,39)$. A decrease in S6K-1 phosphorylation upon arachidonic acid treatment thus, indirectly provides another line of evidence of activation of AMPK by arachidonic acid in our system. Rapamycin, the inhibitor of mTOR abolishes the insulin-mediated induction of G6PD mRNA (Fig. 7A), (6), which suggests that basal level activation of mTOR by insulin, a downstream effector protein of PI3 kinase, is required to mediate the insulin induction on G6PD mRNA. Activation of AMPK by arachidonic acid is the most logical reason for the decrease in the mTOR/S6K-1 pathway. This suggests that arachidonic acid not only attenuates the activation PI3 kinase but also decreases the insulin-mediated basal level activation of mTOR by activating AMPK to prevent the insulin-mediated induction of G6PD mRNA expression.

G6PD is regulated at the level of splicing by polyunsaturated fatty acids. Unpublished data from our laboratory indicates the involvement of various splicing coactivators/repressors in this mechanism. Nuclear localization as well as the posttranslational modifications such as phosphorylation/dephosphorylation status of these splicing factors is important for their activity (40-44). Various reports have demonstrated the involvement of the PI3 kinase as well as various MAP kinase pathways in this regard (45-49). How the activation of AMPK/p38 MAP kinase pathway by arachidonic acid ultimately transduces the signal at the level of splicing of G6PD mRNA in the nucleus is currently under investigation. 


\section{Figure Legends:}

Figure 1. Arachidonic acid induces activation of AMPK. Rat hepatocytes were plated onto collagen coated plates in $\mathrm{Hi} / \mathrm{Wo} / \mathrm{Ba}$ medium plus $5 \%$ newborn calf serum. After 3 to 4h, the medium was changed to serum free medium and after $10 \mathrm{~h}$, matrigel ${ }^{\circledR}$ was added. Twenty-four hours post-isolation, the cells ( 2 plates per treatment) were treated with insulin (0.04 $\square \mathrm{M})$ alone or insulin in the presence of arachidonic acid (175 $\square \mathrm{M})$ or left untreated. Total cell lysates were isolated $10 \mathrm{~min}$ after the treatments. Western blot analysis was performed against phosphorylated AMPK at Thr-172 and total AMPK, phosphorylated ACC at Ser-79, and total ACC, phosphorylated MKK 3/6, and phosphorylated (Thr 180/Tyr 182) and total p38 MAP kinase. A representative blot is shown. Repetition was as follows: $n=3$ experiments for phosphorylated and total AMPK and ACC, $\mathrm{n}=2$ for P-MKK 3/6, $\mathrm{n}=7$ for phosphorylated and total p38 MAP kinase. $P$ $A M P K$, phosphorylated AMPK, $P$-ACC, phosphorylated ACC, $P-M K K 3 / 6$, phosphorylated MKK 3/6, $P$-p38, phosphorylated p38 MAP kinase, $F A$, arachidonic acid.

\section{Figure 2. Activators of AMPK inhibit insulin-mediated induction of G6PD mRNA.} Rat hepatocytes were treated with insulin $(0.04 \square \mathrm{M})$ alone or insulin in the presence of AICAR $(0.5 \mathrm{mM})$. The medium was changed every $12 \mathrm{~h}$ of incubation with one of the same composition and treatments. After $24 \mathrm{~h}$, total RNA was isolated. Real time RT-PCR using a Taqman probe was used to measure the expression of G6PD mRNA. Quantitative analysis of G6PD mRNA expression is shown for $n=4$ experiments. Each bar represents the mean $\pm \mathrm{SE}$ and the values are expressed relative to the absence of the treatment. $N A$, no addition, $I$, insulin.

Figure 3. AICAR increases phosphorylation of p38 MAP kinase. Rat hepatocytes were treated with insulin $(0.04 \square \mathrm{M})$ alone or insulin in the presence of AICAR $(0.5 \mathrm{mM})$ for 10 minutes. Total cell lysates were isolated and western blot analysis was performed against phosphorylated AMPK at Thr-172, and phosphorylated and total p38 MAP 
kinase. A representative blot is shown in the left panel. Quantitative analysis of the amount of phosphorylated $\mathrm{p} 38$ is shown in the right panel for $n=4$ experiments. Each bar represents the mean $\pm \mathrm{SE}$ and the values are expressed relative to the absence of the treatment. $N A$, no addition, $I$, insulin.

\section{Figure 4. AICAR mediated inhibition of G6PD mRNA induction involves the p38} MAP kinase pathway. Rat hepatocytes were incubated with $10 \square \mathrm{M}$ of the p38 MAP kinase inhibitor SB203580 for 1h. The cells were then incubated with AICAR or left untreated for an additional $2 \mathrm{~h}$. After pre-incubation with SB203580 and AICAR the cells were treated with or without insulin $(0.04 \square \mathrm{M})$. Medium was changed every $12 \mathrm{~h}$ to one of the same composition of the inhibitor, AICAR and insulin. Total RNA was isolated 24h after the addition of the insulin. Real time RT-PCR was performed to measure the expression of G6PD mRNA. Quantitative analysis of G6PD mRNA expression is shown for $n=3$ experiments. Each bar represents the mean $\pm S E$ and the values are expressed relative to the presence of the inhibitor but absence of the treatments. $S B, \mathrm{SB} 203580, N A$, no addition, $I$, insulin.

\section{Figure 5. AICAR induces Ser-307 phosphorylation of IRS-1 and abolishes Akt-} phosphorylation. Hepatocytes were treated with or without AICAR $(0.5 \mathrm{mM}) 24 \mathrm{~h}$ prior to the addition of insulin $(0.04 \square \mathrm{M})$. Total cell lysates were prepared $10 \mathrm{~min}$ after the addition of insulin. Western blot analysis was performed against total and phosphorylated IRS-1 and Akt. The antibodies specifically detected IRS-1 phosphorylated at Ser-307, and Akt phosphorylated at Ser 473. A representative blot of $\mathrm{n}=4$ experiments is shown. $N A$, no addition, $I$, insulin, $P$-IRS- 1 , phosphorylated IRS-1, $P$-Akt, phosphorylated Akt.

\section{Figure 6. Arachidonic acid does not mediate its inhibitory effect on G6PD mRNA} via activation of PKC. (A) Rat hepatocytes were treated with insulin $(0.04 \square \mathrm{M})$ in the presence or absence of arachidonic acid (175 $\square \mathrm{M})$ or an activator of PKC, TPA $(50 \mathrm{ng} / \mathrm{ml})$, or left untreated. Total cell lysates were isolated after 10 or $30 \mathrm{~min}$ of incubation. Western blot analysis was performed against phosphorylated PKC. A 
representative blot of $n=2$ experiments is shown. (B) Rat hepatocytes were treated with or without insulin $(0.04 \square \mathrm{M})$ in the absence or presence of TPA. Medium was changed after $12 \mathrm{~h}$, and after $24 \mathrm{~h}$, total RNA was isolated. The amount of G6PD mRNA expression was measured by real time RT-PCR. Quantitative analysis of two experiments is shown. Values are expressed relative to the absence of the treatments. (C) Hepatocytes were treated with or without 1 or $5 \square \mathrm{M}$ of the PKC inhibitor, GF-109203X, 1h prior to the addition of arachidonic acid $(175 \square \mathrm{M})$. Insulin $(0,04 \square \mathrm{M})$ was added $4 \mathrm{~h}$ after the addition of arachidonic acid. After 12h, the medium was changed with one of the same composition of the inhibitor and the treatments. Total RNA was isolated after $24 \mathrm{~h}$. The isolated RNA was analyzed by RNase protection assay and quantified using phosphorimaging and ImageQuant software. The values are the amount of G6PD mRNA normalized to the amount of $\square$-actin mRNA and are plotted relative to the amount of RNA in the absence of treatments or inhibitor. Each bar represents the mean \pm SE of $n=3$ experiments for no addition and GF-109203X at $1 \square \mathrm{M}$ concentration, for GF-109203X at $5 \square \mathrm{M}$ concentration, average of $\mathrm{n}=2$ experiments are shown. $P-P K C$, phosphorylated PKC, $N A$, no addition, $I$, insulin, $F A$, arachidonic acid, $G F 1$, GF-109203X at $1 \square \mathrm{M}, G F$ 5, GF-109203X at $5 \square \mathrm{M}$.

\section{Figure 7. Arachidonic acid-mediated inhibition of G6PD mRNA does not involve} the activation of mTOR pathway. (A) Hepatocytes were treated with or without 100 $\mathrm{nM}$ of rapamycin, $4 \mathrm{~h}$ prior to the addition of arachidonic acid (175 $\square \mathrm{M})$. Insulin (0.04 $\square \mathrm{M}$ ) was added $2 \mathrm{~h}$ after the addition of arachidonic acid. After $12 \mathrm{~h}$, the medium was changed with one of the same composition of the inhibitor and the treatments. Total RNA was isolated after $24 \mathrm{~h}$. The isolated RNA was analyzed by RNase protection assay and quantified using phosphorimaging and ImageQuant software. The values are the amount of G6PD mRNA normalized to the amount of $\square$-actin mRNA and are plotted relative to the amount of RNA in the absence of treatments or inhibitor. Each bar represents the mean $\pm \mathrm{SE}$ of $\mathrm{n}=3$ experiments. $N A$, no addition, $I$, insulin, $F A$, arachidonic acid. (B) Hepatocytes were treated with or without AICAR $(0.5 \mathrm{mM})$ either $24 \mathrm{~h}$ prior to the addition of insulin (0.04 $\square \mathrm{M})$ (lanes 1-3), or with insulin (lanes 4-6). Total cell lysates 
were prepared 20 min after the addition of insulin (for lanes 1-3) or the treatments (lanes 4-6). Western blot analysis was performed against phosphorylated-S6K-1. (C) Hepatocytes were treated with or without $175 \square \mathrm{M}$ arachidonic acid $24 \mathrm{~h}$ prior to the addition of $0.04 \square \mathrm{M}$ insulin. Total cell lysates were isolated 5 or $10 \mathrm{~min}$ after the addition of the insulin. Western blot analysis was performed against phosphorylated-S6K-1. P$S 6 K-1$, phosphorylated S6K-1, I, insulin, $F A$, arachidonic acid. 


\section{Bibliography:}

1. Stabile, L. P., Hodge, D. L., Klautky, S. A., and Salati, L. M. (1996) Arch Biochem Biophys 332, 269-279

2. $\quad$ Stabile, L. P., Klautky, S. A., Minor, S. M., and Salati, L. M. (1998) J Lipid Res 39, 1951-1963

3. Salati, L. M., Adkins-Finke, B., and Clarke, S. D. (1988) Lipids 23, 36-41

4. Hodge, D. L., and Salati, L. M. (1997) Arch Biochem Biophys 348, 303-312

5. Talukdar, I., Szeszel-Fedorowicz, W., and Salati, L. M. (2005) J Biol Chem 280, 40660-40667

6. Wagle, A., Jivraj, S., Garlock, G. L., and Stapleton, S. R. (1998) J Biol Chem 273, 14968-14974

7. Kahn, B. B., Alquier, T., Carling, D., and Hardie, D. G. (2005) Cell Metab 1, 1525

8. Suchankova, G., Tekle, M., Saha, A. K., Ruderman, N. B., Clarke, S. D., and Gettys, T. W. (2005) Biochem Biophys Res Commun 326, 851-858

9. Carling, D., Zammit, V. A., and Hardie, D. G. (1987) FEBS Lett 223, 217-222

10. Foretz, M., Carling, D., Guichard, C., Ferre, P., and Foufelle, F. (1998) J Biol Chem 273, 14767-14771

11. Assifi, M. M., Suchankova, G., Constant, S., Prentki, M., Saha, A. K., and Ruderman, N. B. (2005) Am J Physiol Endocrinol Metab 289, E794-800

12. Li, J., Miller, E. J., Ninomiya-Tsuji, J., Russell, R. R., 3rd, and Young, L. H. (2005) Circ Res 97, 872-879

13. Walker, J., Jijon, H. B., Diaz, H., Salehi, P., Churchill, T., and Madsen, K. L. (2005) Biochem J 385, 485-491

14. Lemieux, K., Konrad, D., Klip, A., and Marette, A. (2003) Faseb J 17, 1658-1665

15. Adachi, T., Nakashima, S., Saji, S., Nakamura, T., and Nozawa, Y. (1996) Hepatology 23, 1244-1253

16. Yu, C., Chen, Y., Cline, G. W., Zhang, D., Zong, H., Wang, Y., Bergeron, R., Kim, J. K., Cushman, S. W., Cooney, G. J., Atcheson, B., White, M. F., Kraegen, E. W., and Shulman, G. I. (2002) J Biol Chem 277, 50230-50236

17. Greene, M. W., Morrice, N., Garofalo, R. S., and Roth, R. A. (2004) Biochem J 378, 105-116

18. Lam, T. K., Yoshii, H., Haber, C. A., Bogdanovic, E., Lam, L., Fantus, I. G., and Giacca, A. (2002) Am J Physiol Endocrinol Metab 283, E682-691

19. Harrington, L. S., Findlay, G. M., Gray, A., Tolkacheva, T., Wigfield, S., Rebholz, H., Barnett, J., Leslie, N. R., Cheng, S., Shepherd, P. R., Gout, I., Downes, C. P., and Lamb, R. F. (2004) J Cell Biol 166, 213-223

20. Manning, B. D., and Cantley, L. C. (2003) Trends Biochem Sci 28, 573-576

21. Um, S. H., Frigerio, F., Watanabe, M., Picard, F., Joaquin, M., Sticker, M., Fumagalli, S., Allegrini, P. R., Kozma, S. C., Auwerx, J., and Thomas, G. (2004) Nature 431, 200-205

22. Mooney, R. A., and Lane, M. D. (1981) J Biol Chem 256, 11724-11733

23. Chomczynski, P., and Sacchi, N. (1987) Anal Biochem 162, 156-159 
24. Tao, H., Szeszel-Fedorowicz, W., Amir-Ahmady, B., Gibson, M. A., Stabile, L. P., and Salati, L. M. (2002) J Biol Chem 277, 31270-31278

25. Hawley, S. A., Davison, M., Woods, A., Davies, S. P., Beri, R. K., Carling, D., and Hardie, D. G. (1996) J Biol Chem 271, 27879-27887

26. Munday, M. R., Campbell, D. G., Carling, D., and Hardie, D. G. (1988) Eur J Biochem 175, 331-338

27. Davies, S. P., Sim, A. T., and Hardie, D. G. (1990) Eur J Biochem 187, 183-190

28. Ashcraft, B. A., Fillers, W. S., Augustine, S. L., and Clarke, S. D. (1980) J Biol Chem 255, 10033-10035

29. Clarke, S. D., and Salati, L. M. (1985) Fed Proc 44, 2458-2462

30. Corton, J. M., Gillespie, J. G., Hawley, S. A., and Hardie, D. G. (1995) Eur J Biochem 229, 558-565

31. Zhou, G., Myers, R., Li, Y., Chen, Y., Shen, X., Fenyk-Melody, J., Wu, M., Ventre, J., Doebber, T., Fujii, N., Musi, N., Hirshman, M. F., Goodyear, L. J., and Moller, D. E. (2001) J Clin Invest 108, 1167-1174

32. Formisano, P., and Beguinot, F. (2001) J Endocrinol Invest 24, 460-467

33. Etgen, G. J., Valasek, K. M., Broderick, C. L., and Miller, A. R. (1999) J Biol Chem 274, 22139-22142

34. Wullschleger, S., Loewith, R., and Hall, M. N. (2006) Cell 124, 471-484

35. Manning, B. D. (2004) J Cell Biol 167, 399-403

36. Inoki, K., Zhu, T., and Guan, K. L. (2003) Cell 115, 577-590

37. Jump, D. B. (2002) Curr Opin Lipidol 13, 155-164

38. Amir-Ahmady, B., and Salati, L. M. (2001) J Biol Chem 276, 10514-10523

39. Kimura, N., Tokunaga, C., Dalal, S., Richardson, C., Yoshino, K., Hara, K., Kemp, B. E., Witters, L. A., Mimura, O., and Yonezawa, K. (2003) Genes Cells 8, 65-79

40. Ge, H., and Manley, J. L. (1990) Cell 62, 25-34.

41. Krainer, A. R., Conway, G. C., and Kozak, D. (1990) Genes Dev 4, 1158-1171.

42. Xiao, S. H., and Manley, J. L. (1997) Genes Dev 11, 334-344.

43. Zahler, A. M., Lane, W. S., Stolk, J. A., and Roth, M. B. (1992) Genes Dev 6, 837-847.

44. Yeakley, J. M., Tronchere, H., Olesen, J., Dyck, J. A., Wang, H. Y., and Fu, X. D. (1999) J Cell Biol 145, 447-455.

45. Blaustein, M., Pelisch, F., Coso, O. A., Bissell, M. J., Kornblihtt, A. R., and Srebrow, A. (2004) J Biol Chem 279, 21029-21037

46. Patel, N. A., Chalfant, C. E., Watson, J. E., Wyatt, J. R., Dean, N. M., Eichler, D. C., and Cooper, D. R. (2001) J Biol Chem 276, 22648-22654

47. Patel, N. A., Kaneko, S., Apostolatos, H. S., Bae, S. S., Watson, J. E., Davidowitz, K., Chappell, D. S., Birnbaum, M. J., Cheng, J. Q., and Cooper, D. R. (2005) J Biol Chem 280, 14302-14309

48. van der Houven van Oordt, W., Diaz-Meco, M. T., Lozano, J., Krainer, A. R., Moscat, J., and Caceres, J. F. (2000) J Cell Biol 149, 307-316

49. Weg-Remers, S., Ponta, H., Herrlich, P., and Konig, H. (2001) Embo J 20, 41944203 
Figure 1

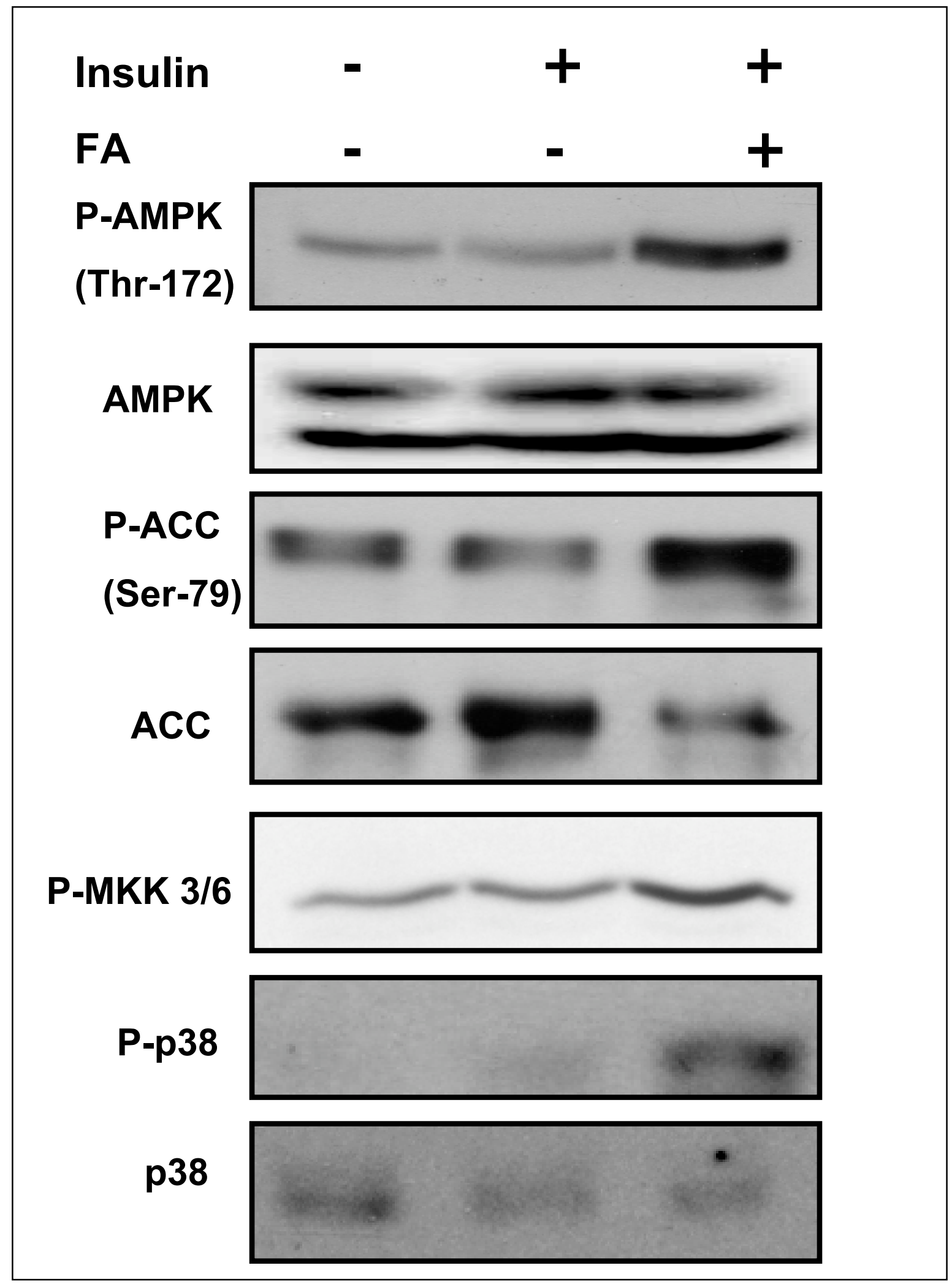


Figure 2

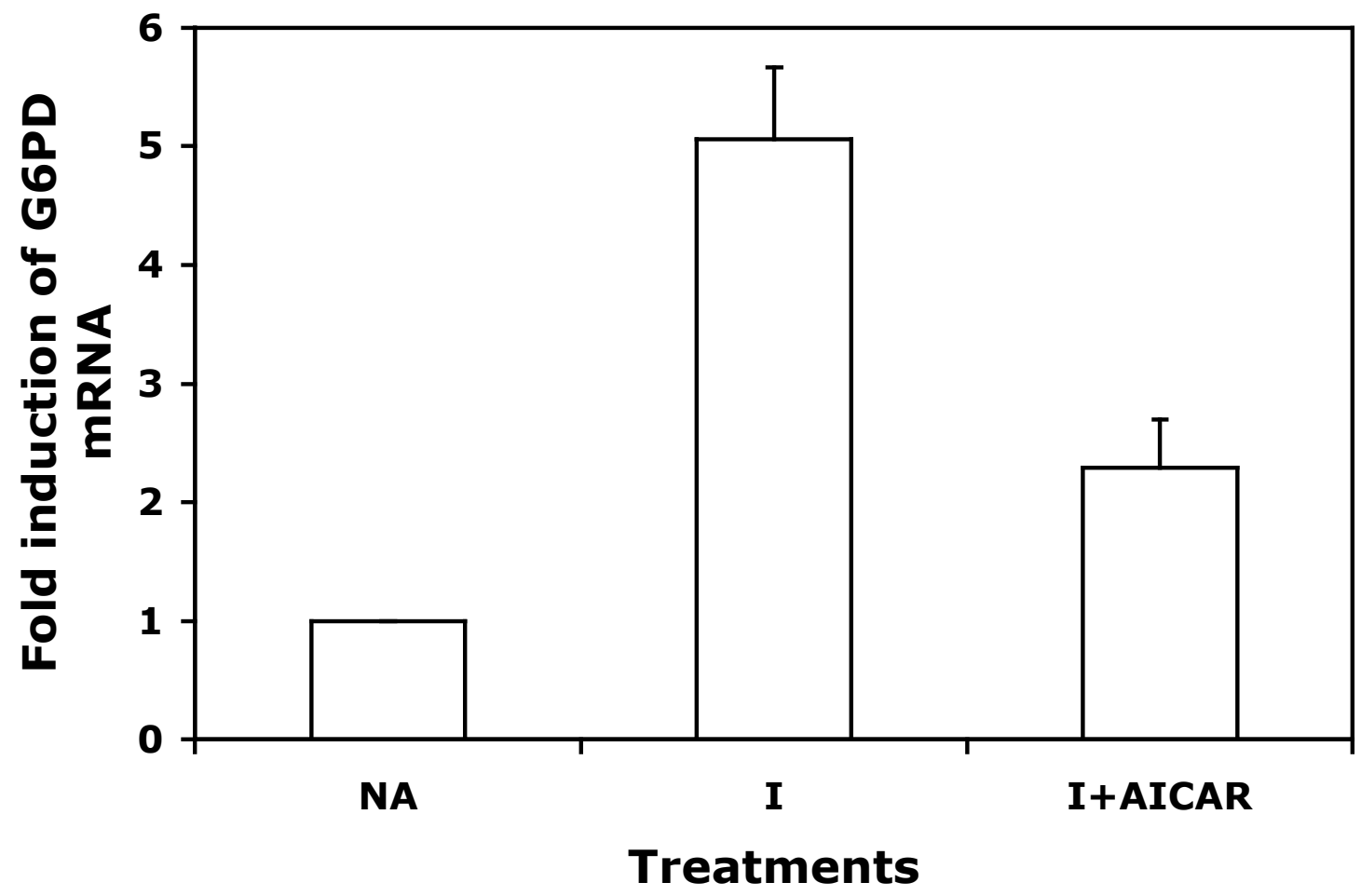


Figure 3

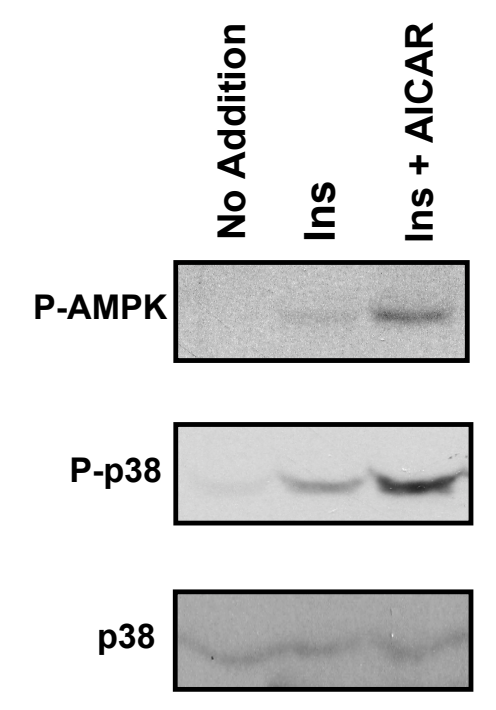

Fold induction of P-p38

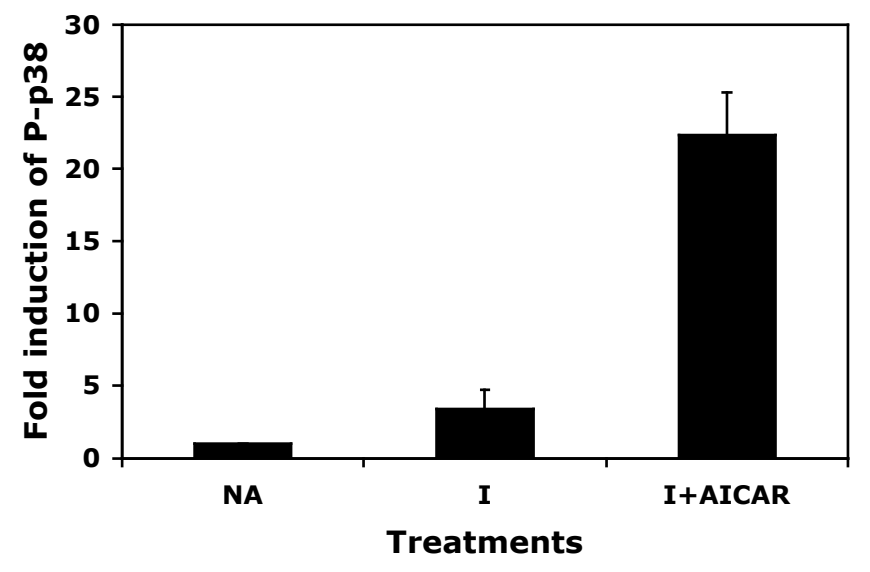


Figure 4

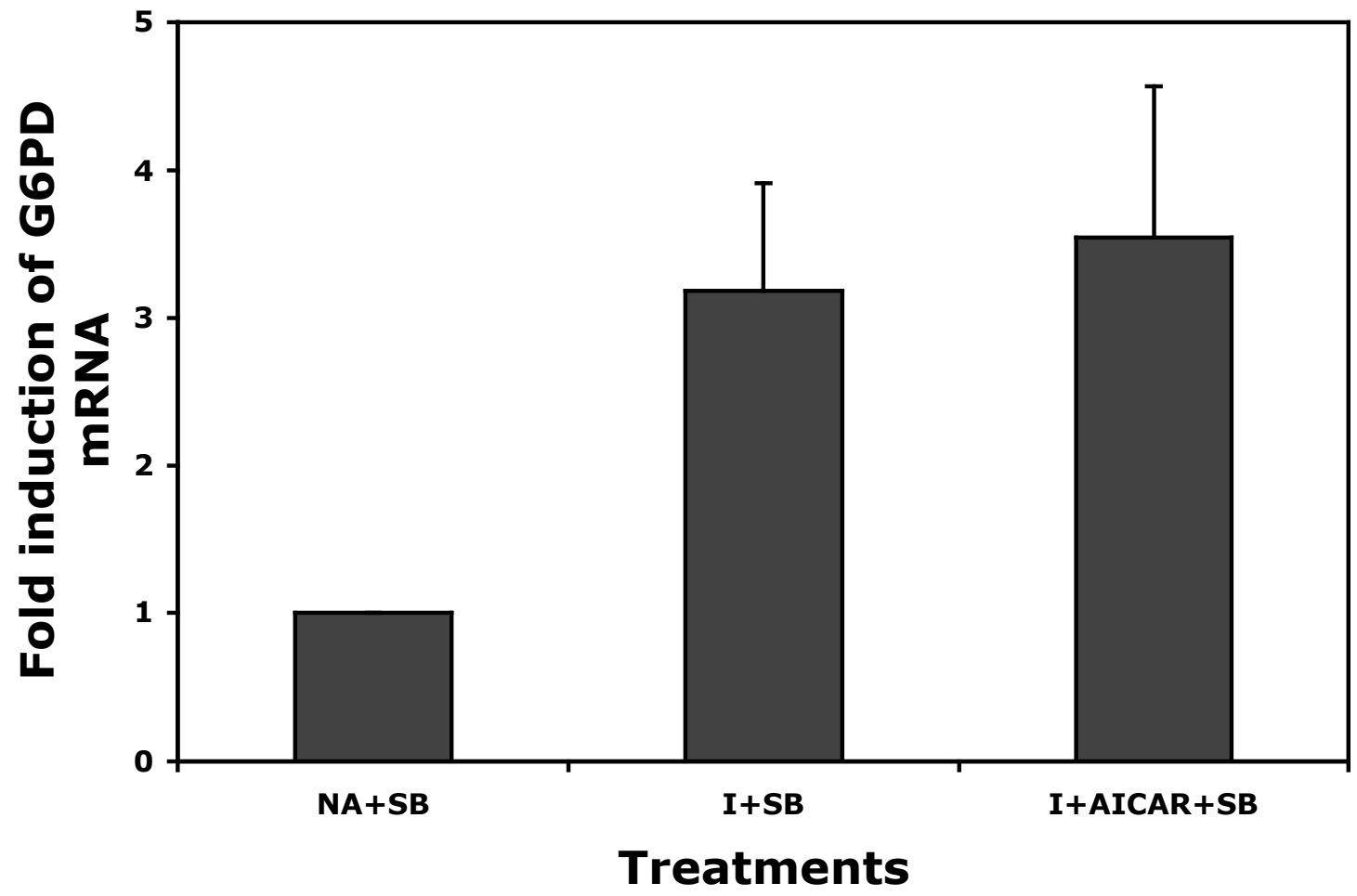


Figure 5

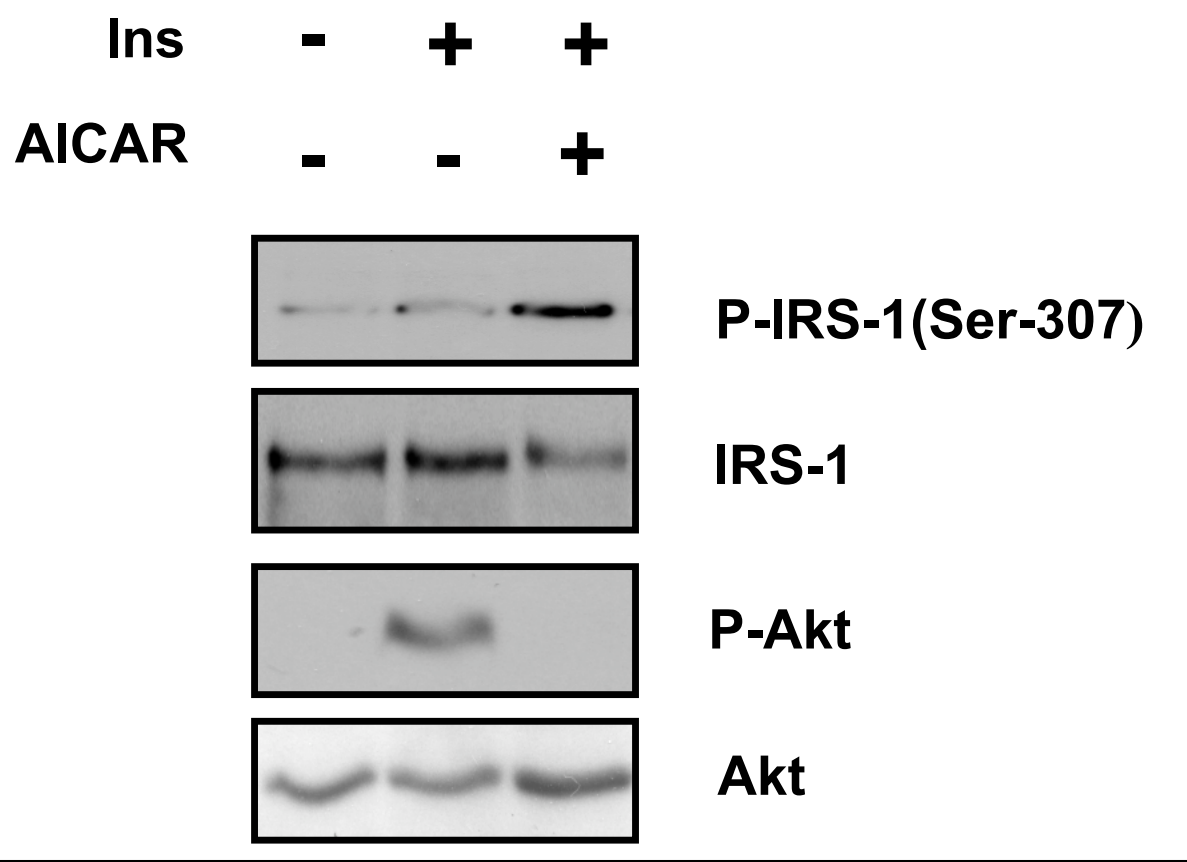




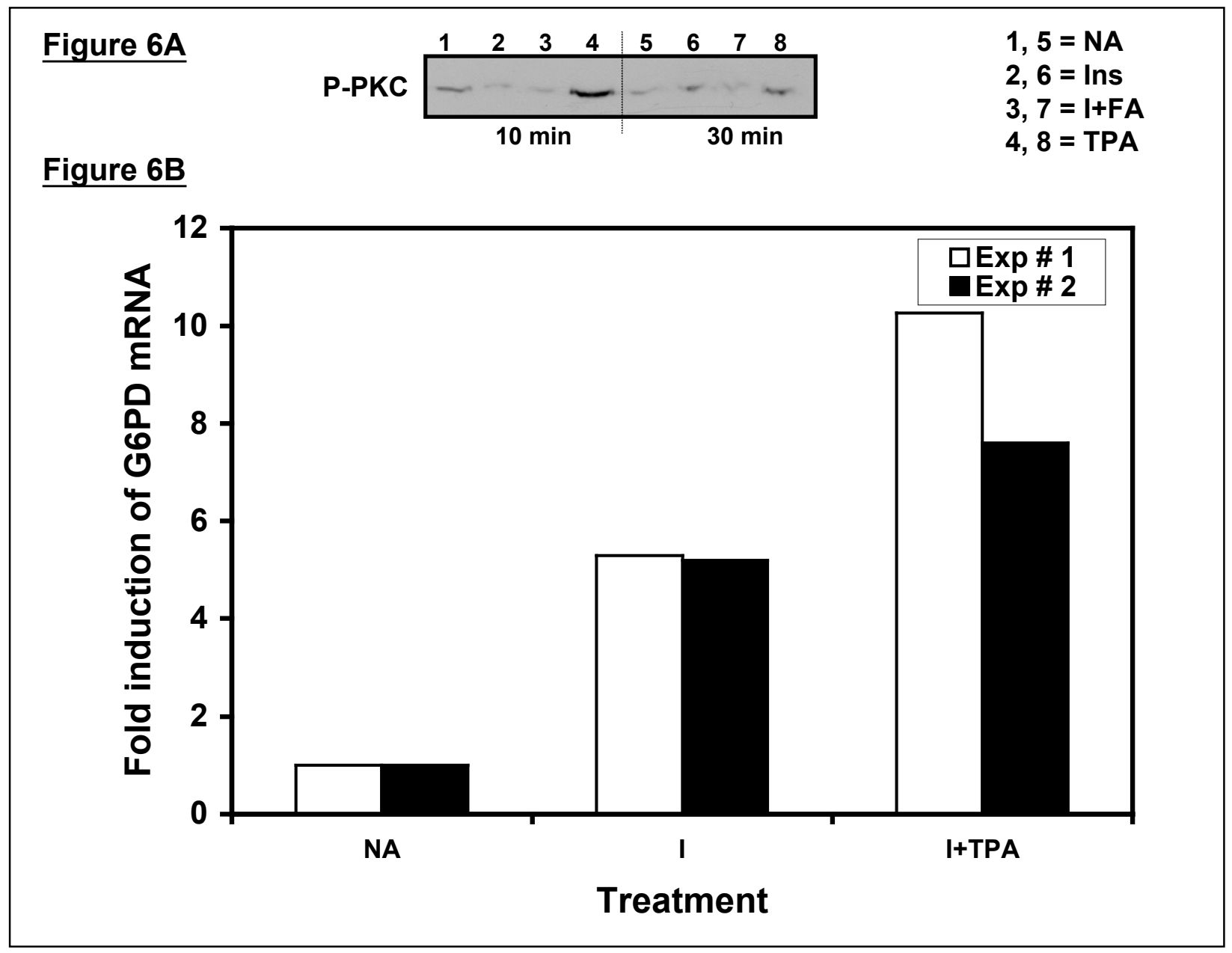


Figure 6C

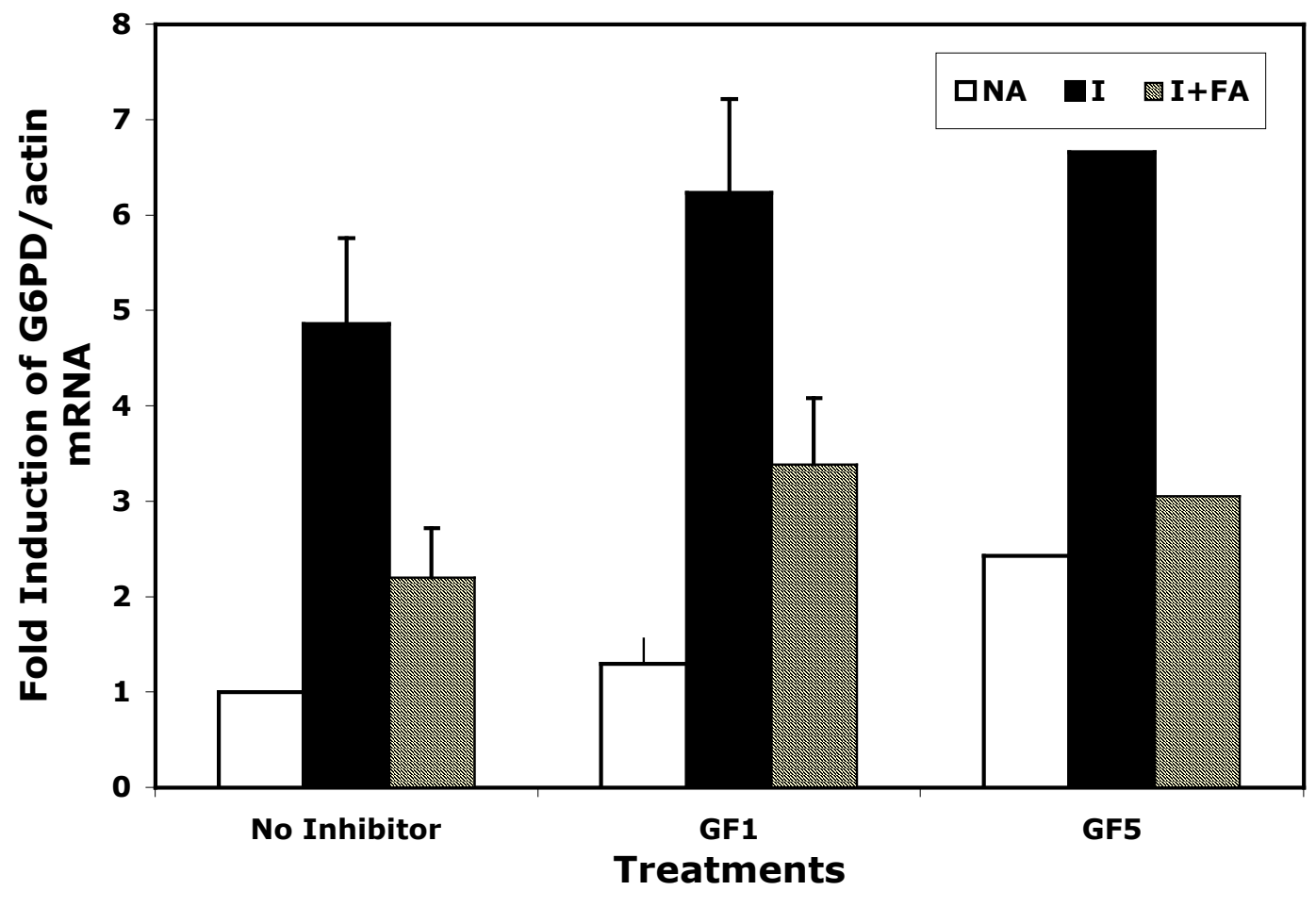


Figure 7A

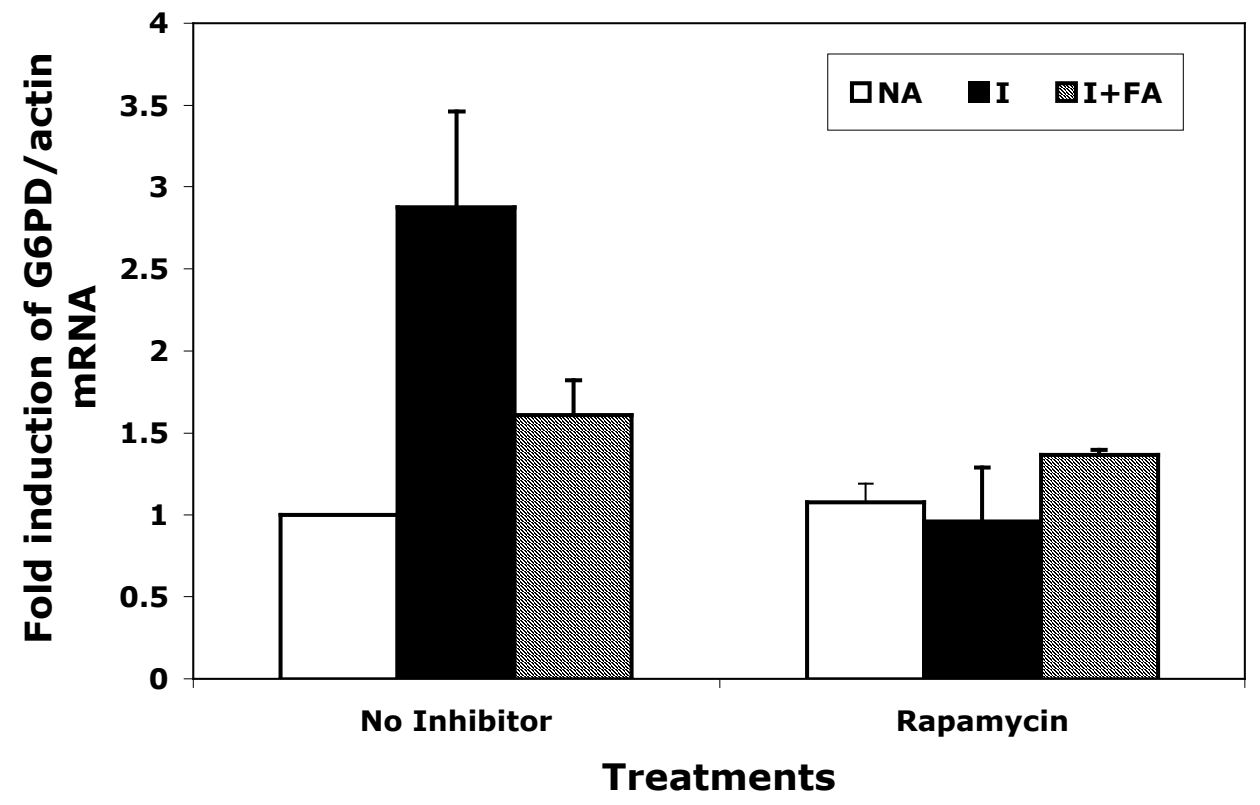




\section{Figure 7B}

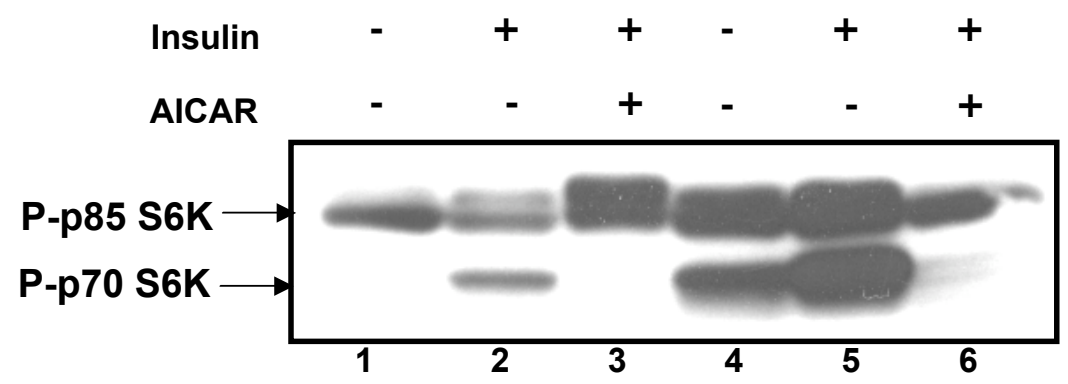

Figure 7C

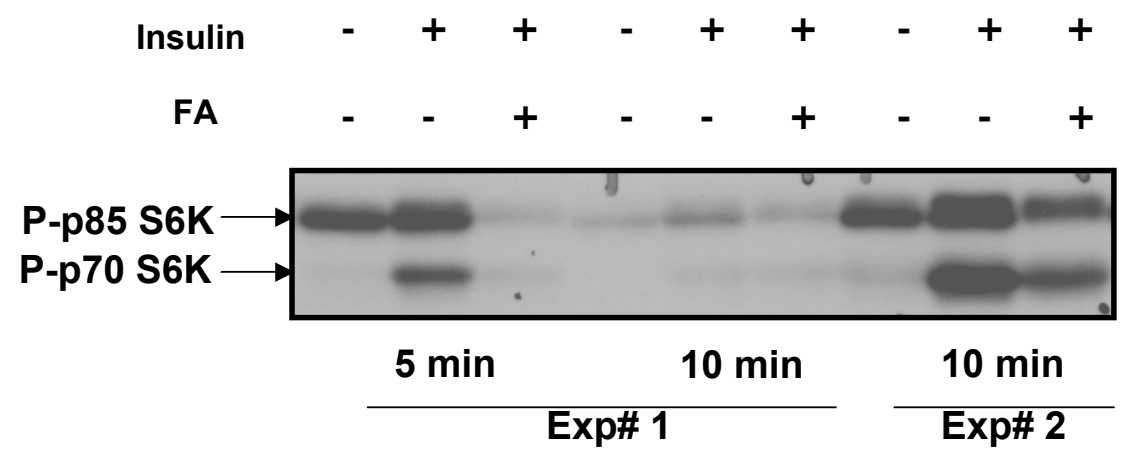




\section{Summary:}

Based on the results in chapter 2 and 3, we have concluded that insulin-mediated induction of G6PD follows the activation of the PI3 kinase pathway in primary rat hepatocytes. Addition of arachidonic acid, a polyunsaturated fatty acid, in the medium interferes with the PI3 kinase pathway, and thus inhibits the insulin-mediated induction of G6PD. The findings from this study reveal that arachidonic acid in the presence of insulin induces p38 MAP kinase pathway to a greater extent than insulin or arachidonic acid treatments alone. This increase in induction of p38 MAP kinase interferes with the insulin signal transduction pathway, by phosphorylating IRS-1 at Ser-307 and preventing PI3 kinase activation and Akt-phosphorylation. Inhibition of the p38 MAP kinase pathway by using a specific inhibitor, SB203580, attenuates the inhibitory effect of arachidonic acid on G6PD and at the same time reverses its effect on IRS-1 and Aktphosphorylation. Other polyunsaturated fatty acids, linoleic, $\square$-linolenic and eicosapentanoic acids, also induce p38 MAP kinase, decrease Akt-phosphorylation and prevent G6PD induction, eicosapentanoic acid being the most effective one. TNF- $\square$, a known inducer of p38 MAP kinase and an inhibitor of the PI3 kinase pathway, is capable of reducing G6PD gene induction. This data together suggests that activation of p38 MAP kinase pathway is necessary if not sufficient, for the inhibition of G6PD mRNA accumulation.

We also have studied the possible involvement of AMPK, PKC or mTOR pathways in the regulation of G6PD by arachidonic acid. We found that arachidonic acid activates AMPK by phosphorylating it at Thr-172. Activators of AMPK, AICAR and metformin inhibit the induction of G6PD by insulin. This study also reveals that AICAR induces p38 MAP kinase phosphorylation in primary rat hepatocytes and inhibition of this induction abolishes the inhibitory effect of AICAR on G6PD. Addition of arachidonic acid inhibits the phosphorylation of the downstream effector protein of mTOR, S6K-1 at Thr-389. This provides indirect evidence of the activation of AMPK by arachidonic acid, as activation of AMPK results in the inhibition of mTOR/S6K-1. However, inhibition of mTOR, rather than activation, rules out the possibility of 
involvement of this pathway in the interference of the PI3 kinase activation upon arachidonic acid treatment. We also have ruled out the possibility of involvement of $\mathrm{PKC}$, as neither activators of PKC mimic the action of arachidonic acid on G6PD nor inhibitors of PKC can abolish the effect of arachidonic acid on G6PD gene expression. This study provides a novel mechanism by which a polyunsaturated fatty acidsignal is transduced in hepatocytes. While other lipogenic genes are regulated at the transcriptional level, G6PD is unique in the sense that it is regulated at the level of splicing by polyunsaturated fatty acids (Amir-Ahmady and Salati, 2001, Tao et al, 2002). How the signal transduction cascade, which starts at the cell membrane, transduces its signal to the event of splicing in the nucleus is largely unknown. Investigation from our laboratory revealed the involvement of various splicing factors in the regulation of splicing of G6PD (Griffith, B and Salati, LM, unpublished). Involvement of various signal transduction pathways in the activation of these splicing factors has been reported (Patel et al, 2001, Patel et al, 2003, Konig et al, 1998, van der Houven van Oordt et al, 2000, Weg-Remers et al, 2001). Establishment of a functional co-relation between the signal transduction pathway, which starts with an AMPK/p38 MAP kinase activation by arachidonic acid and eventually regulates splicing of G6PD is the future goal of this study. 


\section{Appendix:}

In this section I am summarizing the results of the experiments, which could not be inserted in chapters 2 or 3 but are relevant to those studies. Some preliminary experiments, which are not related to those two chapters and are not making a complete story, are also included in this section.

\section{Figure A-1. A PI3kinase inhibitor LY294002 abolishes the insulin-mediated} induction of G6PD. Rat hepatocytes were incubated with $75 \square$ M LY294004, 1 hr prior to the addition of insulin $(\mathbf{I})(0.04 \square \mathrm{M})$ or insulin + arachidonic acid (175 $\square \mathbf{M})(\mathbf{I + F A})$. The control group (No Addition) was treated with DMSO (solvent used for the inhibitor) $1 \mathrm{~h}$ prior to the addition of the treatments. After $12 \mathrm{~h}$, culture medium was changed to one of the same composition and after $24 \mathrm{~h}$ total RNA was isolated. RNase protection assay was performed to determine the fold induction of G6PD expression. Expression of $\square$ actin was also determined from each sample as a negative control. The figure represents $\mathrm{n}=4$ experiments.

Results: The induction of G6PD mRNA by insulin occurs via the PI3-kinase signal transduction pathway (Stapleton et al. J Biol. Chem, 1998, 273:14968-14974). We have confirmed that an inhibitor of this pathway, (LY294002), abolishes the effect of insulin on G6PD mRNA expression. As shown in figure A-1, pre-incubation of hepatocytes with $75 \square \mathrm{M}$ LY294002, $1 \mathrm{~h}$ prior to the addition of insulin abolishes the insulin-mediated induction of G6PD mRNA. We have used different concentrations of the inhibitor and found that the inhibitor has its maximum effect at $75 \square \mathrm{M}$, which is maintained at $100 \square \mathrm{M}$ (Data not shown). I, insulin, FA, arachidonic acid.

\footnotetext{
Figure A-2. An Erk MAP kinase inhibitor PD98059 has no effect on arachidonic acid mediated inhibition of G6PD. Hepatocytes were incubated in the absence or presence of $50 \square \mathrm{M}$ Erk MAP kinase inhibitor PD98059, when hepatocytes were treated either with insulin $(0.04 \square \mathrm{M})+/$ - arachidonic acid (175 $\square \mathrm{M})$ or kept untreated. The
} 
inhibitor was added $1 \mathrm{~h}$ prior to the addition of arachidonic acid. Insulin was added $3 \mathrm{~h}$ later. After $12 \mathrm{~h}$, medium was changed with medium containing the inhibitor and the treatments together. After $24 \mathrm{~h}$ total RNA was isolated. Quantitative analysis of fold induction of G6PD in two experiments is shown in figure A-2. Values are normalized to no treatment in the absence of the inhibitor.

Results: The Erk inhibitor seems to have no effect on the arachidonic acid-mediated inhibition of G6PD. I, insulin, FA, arachidonic acid, PD, PD98059.

\section{Figure A-3. Farnesyl transferase inhibitor B581 inhibits MKK 3/6 and p38 activation and also abolishes the effect of arachidonic acid on G6PD mRNA expression; a possible role of Ras as an upstream effector protein. (A) Rat} hepatocytes were treated with or without $50 \square \mathrm{M}$ of B581 $1 \mathrm{~h}$ prior to the addition of insulin $(0.04 \square \mathrm{M})$ in the absence or presence of arachidonic acid (175 $\square \mathrm{M})$ or left untreated. After $10 \mathrm{~min}$, a total cell lysate was isolated and western blot analysis was performed against phosphorylated MKK3/6 and phosphorylated and total p38 MAP kinase. A representative blot of $n=2$ experiments is shown. (B) Hepatocytes were treated with or without $50 \square \mathrm{M}$ of B581 1h prior to the addition of arachidonic acid. After 4h, insulin was added. After $12 \mathrm{~h}$, medium was changed with the same composition of the inhibitor and the treatments. Total RNA was isolated after $24 \mathrm{~h}$. The isolated RNA was analyzed by RNase protection assay and quantified using phosphorimaging and ImageQuant software. The values are the amount of G6PD mRNA normalized to the amount of $\square$-actin mRNA and are plotted relative to the amount of RNA in the absence of treatments in the absence or presence of the inhibitor. Each bar represents the mean $\pm \mathrm{SE}$ of $n=6$ experiments.

Results: We wanted to determine if B581 can abolish the arachidonic acid-mediated activation of p38 MAP kinase and if it has any effect on G6PD mRNA expression by arachidonic acid. Western blot analysis shows that B581 not only abolishes p38 MAP kinase activation but also inhibits the upstream MKK3/6 phosphorylation. However, total p38 MAP kinase expression did not change. 
We also tested if this inhibitor can abolish the effect of arachidonic acid on G6PD. In the absence of the inhibitor, arachidonic acid inhibits insulin induction by $49 \pm$ $4.5 \%$, whereas, in the presence of B581, the arachidonic acid-mediated inhibition is only $15 \pm 5.4 \%$ and this decrease is not significantly different from insulin + B581 treatment. B581, however, did decrease the insulin-mediated induction of G6PD mRNA and this decrease is statistically significant $(\mathrm{P}<0.05)$. In the absence of the inhibitor we see 4.8fold induction over no addition, which is reduced to 3 -fold in the presence of the inhibitor. This is probably due to the fact that Ras also contributes to the activation of the PI3kinase pathway and the activation of this pathway is necessary for the activation of G6PD mRNA. Inhibition of Ras-farnesylation can cause a decrease in the activation of the PI3kinase, which in turn can decrease the extent of G6PD induction by insulin. However, there is still 3-fold induction by insulin in the presence of the inhibitor which arachidonic acid could not inhibit. This data suggests that inhibition of Ras-farnesylation abolishes the inhibitory effect of arachidonic acid on G6PD mRNA expression. NA, no addition, I, insulin, FA arachidonic acid.

\section{Figure A-4. Effect of AMPK activators on G6PD, at an earlier time point (10h). Rat} hepatocytes were treated with insulin $(0.04 \square \mathrm{M})$ alone or insulin in the presence of AICAR $(0.5 \mathrm{mM})$, metformin $(1 \mathrm{mM})$ or 2,4 , DNP $(0.1 \mathrm{mM})$. Total RNA was isolated after 10h. Real time RT-PCR using Taqman probe was used to measure the expression of G6PD mRNA. Quantitative analysis of G6PD mRNA expression is shown for $n=1$ experiment. Each bar represents the values relative to the absence of the treatment. Results: Incubation of rat hepatocytes with AMPK activators for a shorter period of time showed that, AICAR and 2,4 DNP inhibited the induction of G6PD mRNA to about 30\% and $50 \%$ respectively. AICAR mediated inhibition is greater at $24 \mathrm{~h}$ time point $(50 \%)$. On the other hand, metformin, contrary to the later time point (24h) did not inhibit the insulin induction. 
Figure A-5. Effect of various polyunsaturated fatty acids (PUFAs) on P-AMPK, Pp38 and G6PD: A) Rat hepatocytes were incubated, with or without insulin $(0.04 \square \mathrm{M})$ in the absence or presence of various PUFAs (175 $\square \mathrm{M})$. Total cell lysate was isolated after 10 min. Western blot analysis was performed against phospho and total AMPK and p38 MAP kinase. Quantitation of the P-AMPK ( $n=3$ for all Fatty acids, except $n=2$ for 18:3) and P-p38 ( $\mathrm{n}=3$ experiments) was performed using densitometric analysis and ImageQuant software. Each bar represents the mean $\pm \mathrm{SE}$ and the values are expressed relative to the insulin treatment for P-AMPK and relative to the no addition for P-p38. B) Rat hepatocytes were treated with or without insulin in the absence or presence of 175 $\square \mathrm{M}$ of the designated PUFAs. After $12 \mathrm{~h}$, the medium was changed. After $24 \mathrm{~h}$, total RNA was isolated and real time RTPCR was performed against G6PD and beta-actin (as a control). Quantitative analysis of $n=3$ experiments are shown. Each bar represents the mean $\pm \mathrm{SE}$ and the values are expressed relative to the no addition sample.

Results: The result for P-AMPK suggests that insulin reduces AMPK phosphorylation over no addition (NA). Upon treatment with 18:2 or 20:5 fatty acids, the P-AMPK values are increased compared to insulin treatment alone. To conclude about the effect of 18:3, more experiments are required since the values are variable. On the other hand, all these fatty acids induce p38-phosphorylation with a maximum effect of 20:5. All these fatty acids also reduce G6PD mRNA abundance with a maximum effect of 20:5.

\section{Figure A-6. Effect of fibroblast growth factor 19 (FGF-19), and chenodeoxycholic acid (CDCA) on G6PD mRNA level: Effect of FGF-19 and CDCA on G6PD were} examined in the presence of insulin and LXR agonist T0-901317 (T-17) (This was a collaborative project with Sushant Bhatnagar in Dr. Brad Hillgartner's lab). Hepatocytes were incubated in the presence of insulin and T-17 $(6.5 \mathrm{mg} / \mathrm{ml})$ with or without FGF-19 (50 ng/ml), or CDCA (50 and $75 \square \mathrm{M}$ ). Medium was changed after $12 \mathrm{~h}$ and total RNA was isolated $24 \mathrm{~h}$ after the addition of the treatments. The isolated RNA was analyzed by RNase protection assay and quantified using phosphorimaging and ImageQuant software. The value of $n=1$ experiment is shown. The amount of G6PD mRNA was normalized to the amount of $\square$-actin mRNA and plotted relative to the amount of RNA in the presence 
of insulin and T-17. The blank lane where the sample was lost during the assay contained $500 \mathrm{ng} / \mathrm{ml} \mathrm{FGF-19} \mathrm{in} \mathrm{the} \mathrm{presence} \mathrm{of} \mathrm{insulin} \mathrm{and} \mathrm{T17.}$

Results: From the preliminary experiment it seems that both FGF-19 and CDCA, two known potent inhibitors of lipogenic genes, also inhibit the expression of G6PD in the presence of insulin and T-17.

\section{Figure A-7. Effect of insulin and arachidonic acid on the splicing of rat G6PD}

mRNA. In order to determine how insulin and arachidonic acid affect the splicing of rat G6PD mRNA (all work on the splicing of G6PD was done before with mouse G6PD gene either from intact animals or from transiently transfected mouse G6PD reporter RNA into rat hepatocytes), nuclear RNA was isolated from rat hepatocytes treated with insulin in the absence or presence of arachidonic acid or from the untreated group. After $12 \mathrm{~h}$ of treatment, the medium was changed and after $24 \mathrm{~h}$ nuclear RNA was isolated from 12-15 plates per treatment group. We already have shown that the regulatory element of mouse G6PD gene is located within exon 12. Thus, we performed RNase protection assay with a probe, spanning rat G6PD exons 10-12 and the intervening introns (pAB2).

A) The cartoon shows the diagram and size of the full-length, partially-spliced and fullyspliced probe. The unspliced probe is 364 nucleotides (nt). The predicted size of the two partially spliced products containing exon 11, intron 11 and exon 12 or exon 10, intron 10 and exon 11 are 234 and 207 nt, respectively. The fully spliced products should be 77 (exon 11), 60 (exon 12) and 22 (exon 10) nt. B) A representative RNase protection assay gel is shown. From the gel we were able to detect the unspliced, the partially spliced (containing exon 10, intron 10 and exon 11) and the fully spliced (containing exon 11) probes. The quantitation of these products was done using ImageQuant software. The value of each band for the I+FA treatment as a percentage of insulin treatment alone is shown for $n=4$ individual experiments. The unspliced probe was not detectable in two experiments.

Results: The result is largely inconclusive at this moment except that the percent expression of the fully spliced product in the presence of arachidonic acid is always less 
than the partially spliced or the unspliced probe. This might suggest an involvement posttranscriptional mechanism by arachidonic acid for rat G6PD gene expression.

Figure A-8. Stable transfection of the construct containing mouse exon 7-13 into the L6 cell line. Stable transfection of the mouse G6PD gene construct containing exon 7-13 and driven by a CMV promoter was performed in rat L6 cell line by Effectene transfection reagent. After clonal isolation, real time RT-PCR was performed to detect mouse G6PD in these cells. Agarose gel was run with the PCR products. As shown all the clones are expressing mouse G6PD construct.

Figure A-9A. Effect of arachidonic acid, the PI3 kinase inhibitor LY294002 and the p38 MAP kinase inhibitor, SB203580 on steroyl-coA-desaturase (SCD) gene expression A) Primary rat hepatocytes were incubated with 75 or $100 \square$ M LY294004 (LY 75 and LY100 respectively), $1 \mathrm{hr}$ prior to the addition of insulin, or insulin + arachidonic acid. The control group was treated with DMSO (solvent used for the inhibitor) $1 \mathrm{~h}$ prior to the addition of the treatments (Experiment \# 3). In two other experiments hepatocytes were treated either with insulin or arachidonic acid alone or with both (Experiment \# 1 and 2). After $12 \mathrm{~h}$, culture medium was changed to one of the same composition and after $24 \mathrm{~h}$ total RNA was isolated. Northern blot analysis was performed to determine the fold induction of SCD expression. The values are the amount of SCD mRNA plotted relative to the amount of RNA in the absence of treatments and in the absence or presence of the inhibitor. The picture of $18 \mathrm{~S}$ and $28 \mathrm{~S}$ rRNA is shown as a loading control. B) Rat hepatocytes were incubated with or without $10 \square \mathrm{M}$ of p38 MAP kinase inhibitor SB203580. After 1h, cells were treated with arachidonic acid or left untreated. $2 \mathrm{~h}$ after that cells were treated with or without insulin. Medium was changed after $12 \mathrm{~h}$ with the same composition of the inhibitor, arachidonic acid and insulin. Total RNA was isolated $24 \mathrm{~h}$ after the addition of the treatment. Northern blot analysis was performed to measure the expression of SCD mRNA. Percentage of inhibition of SCD gene expression by arachidonic acid in the absence or presence of SB203580 compared 
to insulin treatment alone is shown for two separate experiments. The picture of $18 \mathrm{~S}$ and $28 \mathrm{~S}$ rRNA is shown as a loading control.

Results: A) Insulin induces SCD several fold. Arachidonic acid reduces the expression of both the basal and the insulin-induced expression of SCD. The insulin-mediated induction of SCD is completely abolished by the PI3kinase inhibitor LY294002 at both 75 and $100 \square \mathrm{M}$ concentrations. B) The p38 MAP kinase inhibitor SB203580 slightly reduces the \% of inhibition of the SCD gene expression by arachidonic acid. 
Fig. A-1

\section{Effect of the PI3kinase inhibitor on G6PD gene expression}

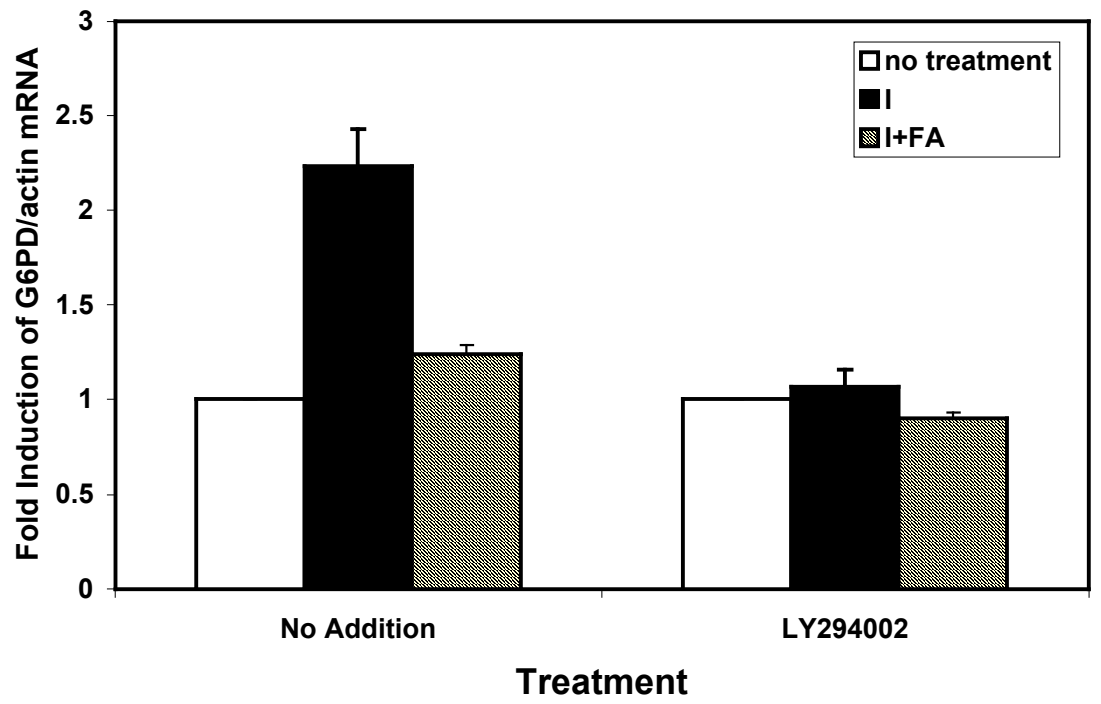


Fig. A-2

Effect of PD98059

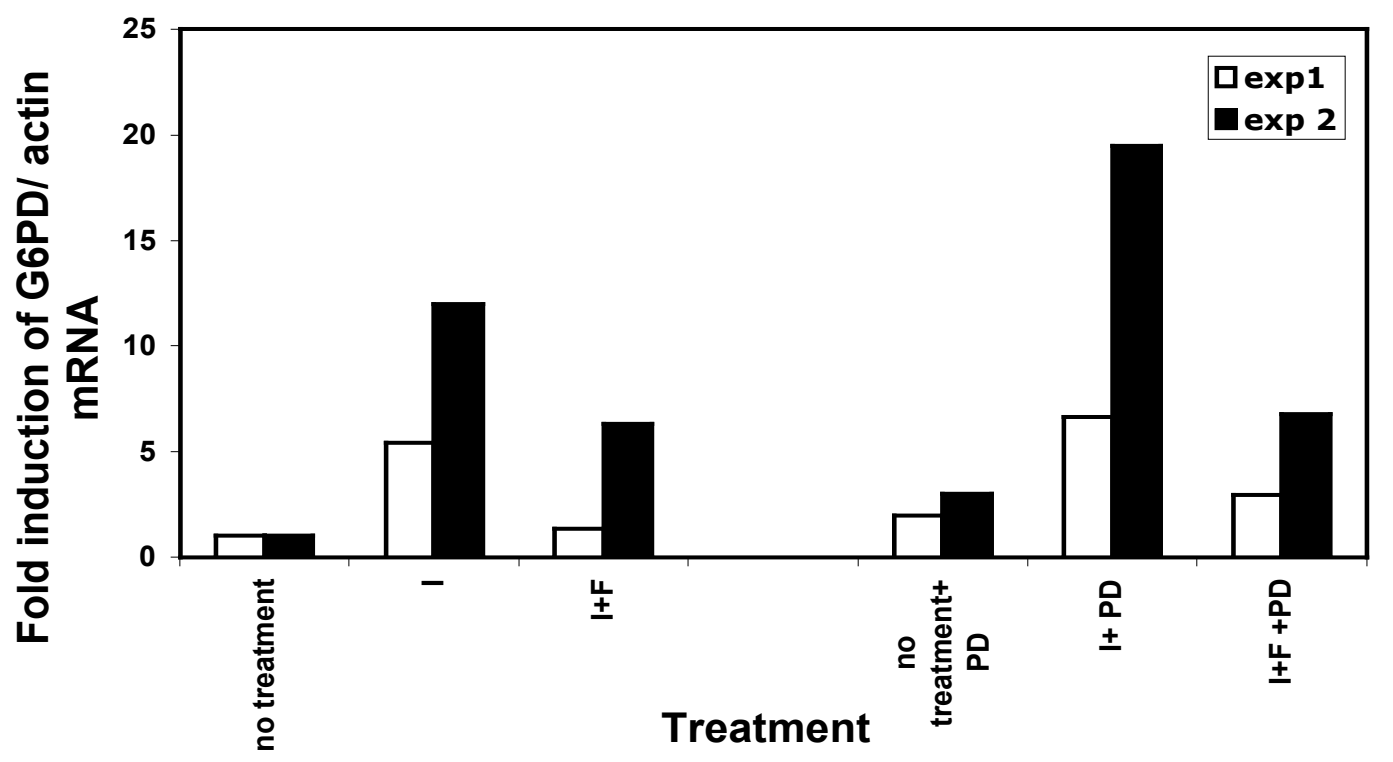


Fig. A-3a

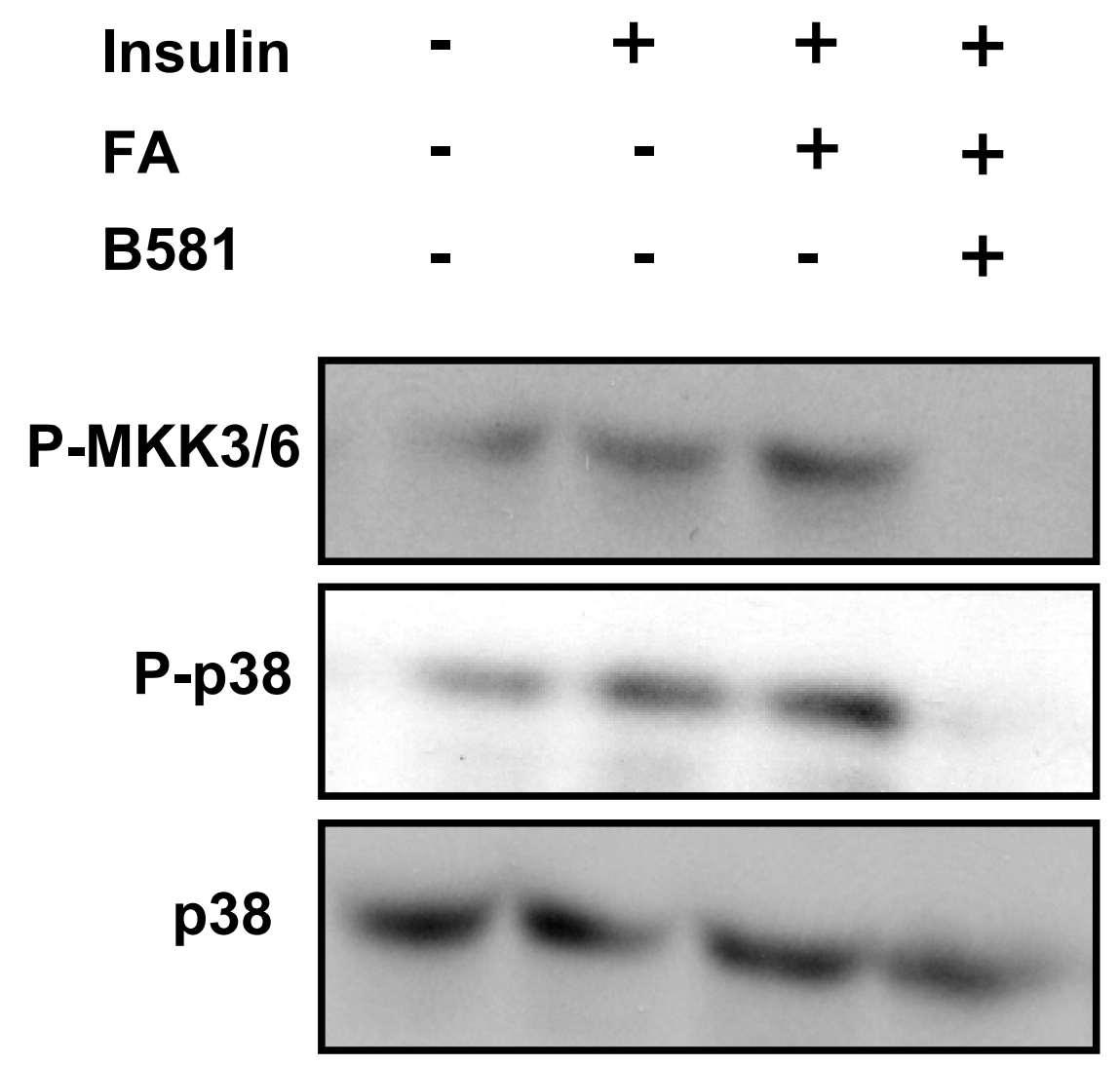


Fig. A-3b

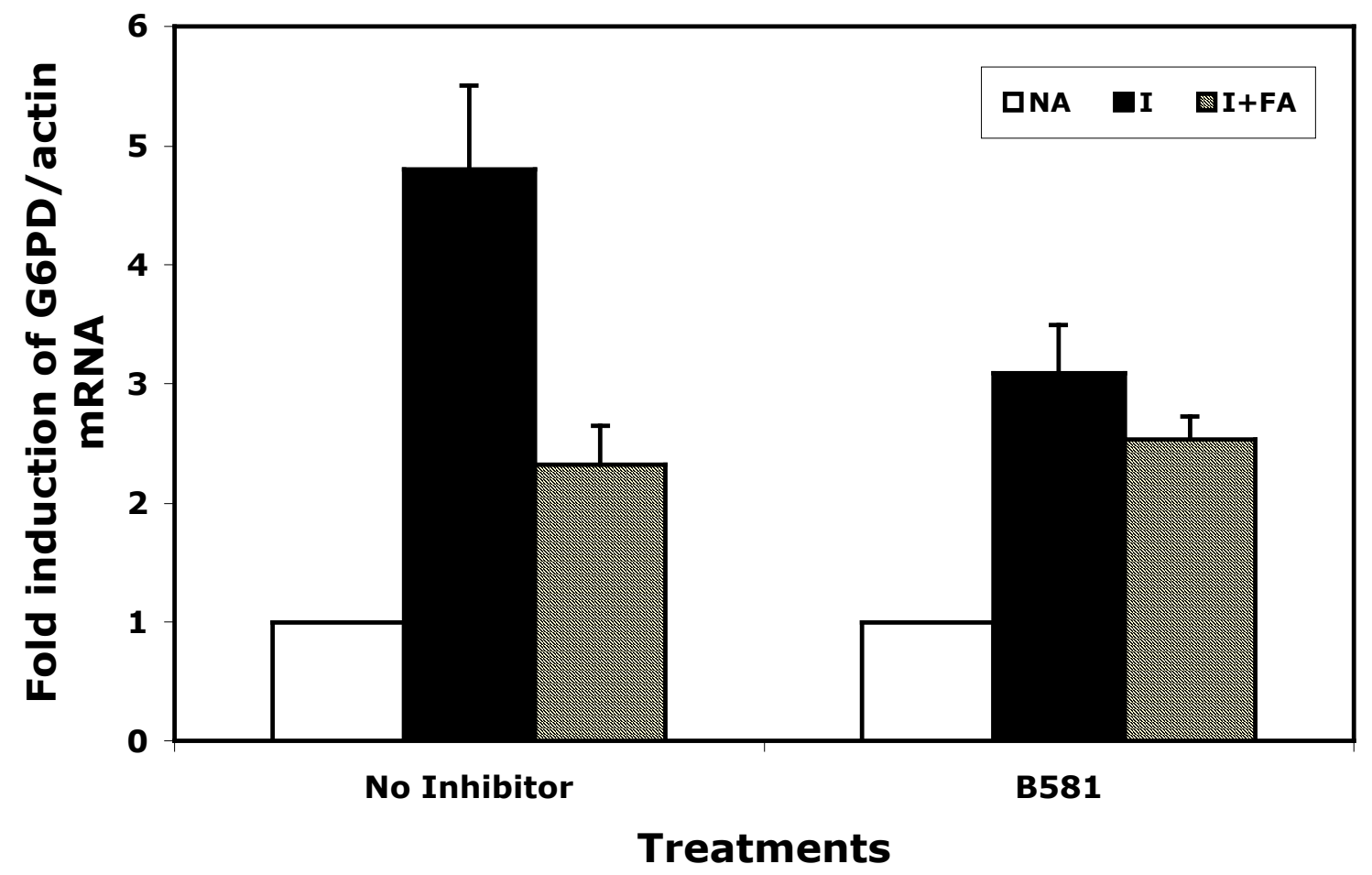


Fig. A-4

Effect of AMPK activators on G6PD mRNA (10 h)

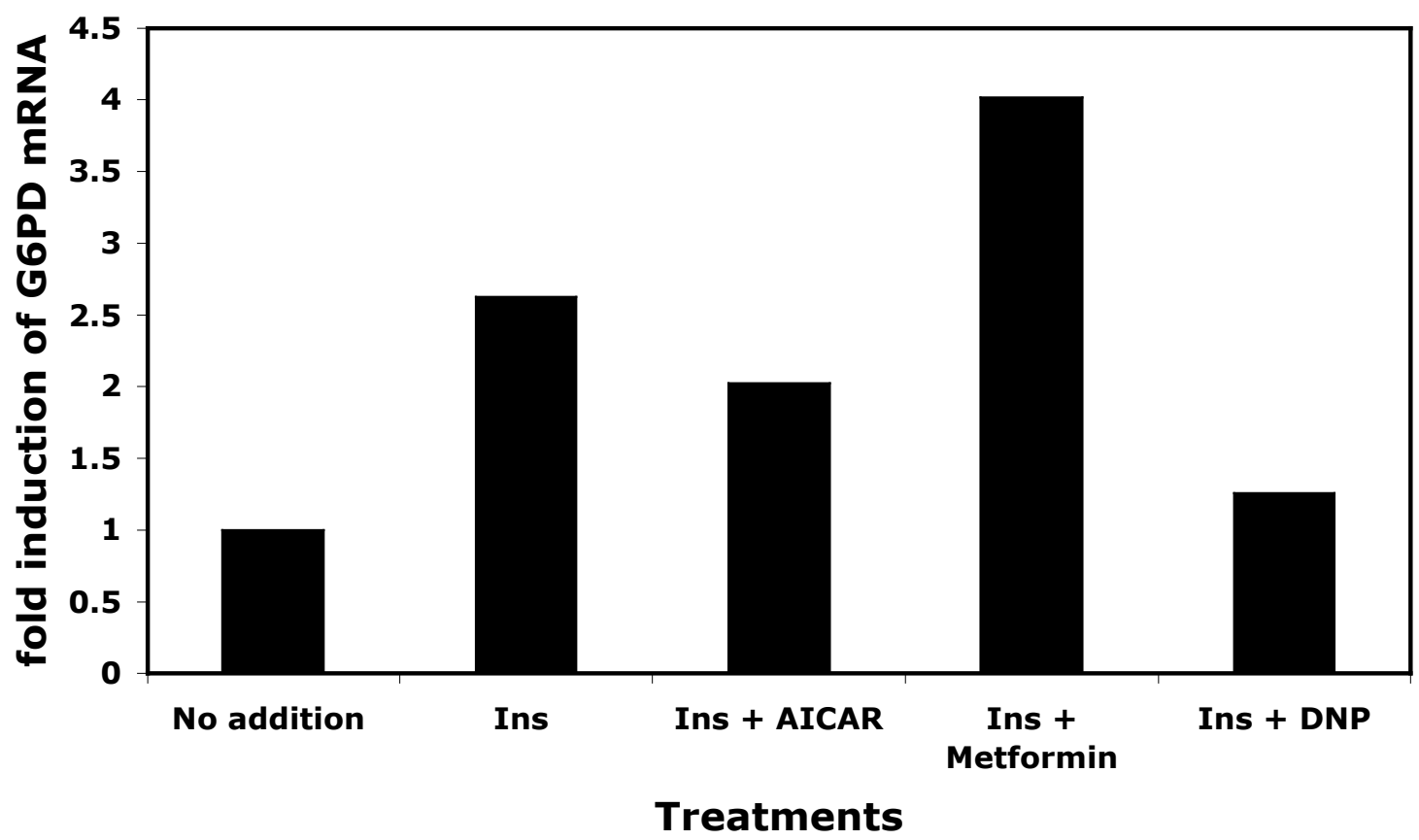


Fig. A-5A
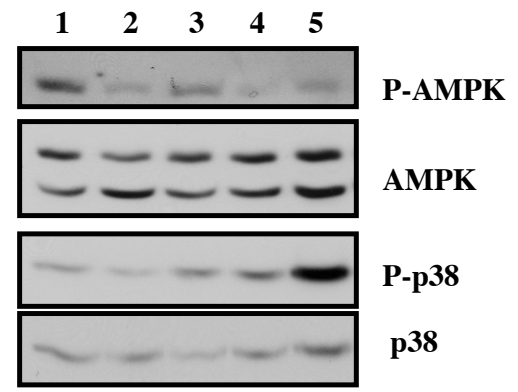

P-p38

p38

$1=$ NA

$2=$ Ins

$3=$ Ins + 18:2

$4=$ Ins + 18:3

$5=$ Ins $+20: 5$

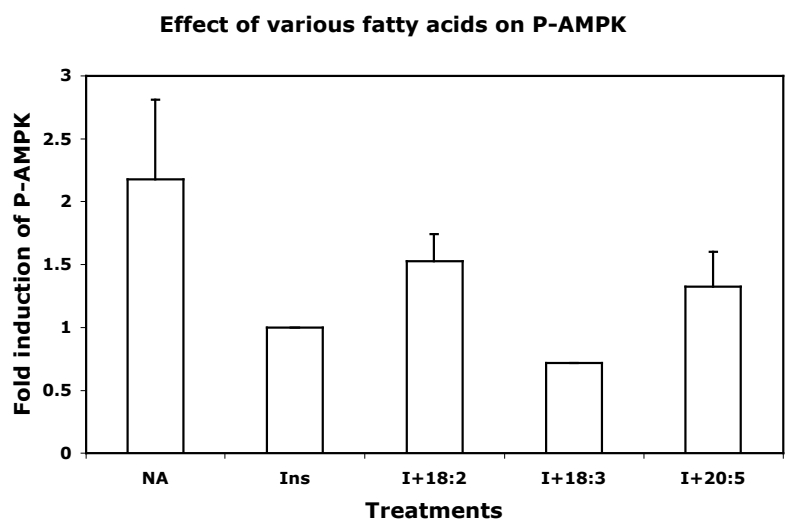

Effect of various fatty acids on P-p38

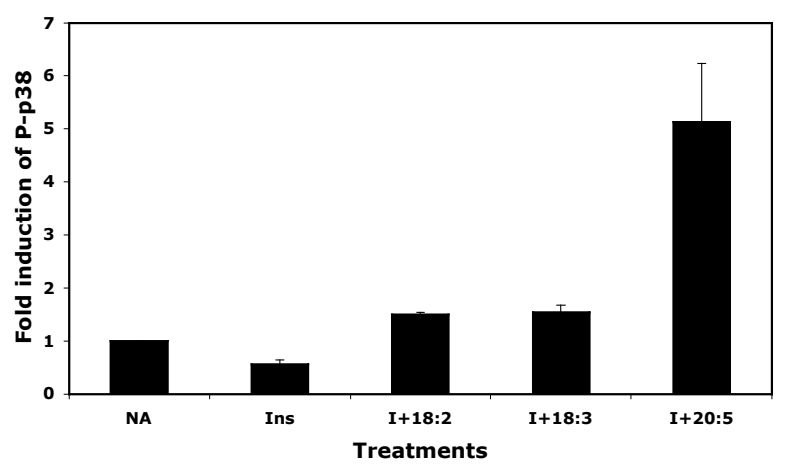


Fig. A-5B

\section{Effect of various fatty acids on G6PD}

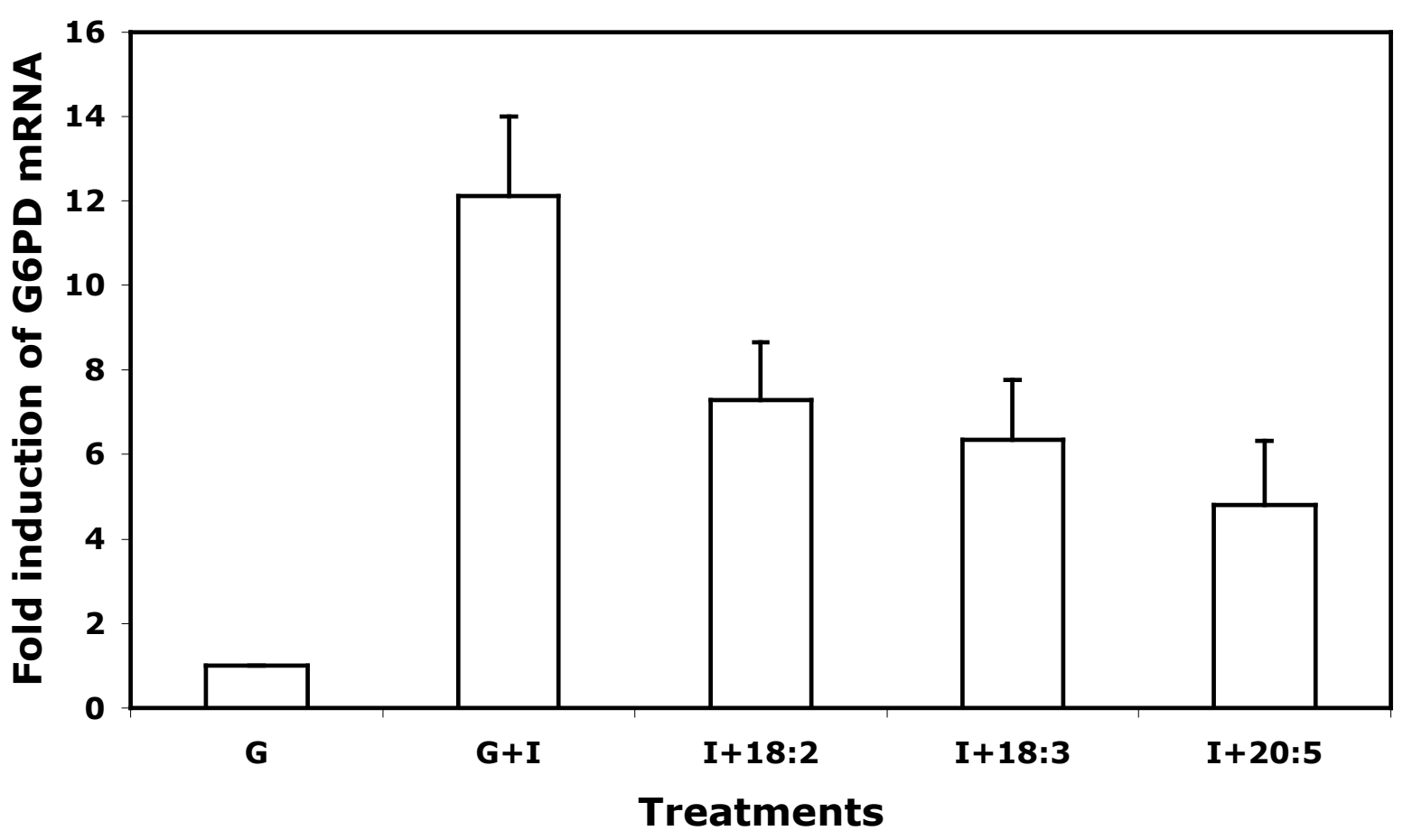




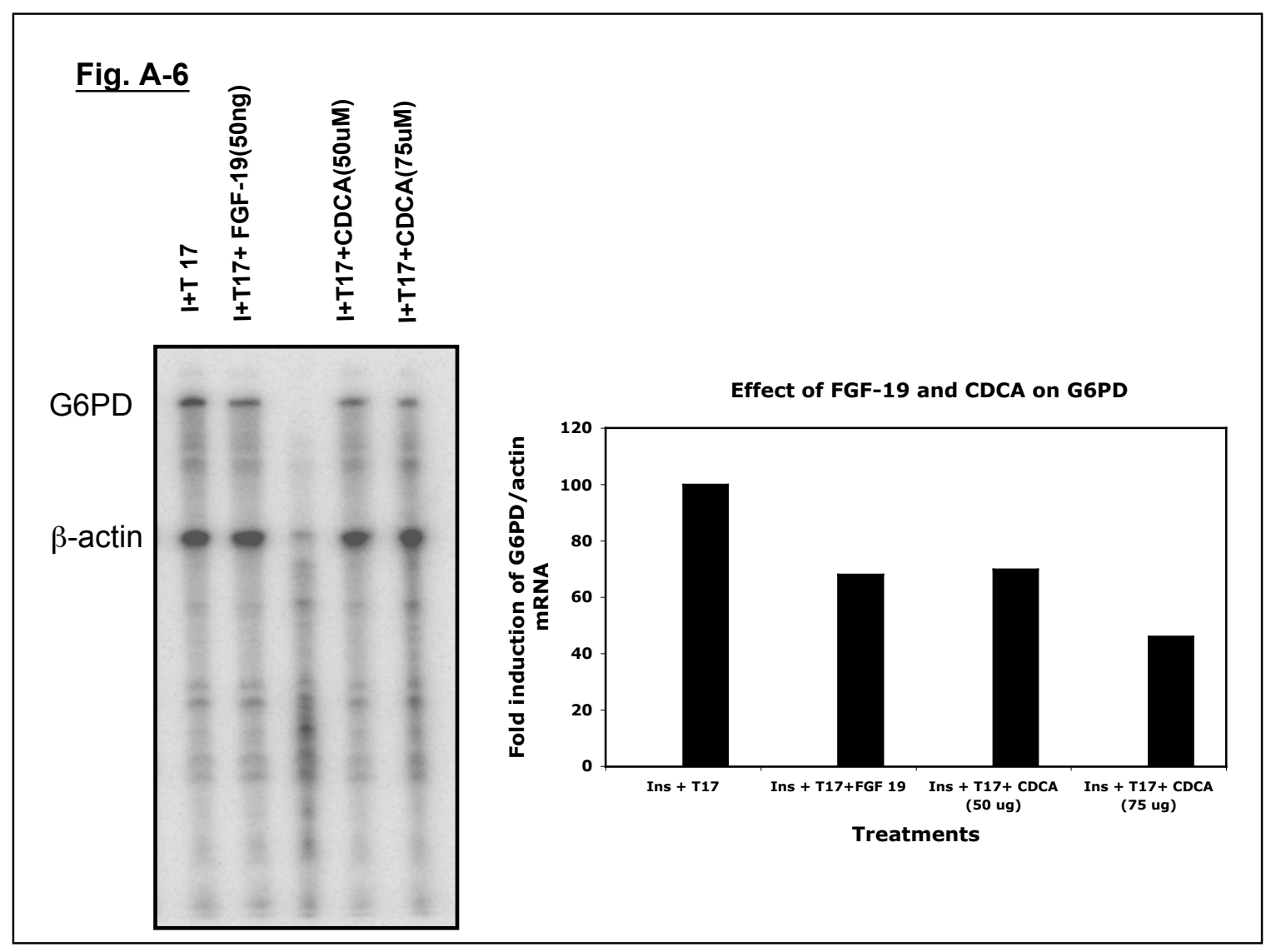




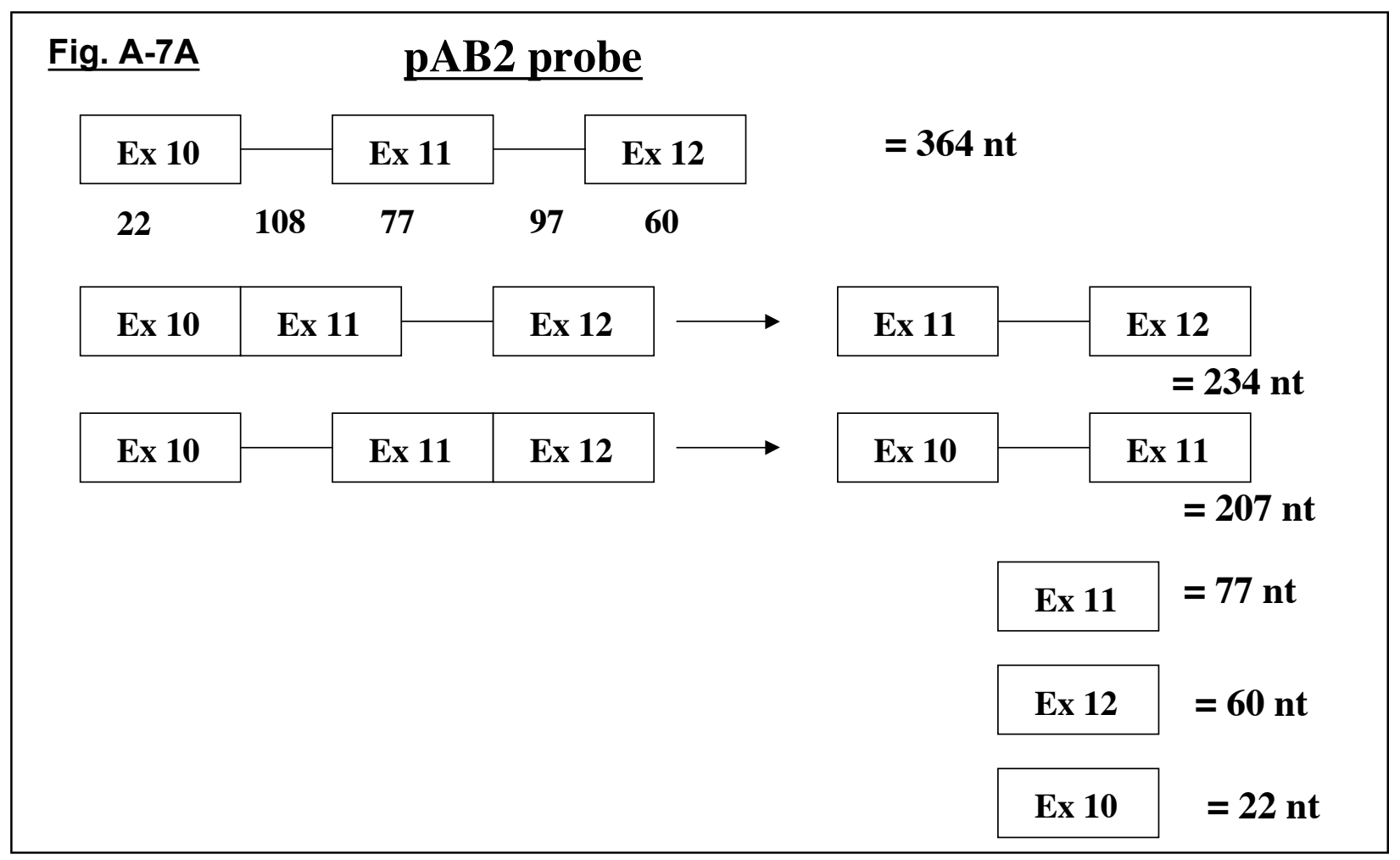


Fig. A-7B

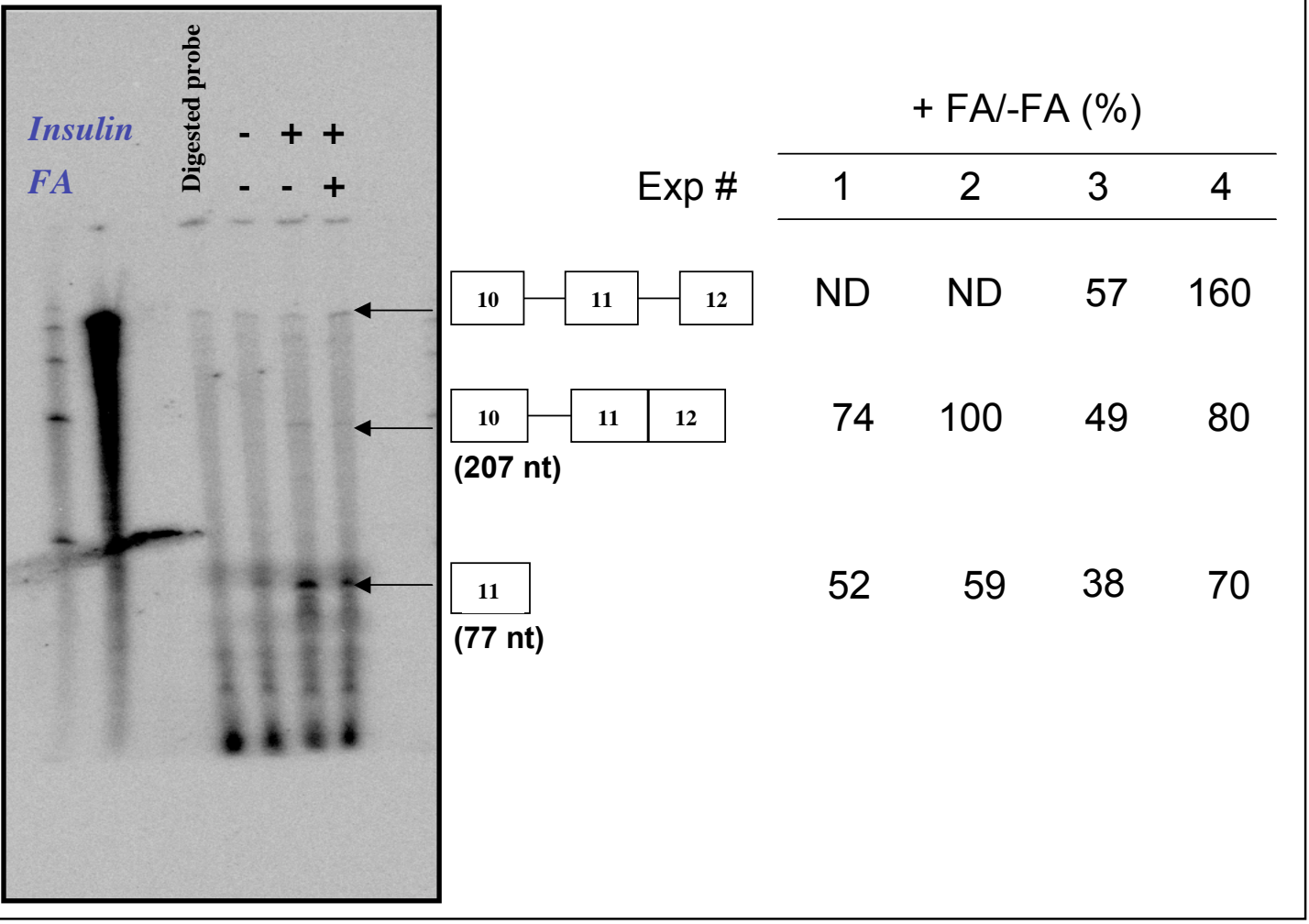


Fig. A-8

\section{Stable Transfection in L6 cells}

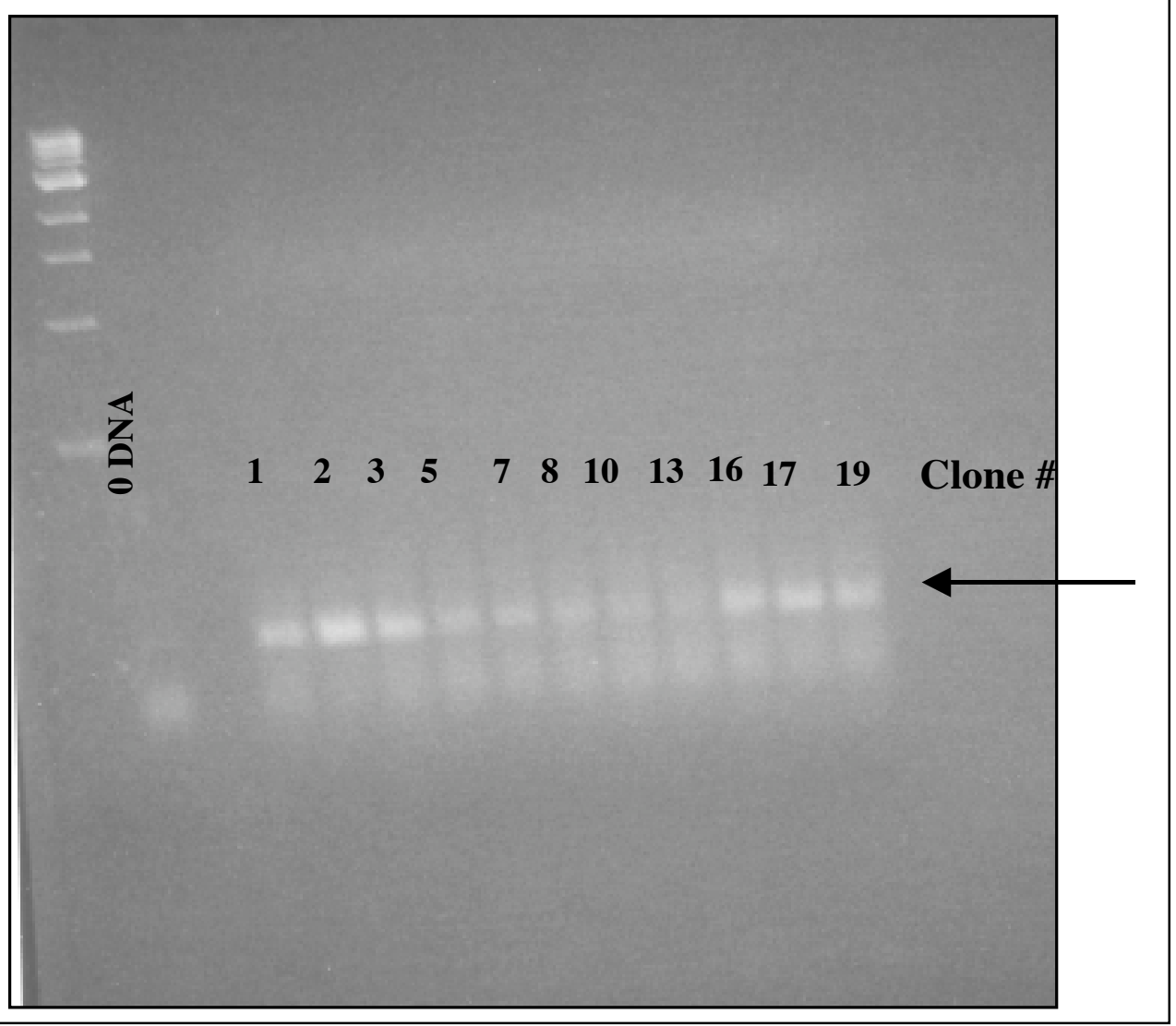




\section{Fig. A-9A}

Exp \# 1

\section{Exp \# 2}

Exp \# 3
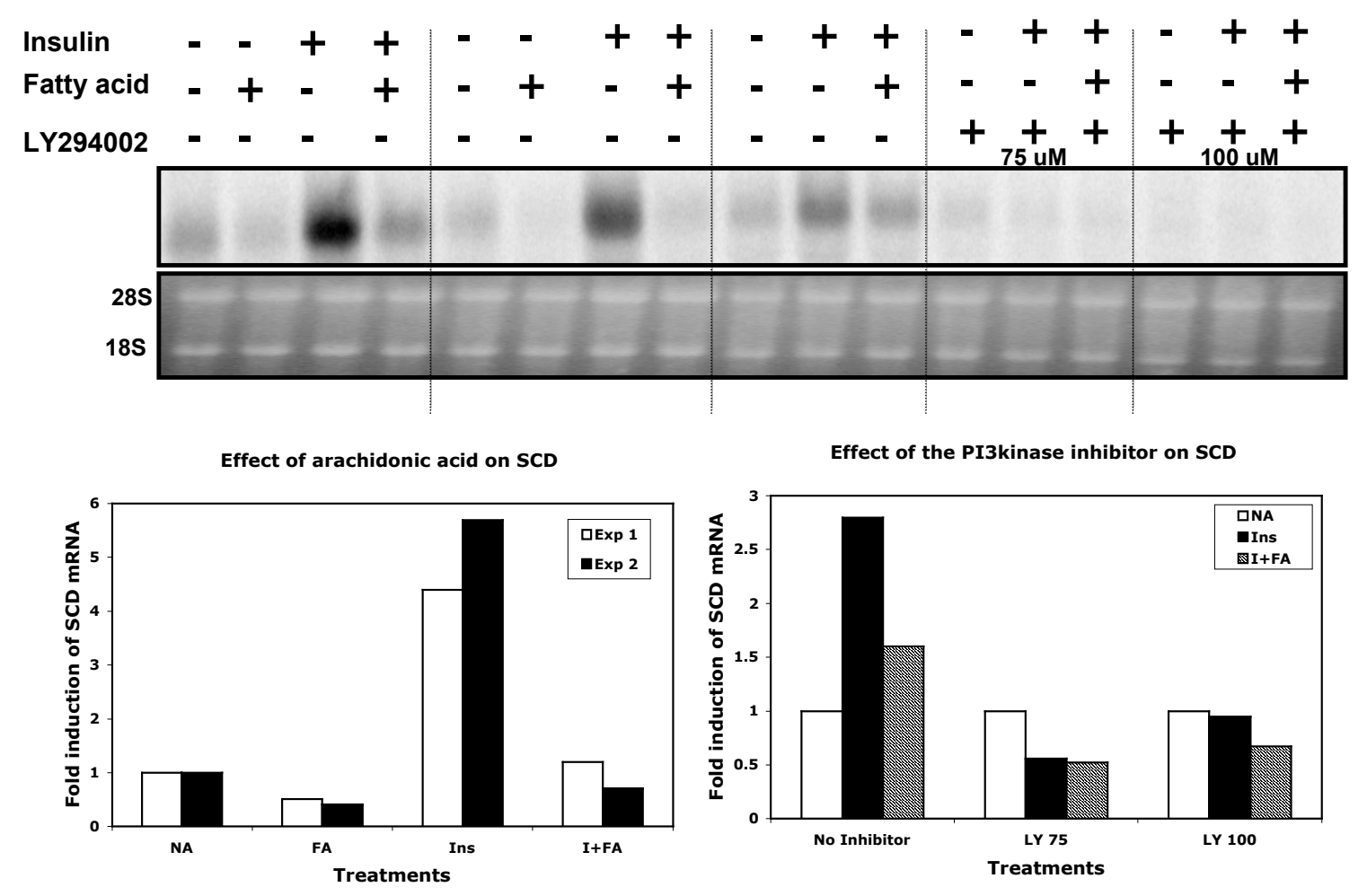


\section{Fig. A-9B}

\begin{tabular}{lllllll|llll} 
Insulin & - & + & + & - & + & + & + & + & + & + \\
Fatty acid & - & - & + & - & - & + & - & + & - & + \\
SB203580 & - & - & - & + & + & + & - & - & + & +
\end{tabular}
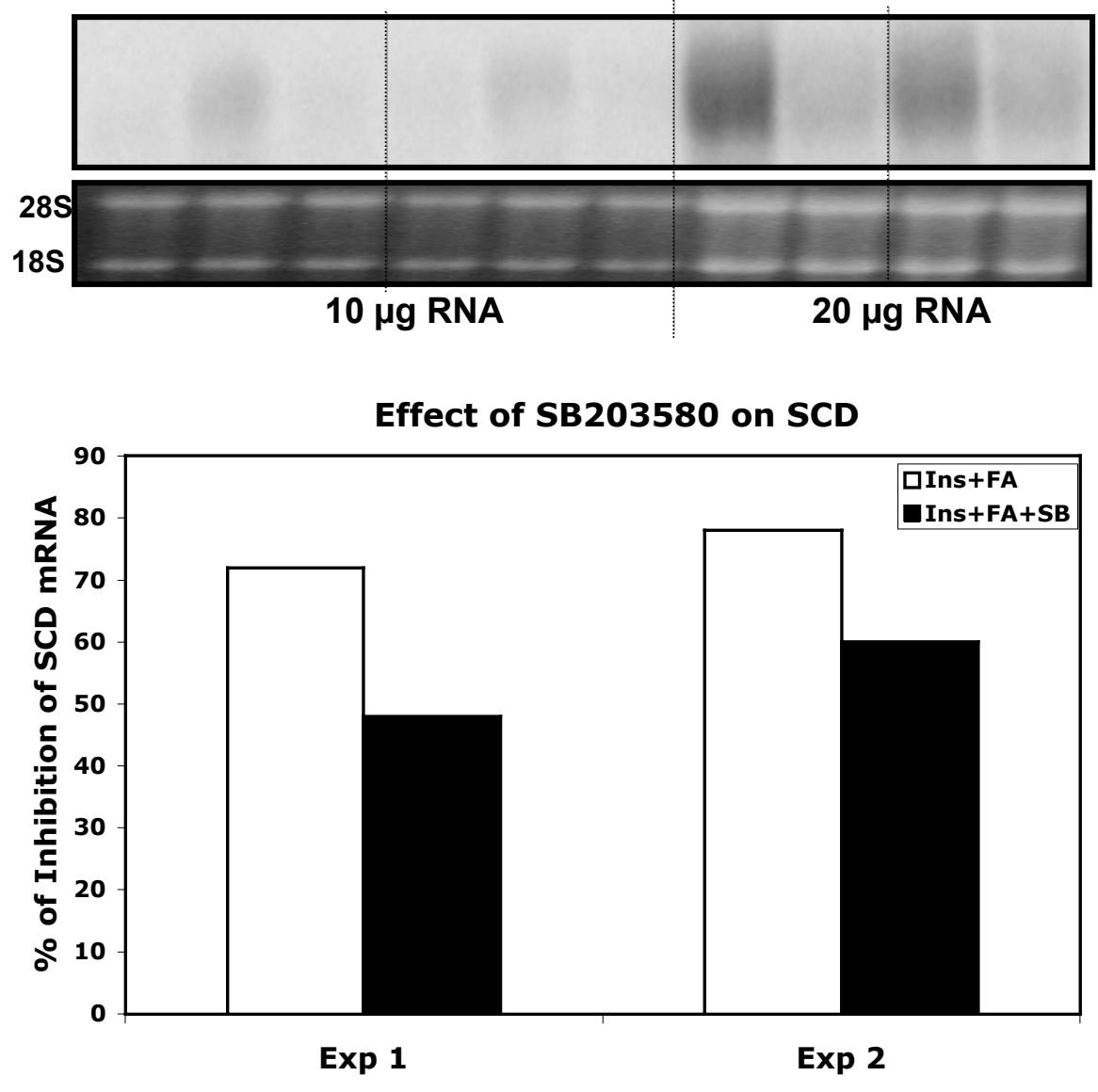